ESRI

RESEARCH

SERIES

NUMBER 83

December 2018

\section{APPROACHES TO UNACCOMPANIED MINORS FOLLOWING STATUS DETERMINATION IN IRELAND}

SARAH GROARKE AND SAMANTHA ARNOLD

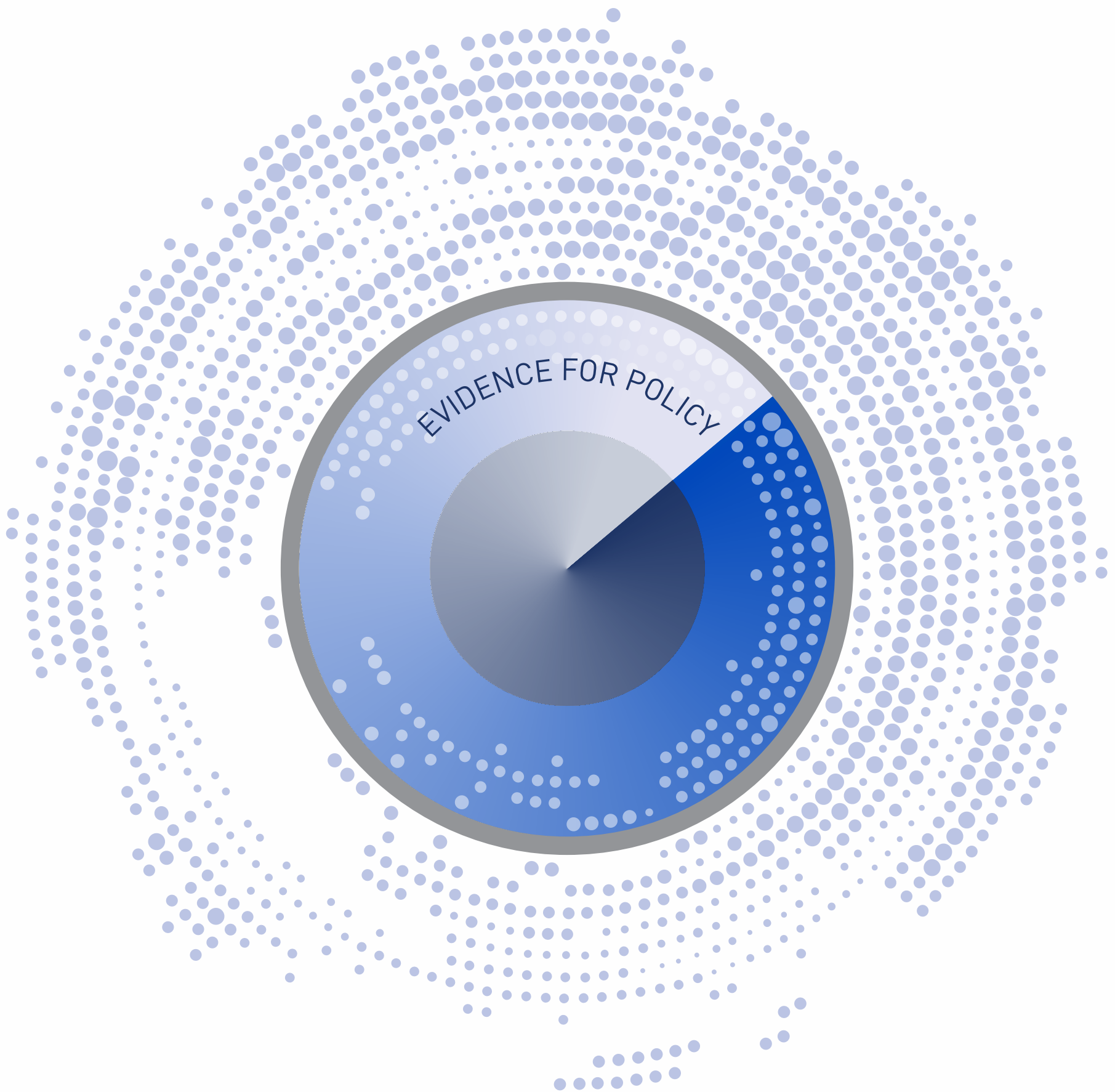




\section{APPROACHES TO UNACCOMPANIED MINORS FOLLOWING STATUS DETERMINATION IN IRELAND}

Sarah Groarke

Samantha Arnold

December 2018

\section{RESEARCH SERIES}

\section{NUMBER 83}

Study completed by the Irish National Contact Point of the European Migration Network (EMN), which is financially supported by the European Union and the Irish Department of Justice and Equality. The EMN was established via Council Decision 2008/381/EC.

Available to download from www.emn.ie

(C) The Economic and Social Research Institute

Whitaker Square, Sir John Rogerson's Quay, Dublin 2

ISBN: 978-0-7070-0476-1

DOI: https://doi.org/10.26504/rs83

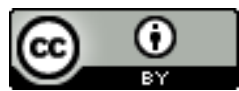

This Open Access work is licensed under a Creative Commons Attribution 4.0 International License, which permits unrestricted use, distribution, and reproduction in any medium, provided the original work is properly credited. 


\section{THE EUROPEAN MIGRATION NETWORK}

The aim of the European Migration Network (EMN) is to provide up-to-date, objective, reliable and comparable information on migration and asylum at Member State and EU levels with a view to supporting policymaking and informing the general public.

The Irish National Contact Point of the European Migration Network, EMN Ireland, sits within the Economic and Social Research Institute (ESRI).

\section{ABOUT THE ESRI}

The mission of the Economic and Social Research Institute is to advance evidencebased policymaking that supports economic sustainability and social progress in Ireland. ESRI researchers apply the highest standards of academic excellence to challenges facing policymakers, focusing on 12 areas of critical importance to 21st Century Ireland.

The Institute was founded in 1960 by a group of senior civil servants led by Dr T.K. Whitaker, who identified the need for independent and in-depth research analysis to provide a robust evidence base for policymaking in Ireland.

Since then, the Institute has remained committed to independent research and its work is free of any expressed ideology or political position. The Institute publishes all research reaching the appropriate academic standard, irrespective of its findings or who funds the research.

The quality of its research output is guaranteed by a rigorous peer review process. ESRI researchers are experts in their fields and are committed to producing work that meets the highest academic standards and practices.

The work of the Institute is disseminated widely in books, journal articles and reports. ESRI publications are available to download, free of charge, from its website. Additionally, ESRI staff communicate research findings at regular conferences and seminars.

The ESRI is a company limited by guarantee, answerable to its members and governed by a Council, comprising 14 members who represent a cross-section of ESRI members from academia, civil services, state agencies, businesses and civil society. The Institute receives an annual grant-in-aid from the Department of Public Expenditure and Reform to support the scientific and public interest elements of the Institute's activities; the grant accounted for an average of 30 per cent of the Institute's income over the lifetime of the last Research Strategy. The remaining funding comes from research programmes supported by government departments and agencies, public bodies and competitive research programmes.

Further information is available at www.esri.ie. 


\section{THE AUTHORS}

Sarah Groarke is a Research Assistant at the Irish National Contact Point of the European Migration Network (EMN Ireland), within the ESRI. Samantha Arnold is a Post-Doctoral Research Fellow with EMN Ireland.

\section{ACKNOWLEDGEMENTS}

In compiling this study, valuable assistance was received from representatives of the Child and Family Agency, Tusla's Social Work Team for Separated Children Seeking Asylum, the City of Dublin Education and Training Board's Youth and Education Service for Refugees and Migrants and the Immigrant Council of Ireland. Information was also sought through correspondence with the International Organization for Migration, the International Protection Office, the Irish Refugee Protection Programme, the Irish Naturalisation and Immigration Service, the Legal Aid Board, Spirasi and the Department of Children and Youth Affairs. We also acknowledge the useful comments and suggestions received from the referees. Finally, thanks are due to our colleagues Elaine Byrne, Emma Quinn, Sarah Burns and Christina Durst at the ESRI. We are grateful to everyone who shared their expertise with us for the purpose of writing this study.

\section{ABOUT THIS REPORT}

This European Migration Network study examines the policies and practices on unaccompanied minors following a status decision in Ireland. Principally, this study looks at two potential outcomes for unaccompanied minors in Ireland: a positive decision for immigration permission or international protection and subsequent integration in-country and forced or voluntary return. The report consists of information gathered by way of a common template, primarily for an overview, EU-level synthesis report: Approaches to Unaccompanied Minors Following Status Determination in the EU plus Norway. All reports are made available at: https://ec.europa.eu/home-affairs/what-wedo/networks/european_migration_network_en.

This report has been accepted for publication by the Institute, which does not itself take institutional policy positions. All ESRI Research Series reports are peer reviewed prior to publication. The authors are solely responsible for the content and the views expressed do not represent the position of the Economic and Social Research Institute, the Irish Naturalisation and Immigration Service, the Department of Justice and Equality, or the European Commission, Directorate-General Migration and Home Affairs. 



\section{TABLE OF CONTENTS}

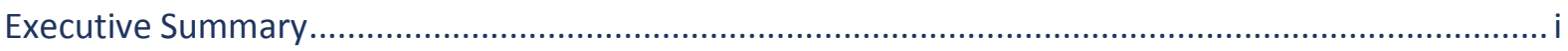

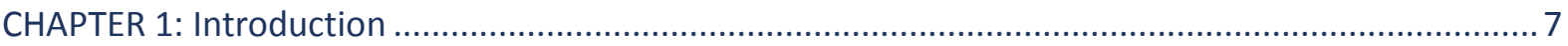

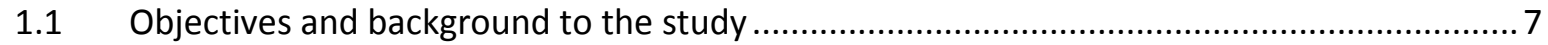

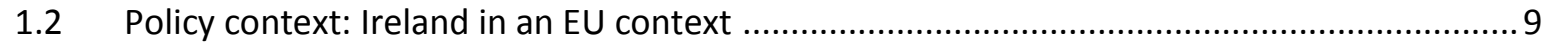

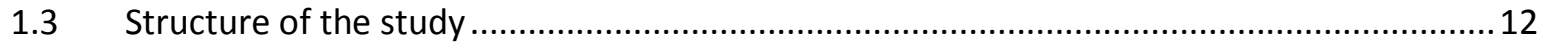

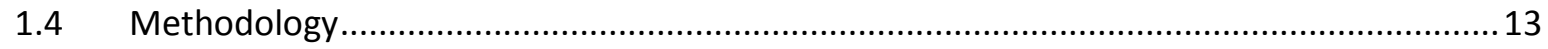

1.5 Definitions and scope................................................................................... 14

CHAPTER 2: Unaccompanied minors in Ireland and the EU: profile, flows and data.......................17

2.1 Overview of main trends regarding unaccompanied minors in Europe............................17

2.2 Overview of main trends regarding unaccompanied minors in Ireland ..........................21

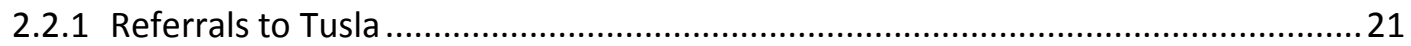

2.2.2 Irish Refugee Protection Programme ........................................................... 23

2.2.3 Protection applications and grants............................................................. 24

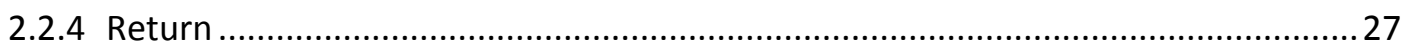

2.2.5 Challenges arising from data gaps ........................................................... 28

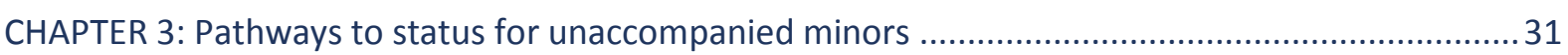

3.1 Unaccompanied minors arriving in Ireland seeking international protection.....................33

3.1.1 International protection and permission to remain ........................................33

3.1.2 Access to international protection for spontaneously arriving unaccompanied minors .................................................................................................... 35

3.1.3 Unaccompanied minors arriving in Ireland through government-led programmes 37

3.2 Alternative immigration statuses for unaccompanied minors .....................................38

3.2.1 Addressing the interaction of children in care with the immigration system .........40

U.3 Unaccompanied minor victims of trafficking ........................................................ 41

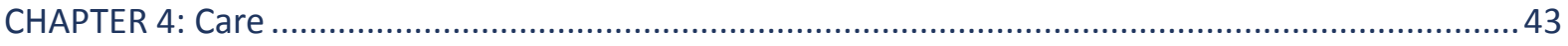

4.1 Care of unaccompanied minors: law and policy ................................................43

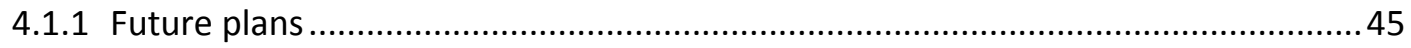

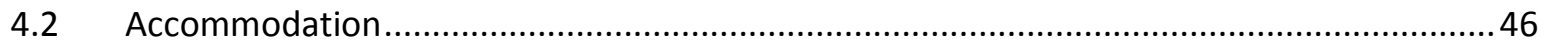

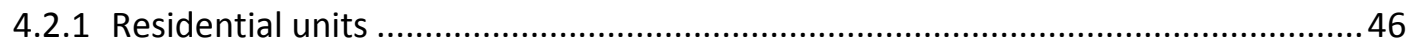

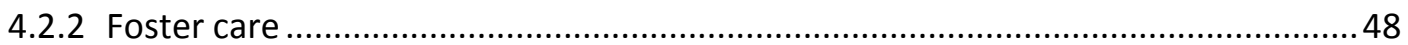

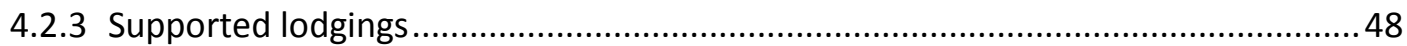


4.3 Appointment of a representative

4.3.1 Tusla 49

4.3.2 Guardian ad litem . 52

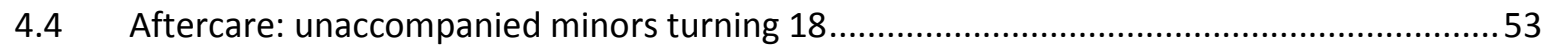

CHAPTER 5: Access to education and employment, social welfare and healthcare .........................59

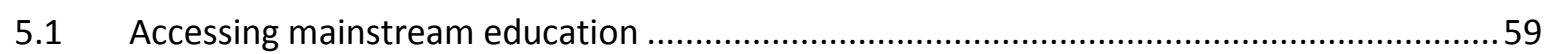

5.1.1 The Youth and Education Service for Refugees and Migrants .............................60

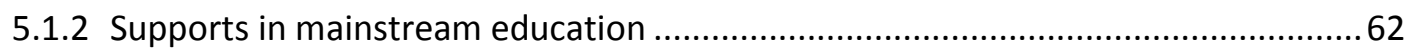

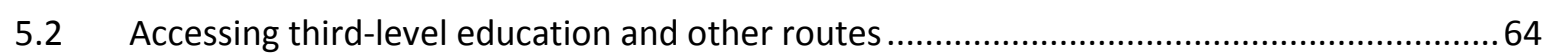

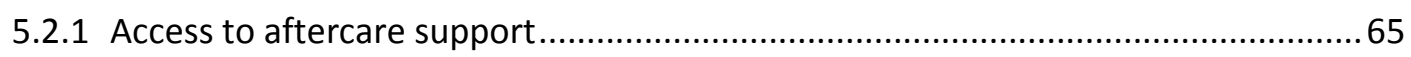

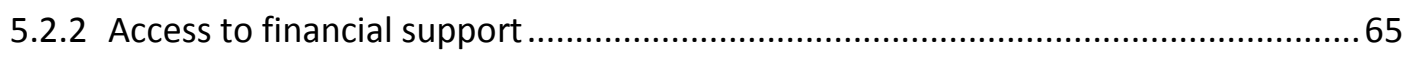

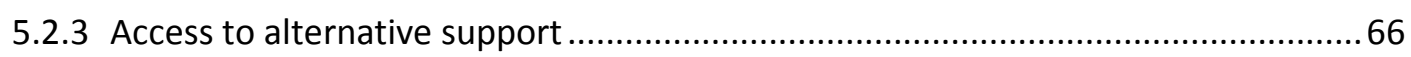

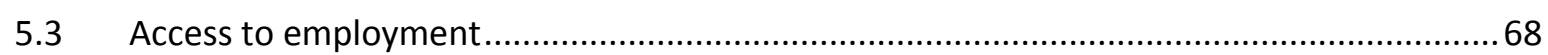



5.3.2 Access to employment for aged-out unaccompanied minors ..............................69

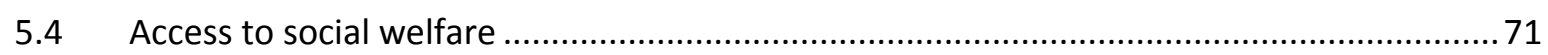

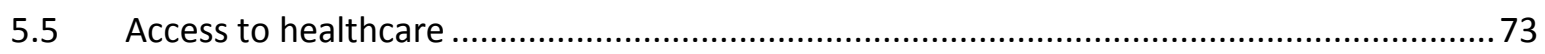

CHAPTER 6: Family reunification in Ireland and returning to family in the country of origin .............77

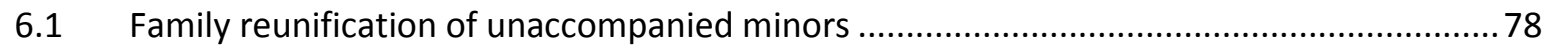

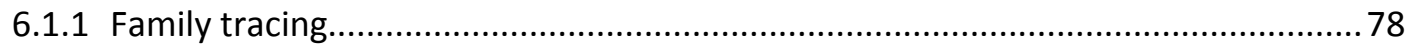

6.1.2 Voluntary return: reuniting with family in the country of origin ......................... 79

6.1.3 Family reunification: reuniting with family in Ireland ....................................8 82

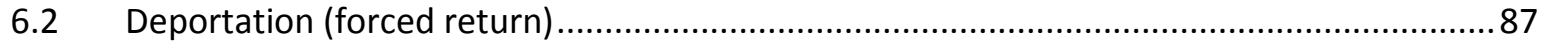

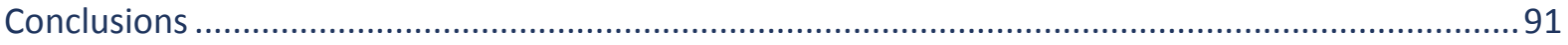

Pathways to status for unaccompanied minors ............................................................ 92

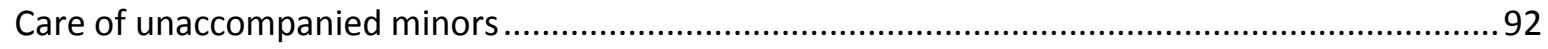

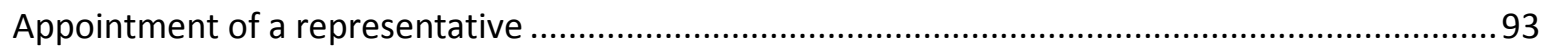

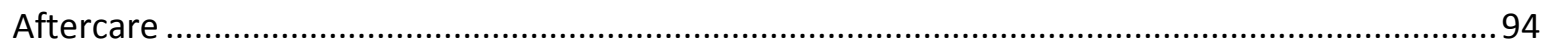

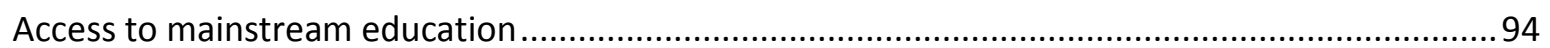

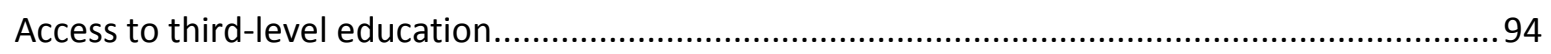

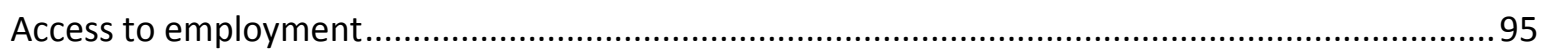

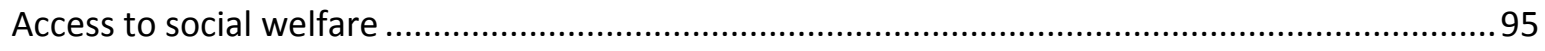

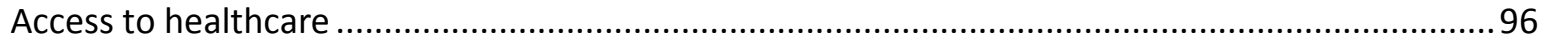

Family reunification in Ireland and returning to family in the country of origin..........................96 


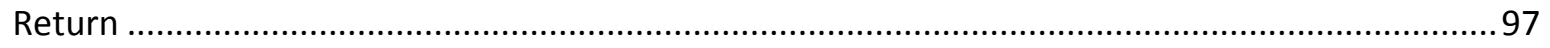

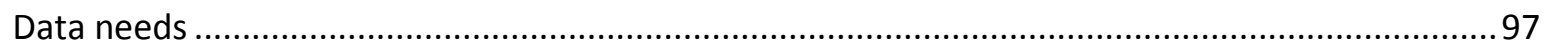

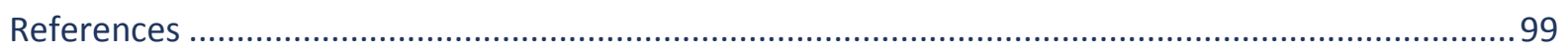

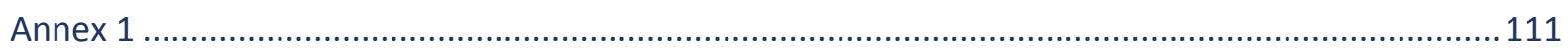

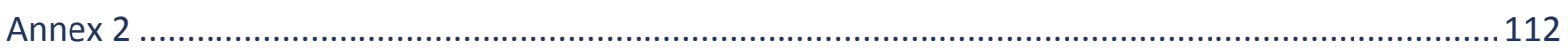




\section{LIST OF FIGURES}

Figure 2.1 Unaccompanied minors seeking international protection in EU Member States and Norway, 2008-2017.

Figure 2.2 Unaccompanied minors seeking international protection in EU Member States and Norway, 2014-2017

Figure 2.3 Unaccompanied minors referred to SWTSCSA and placed in care, and number of international protection applications made by unaccompanied minors, 2014-2017 .....25

\section{LIST OF TABLES}

Table 2.1 Referrals to SWTSCSA, Tusla, 2014-2017

Table 2.2 Total number of applications for international protection in Ireland made by unaccompanied minors according to gender, 2014-2017

Table 2.3 Number of positive decisions on applications for international protection (refugee status and subsidiary protection status) submitted by unaccompanied minors.

\section{LIST OF BOXES}

Box 1 Unaccompanied minors turning 18 without status .56

Box 2 Access to third-level education for unaccompanied minors without status........................67

Box 3 Access to employment for unaccompanied minors without status .................................... 70

Box 4 Access to social welfare for aged-out minors without status.............................................. 72 


\section{ABBREVIATIONS AND IRISH TERMS}

\begin{tabular}{|c|c|}
\hline An Garda Síochána & Irish Police Force \\
\hline CDETB & City of Dublin Education and Training Board \\
\hline CEAS & Common European Asylum System \\
\hline CRA & Children's Rights Alliance \\
\hline CRC & UN Convention on the Rights of the Child \\
\hline EEA & $\begin{array}{l}\text { European Economic Area, which comprises the EU Member States in } \\
\text { addition to Iceland, Liechtenstein and Norway }\end{array}$ \\
\hline EMN & European Migration Network \\
\hline EU & European Union \\
\hline GNIB & Garda National Immigration Bureau \\
\hline GP & General Practitioner \\
\hline GRETA & Group of Experts on Action against Trafficking in Human Beings \\
\hline HIQA & Health Information and Quality Authority \\
\hline HSE & Health Service Executive \\
\hline $\mathrm{ICl}$ & Immigrant Council of Ireland \\
\hline INIS & Irish Naturalisation and Immigration Service \\
\hline IOM & International Organization for Migration \\
\hline IPAT & International Protection Appeals Tribunal \\
\hline IPO & International Protection Office \\
\hline IRC & Irish Refugee Council \\
\hline IRPP & Irish Refugee Protection Programme \\
\hline MAP & Migrant Access Programme \\
\hline Nasc & Nasc, the Migrant and Refugee Rights Centre \\
\hline NGO & Non-Governmental Organisation \\
\hline Oireachtas & Irish Parliament \\
\hline ORAC & Office of the Refugee Applications Commissioner \\
\hline PLC & Post-Leaving Certificate \\
\hline PPSN & Personal Public Service Number \\
\hline RIA & Reception and Integration Agency \\
\hline SUSI & Student Universal Support Ireland \\
\hline SWTSCSA & Social Work Team for Separated Children Seeking Asylum \\
\hline Tusla & Child and Family Agency \\
\hline UNHCR & United Nations High Commissioner for Refugees \\
\hline
\end{tabular}




\section{EXECUTIVE SUMMARY}

An estimated 45,500 unaccompanied minors - children below the age of 18 who are not in the care of, or accompanied by, a responsible adult - lodged asylum applications globally in 2017, ${ }^{1}$ representing a 33 per cent increase since 2014 $(34,300)$ (UNHCR, 2018). In 2017, over 650,000 people lodged an application for international protection in the European Union (EU) (Eurostat, 2018a), 31,395 of whom were unaccompanied minors (Eurostat, 2018b), constituting more than a 30 per cent increase since 2014. The number of unaccompanied minors recorded in Ireland is low compared to other EU Member States. However, consistent with EU and international trends, this number has increased since 2014. In 2017, 175 unaccompanied minors were referred to the Social Work Team for Separated Children Seeking Asylum (Dublin) (SWTSCSA) of the Child and Family Agency, Tusla (Tusla), which is responsible for the care of unaccompanied minors in Ireland, up from 97 in 2014 (Tusla, 2018d, 2018e).

Much comparative information and research exists on the practices in Ireland and in EU Member States concerning unaccompanied minors seeking international protection. There is less research and up-to-date information on the practices and integration measures in place for unaccompanied minors who have received an international protection or immigration status decision.

This study examines the policies and practices on unaccompanied minors following an international protection or immigration status decision in Ireland. Principally, it looks at two potential outcomes for unaccompanied minors in Ireland: a positive decision for immigration permission or international protection and subsequent integration in-country and forced or voluntary return. The study also looks at implications arising from a lack of status.

\section{UNACCOMPANIED MINORS WITH AN INTERNATIONAL PROTECTION OR IMMIGRATION STATUS DECISION}

Despite a 39 per cent increase in the number of unaccompanied minors referred to the SWTSCSA between 2016 and 2017 (from 126 to 175), the number of applications for international protection decreased from 34 in 2016 to 30 in 2017 (Sheridan, 2018).

Unaccompanied minors referred to the SWTSCSA include unaccompanied minors arriving spontaneously in Ireland and unaccompanied minors arriving through 
government-led programmes. The Minister for Justice and Equality reported in May 2017 that 22 unaccompanied minors, including unaccompanied minors as defined by the Greek authorities, had been relocated to Ireland under the Irish Refugee Protection Programme (IRPP). ${ }^{2} \mathrm{~A}$ total of 41 unaccompanied minors were brought from Calais under the Calais Special Project. ${ }^{3}$ Many of these unaccompanied minors were granted programme refugee status on arrival, while others were granted refugee status following the submission of an application for international protection shortly after arriving in Ireland.

In Ireland the majority of unaccompanied minors eventually enter the international protection process, as a minor or later as an adult. ${ }^{4}$ However, most unaccompanied minors do not receive a decision on an application for international protection before turning 18 years of age. ${ }^{5}$ Furthermore, the SWTSCSA reported that alternative immigration permissions are rarely applied for. ${ }^{6} \mathrm{As}$ a result, only a small proportion of unaccompanied minors who arrived spontaneously in Ireland have an immigration status.

Tusla is responsible for making an application on behalf of unaccompanied minors. However, some social workers delay submitting applications (Quinn et al., 2014; Arnold et al., 2015; Mannion, 2016; Arnold and Ní Raghallaigh, 2017) for various reasons including the view that an application is not in the child's best interests and that the child may not be deemed ready for the international protection process (Quinn et al., 2014), as well as the fear that negative decisions would lead to children going missing. ${ }^{7}$

The practice of delaying applications for international protection has met with concern from the Ombudsman for Children's Office, Non-Governmental Organisations (NGOs) and legal professionals assisting in securing legal status for unaccompanied minors. Research has noted that the decision to delay an application may negatively impact on a minor's entitlements, including family reunification (Arnold and Sarsfield Collins, 2011; Mullally, 2011; Arnold, 2013; Arnold et al., 2015; Mannion, 2016) and access to employment, education, citizenship, aftercare services and other supports and services (Horgan et al., 2011; Arnold et al., 2015; ICl, 2016; Mannion, 2016; Ní Raghallaigh and Thornton, 2017; Sirriyeh and Ní Raghallaigh, 2018).

Parliamentary Question 30 May 2017 [25828/17], oireachtasdebates.oireachtas.ie.

Consultation with SWTSCSA, February 2018.

Interview with SWTSCSA, January 2018.

Ibid.

Interview with SWTSCSA, January 2018.

Ibid. 


\section{CARE}

Since 2010, the SWTSCSA has provided care to unaccompanied minors on the basis of an 'equity of care' principle, according to which all unaccompanied minors receive care on a par with other children in the care system up to the age of 18 . In line with this approach, all unaccompanied minors are assigned a social worker and placed in foster care, supported lodgings or residential units (Quinn et al., 2014). Research has indicated that unaccompanied minors in Ireland receive a high standard of care in comparison with other EU countries (Arnold and Ní Raghallaigh, 2017; Brindle, 2017).

\section{APPOINTMENT OF A REPRESENTATIVE}

In June 2018, the government opted into the recast Reception Conditions Directive (the Directive), which was transposed into national law with the adoption of the European Communities (Reception Conditions) Regulations 2018 (2018 Regulations). ${ }^{8}$ The 2018 Regulations provide for the appointment of a Tusla employee or other individual to represent and assist the unaccompanied minor in line with the Directive. ${ }^{9}$

Tusla's ability to exercise legal capacity for unaccompanied minors where necessary depends on the section of the Child Care Act 1991, as amended (1991 Act) utilised by Tusla to take them into its care. Typically, the SWTSCSA takes unaccompanied minors into care on the basis of section 4 of the 1991 Act (Quinn et al., 2014). Under section 4, parental consent to the child being taken into care must be provided. However, following the inspection of care facilities provided to unaccompanied minors in January 2018, the Health Information and Quality Authority (HIQA) (2018a) highlighted that such consent was missing and admission into care under section 4 was a source of uncertainty for care staff, such as in relation to providing consent for school activities.

In contrast, where the SWTSCSA takes the child into its care on the basis of a full care order granted by the court under section 18 of the 1991 Act, the SWTSCSA has 'the like control over the child as if it were his parent'. ${ }^{10}$ Tusla is therefore entitled to make all decisions concerning the welfare of the child until the child reaches the age of 18. While research has indicated that applications for care orders have been made infrequently in practice (Arnold and Kelly, 2012; Arnold, 2013; Horgan and

S.I. No. 230 of 2018, European Communities (Reception Conditions) Regulations 2018.

Ibid., Regulation 10.

Child Care Act 1991, s 18(3)(a). 
Ní Raghallaigh, 2017), the SWTSCSA stated that the pursuance of care orders is becoming more common. ${ }^{11}$

\section{AFTERCARE}

The National Aftercare Policy for Alternative Care identifies unaccompanied minors seeking international protection as requiring particular support in aftercare planning (Tusla, 2017b). Section 45 of the 1991 Act places a statutory duty on Tusla to undertake a needs assessment of eligible children leaving care to determine the supports and services they require. The assistance provided in accordance with an aftercare plan depends on Tusla's assessment of the child's needs and age. Eligible children are those who have been in the care of the State for at least 12 months between the ages of 13 and $18 .{ }^{12}$ As more than 50 per cent of unaccompanied minors referred to the SWTSCSA are aged between 16 and 17,13 some unaccompanied minors may not meet the eligibility requirements for aftercare.

HIQA (2018a, 2018b) has highlighted that aftercare planning for unaccompanied minors in residential centres is inconsistent. HIQA (2018a) reported instances of unaccompanied minors aged 17 years and with refugee status not having an aftercare plan in place or inadequate plans having been developed.

\section{MAINSTREAM EDUCATION}

All unaccompanied minors, regardless of their status, are entitled to primary and secondary education in Ireland. The SWTSCSA usually refers unaccompanied minors to the City of Dublin Education and Training Board (CDETB)'s Youth and Education Service for Refugees and Migrants (YES) (formerly the Separated Children's Service) for introductory English classes and other supports prior to entry into mainstream education (Quinn et al., 2014).

While many unaccompanied minors may be capable of entering mainstream education without difficulty, YES highlighted the need to provide access to alternative education routes for some unaccompanied minors aged 16 to 23 years. YES noted that such alternative routes could take the form of vocational education programmes and training programmes. ${ }^{14}$

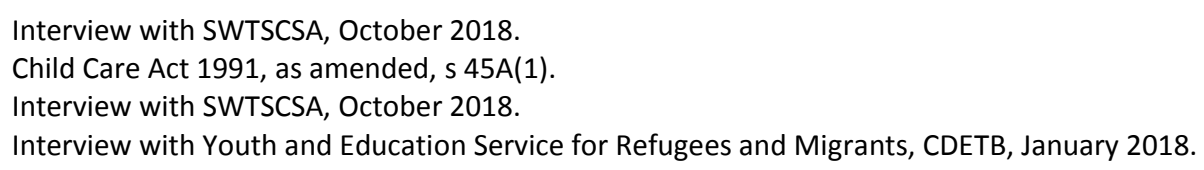




\section{THIRD-LEVEL EDUCATION}

Unlike ordinarily resident young people in Ireland, aged-out minors (or unaccompanied minors aged 18 and over) are not automatically entitled to access free third-level education. As part of aftercare policy, Tusla may cover fees for Post Leaving Certificate courses, which offer level 5 and 6 qualifications aimed at vocational and technological skills (Tusla, 2017c).

Aged-out minors with refugee status, subsidiary protection status or other residence permission may be entitled to free third-level education under the Free Fees Initiative led by the Department of Education and Skills and administered by Student Universal Support Ireland (SUSI). ${ }^{15}$ However, many unaccompanied minors may be precluded from receiving the grant as they are unlikely to have spent the required three years in the Irish State with a legal immigration status.

\section{EMPLOYMENT}

Pursuant to section 53(a) of the International Protection Act 2015 (2015 Act), beneficiaries of international protection are entitled to seek and enter employment.

Racism and discrimination, limited social networks, lack of recognition of prior learning or foreign qualifications, and immigration status are identified as potential barriers to training and employment (CDETB Youth and Education Service for Refugees and Migrants, 2018).

Research on migrant children has highlighted how the lack of an immigration status, or an inappropriate immigration permission being granted, can affect migrant children's eligibility to seek employment, which may impact negatively on their employment prospects (Mannion, 2016).

\section{SOCIAL WELFARE}

Tusla provides a weekly Foster Care Allowance to foster carers of children, including unaccompanied minors, while foster carers may also receive various additional financial supports provided by the State to families with children. Unaccompanied minors who are granted Stamp 4 permission are also entitled to access some social welfare payments on reaching the age of 18. In addition, agedout minors who have been granted a status and are in education/training are entitled to the Standardised National Aftercare Allowance on reaching the age of 18. Aged-out minors who are still awaiting a final decision on their application for

15 Higher Education Authority, 'Free Fees Initiative', http://hea.ie/funding-governance-performance/funding/studentfinance/course-fees/. 
international protection and living in Direct Provision are entitled to a small weekly allowance of $€ 21.60$ (which will be increased to $€ 38.30$ per week in 2019).

\section{HEALTH}

All unaccompanied minors have access to the public healthcare system in Ireland. HIQA (2018a) however reported in January 2018 that, while medical screening was provided on admission, a comprehensive assessment of emotional needs was absent from some of the care plans of unaccompanied minors in residential care, and therapeutic needs of all children were not adequately assessed and addressed through referrals to specialist services.

\section{REUNITING WITH FAMILY}

Under the 2015 Act, an unaccompanied minor is entitled to reunification with his or her parents and the parents' children under the age of 18. Aged-out minor beneficiaries of international protection who submit applications for family reunification after turning 18 years old may face difficulties in making successful applications for family reunification as they are no longer treated as children at the time of application (Cosgrave and Thornton, 2015).

Unaccompanied minors who are not granted international protection status but are granted permission to remain or other residence permission have no automatic entitlement to family reunification. A smaller number of unaccompanied minors reunite with family through voluntary return to their country of origin.

Much of the SWTSCSA's work relates to reuniting unaccompanied minors with their families in Ireland. ${ }^{16}$ The SWTSCSA stated that social workers may face difficulties in allocating sufficient resources to supporting families of unaccompanied minors, noting in particular the housing crisis and administrative barriers as preventing access to housing and supports on arrival. ${ }^{17}$

\section{DEPORTATION}

While no legislative prohibition exists for the deportation of unaccompanied minors, deportations of unaccompanied minors do not normally take place in practice. ${ }^{18}$ Research indicates that the uncertainty surrounding the international protection process is found to raise fears of being deported among unaccompanied minors (Ní Raghallaigh, 2013).

Interview with SWTSCSA, January 2018.

lbid.

Consultation with Repatriation Division, INIS, February 2018. 


\section{Introduction}

\subsection{OBJECTIVES AND BACKGROUND TO THE STUDY}

The number of people forcibly displaced worldwide reached a record high of 68.5 million by the end of 2017, including 25.4 million refugees, 52 per cent of whom were children (UNHCR, 2018). Many of these children were unaccompanied minors, or children below the age of 18 who were not in the care of, or accompanied by, a responsible adult, who are recognised as being in a particularly vulnerable situation in the context of migration (UNHCR, 2018). ${ }^{19}$ An estimated 45,500 unaccompanied minors lodged international protection applications globally in 2017 (UNHCR, 2018). ${ }^{20}$ While this represented a reduction in the number of unaccompanied minors seeking international protection since 2016, when 75,000 unaccompanied minors sought protection at the peak of the global refugee and migrant crisis, there had been a 33 per cent increase since 2014 $(34,300)$ (UNHCR, 2018). These figures make up only a portion of the total number of unaccompanied minors worldwide, as many migrate for reasons other than seeking international protection and are therefore not captured in the data.

Over 100,000 children arrived in the European Union (EU) in 2016, more than a third of whom were unaccompanied or separated from their families (UNHCR, UNICEF and IOM, 2017). In 2017, over 650,000 people lodged an application for international protection in the EU, 31,395 of whom were unaccompanied minors (Eurostat, 2018b). Reflecting international trends, this represented a reduction in the number of unaccompanied minors seeking international protection compared to 2016; however, it constituted more than a 30 per cent increase since 2014 (see Section 2.1). EU Member States have also recorded a significant number of unaccompanied minors who are not seeking international protection and who do not submit applications for international protection (EMN, 2018a). Thus, in addition to escaping war, conflict and persecution, unaccompanied minors arrive in Europe for a range of reasons including to escape poverty or discrimination, to join family members (European Commission, 2010) and for education reasons (UNICEF and REACH, 2017).

The number of unaccompanied minors recorded in Ireland is low compared to many other EU Member States. However, consistent with EU and international trends, the number of unaccompanied minors referred to the Child and Family Agency, Tusla (Tusla), Social Work Team for Separated Children Seeking Asylum 
(SWTSCSA), which is based in Dublin and is responsible for the care of unaccompanied minors in Ireland, has increased since 2014. In 2017, 175 unaccompanied minors were referred to the SWTSCSA, up from 97 in 2014 (Tusla, 2018d, 2018e). As in other EU Member States, unaccompanied minors arrive in Ireland for a variety of reasons, including seeking international protection, reunification with family members living in Ireland or the United Kingdom (UK), or as victims of trafficking (Quinn et al., 2014).

There is no specific legal status for unaccompanied minors in Ireland. The majority of unaccompanied minors eventually enter the international protection process as a minor or later as an adult. ${ }^{21}$ As most unaccompanied minors do not receive a decision on an application for international protection before turning 18 years of age and alternative immigration permissions are rarely applied for, ${ }^{22}$ only a small proportion of unaccompanied minors present in Ireland have an immigration status. In 2014, 30 applications for international protection were submitted by unaccompanied minors, while 33 were submitted in 2015 and 34 in 2016 (ORAC, $2015,2016,2017)$. Despite a 39 per cent increase in the number of unaccompanied minors referred to Tusla between 2016 and 2017, the number of applications for international protection decreased in 2017 to 30 (Sheridan, 2018).

In response to the sustained increase in displaced persons, the United Nations (UN) adopted the New York Declaration in 2016, in which UN Member States reaffirmed their commitment to protect the human rights of migrants, including in particular unaccompanied minors, regardless of their immigration status. ${ }^{23}$ International standards for protecting the rights of children are set out in a number of treaties including the UN Convention on the Rights of the Child (CRC), the application of which the UN Committee on the Rights of the Child (the Committee) and the UN Refugee Agency (UNHCR) clarified in respect of unaccompanied minors (the Committee, 2005; UNHCR, 2009).

Globally, the Committee observed that data collection is a persistent challenge, with limited and inconsistent figures hindering a more comprehensive analysis of unaccompanied minors and their needs (the Committee, 2005). Bhabha (2001, 2014) argued that insufficient collaboration among governmental departments and a lack of legal expertise and awareness among child protection officials of immigration options available to unaccompanied minors can result in delays in resolving their immigration status. Bhabha $(2001,2014)$ argued that this can lead to a 'limbo of indeterminacy' and significant uncertainties upon reaching the age of majority. The Committee also noted that prompt access to robust guardianship systems and legal advice is not always provided and that many unaccompanied 
minors experience discrimination and are denied access to education and employment (the Committee, 2005).

Much comparative information and research exists on the practices in Ireland and in EU Member States concerning unaccompanied minors seeking international protection. There is less research and up-to-date information on the practices and integration measures in place for unaccompanied minors who have received an international protection or immigration status decision. EU law does not set out standards relating to the situation when unaccompanied minors turn 18. This is left largely to the discretion of the Member States (EMN, 2018a).

This study examines the policies and practices on unaccompanied minors following a status decision in Ireland. It does not examine status determination procedures; rather it looks at what happens once an international protection or immigration decision is made. Principally, this study looks at two potential outcomes for unaccompanied minors in Ireland: a positive decision for immigration permission or international protection and subsequent integration in-country and forced or voluntary return. The study focuses particularly on provision of care and assistance for unaccompanied minors approaching 18 years of age. It also looks at implications arising from a lack of status.

\subsection{POLICY CONTEXT: IRELAND IN AN EU CONTEXT}

Previous European Migration Network (EMN) studies on unaccompanied minors have acknowledged improvements made to standards of care provided to unaccompanied minors across the EU (Joyce and Quinn, 2009; EMN, 2010, 2015; Quinn et al., 2014). However, EMN studies have also highlighted concerns regarding gaps in data, collaboration between various authorities dealing with unaccompanied minors, the role and appointment of a guardian or representative, the identification of durable solutions for unaccompanied minors and varied supports provided to unaccompanied minors turning 18 (Joyce and Quinn, 2009; EMN, 2010, 2015, 2018a).

Four of the primary instruments making up the legislative framework of the Common European Asylum System (CEAS) - the (recast) Asylum Procedures Directive, ${ }^{24}$ the (recast) Qualification Directive, ${ }^{25}$ the (recast) Reception Conditions

24 Directive 2013/32/EU of the European Parliament and of the Council of 26 June 2013 on common procedures for granting and withdrawing international protection (recast).

25 Directive 2011/95/EU of the European Parliament and of the Council of 13 December 2011 on standards for the qualification of third-country nationals or stateless persons as beneficiaries of international protection, for a uniform status for refugees or for persons eligible for subsidiary protection, and for the content of the protection granted (recast). 
Directive, ${ }^{26}$ and the (recast) Dublin Regulation ${ }^{27}$ - contain a number of specific provisions for unaccompanied minors. In developing the CEAS, the Commission recognised the need for proper identification and responses to the needs of children, especially unaccompanied minors (European Commission, 2007). As provided for in Protocol 21 annexed to the Treaty on the Function of the European Union, Ireland does not take part in the adoption of measures in the area of Freedom, Security and Justice, including in relation to the CEAS, unless Ireland notifies the European Council of its wish to take part in the adoption and application of such measures. Ireland has exercised its right to opt in to the original Asylum Procedures Directive, ${ }^{28}$ the original Qualification Directive, ${ }^{29}$ the (recast) Reception Conditions Directive and the (recast) Dublin Regulation.

While acknowledging that EU legislative instruments address the specific situation of unaccompanied minors in the context of international protection, the EU Action Plan on Unaccompanied Minors 2010-2014 stated that greater coherence and cooperation was necessary for a common EU approach to unaccompanied minors (European Commission, 2010). The Action Plan specifically identified shortcomings in consistent data collection among EU Member States, particularly because several government departments may be responsible for the reception and care of unaccompanied minors. It stated that statistics should cover all unaccompanied minors arriving in the EU, including those who do not apply for international protection, in order to develop appropriate solutions. In its report on the implementation of the Action Plan, the Commission noted that several Member States do not collect such data and do not make use of the statistical category introduced by Eurostat in relation to non-international protection seeking unaccompanied minors (European Commission, 2012). The Action Plan also highlighted the need for durable solutions in relation to the future of each unaccompanied minor and relevant authorities should decide on such a solution within the shortest possible period (European Commission, 2010).

In May 2015, the European Commission adopted the European Agenda on Migration, in which it stated that it would develop a comprehensive strategy to follow up on the Action Plan on Unaccompanied Minors (European Commission, 2015). Later that year, the EU Agency for Fundamental Rights in co-operation with the European Commission published a handbook on guardianship systems for

26 Directive 2013/33/EU of the European Parliament and of the Council of 26 June 2013 laying down standards for the reception of applicants for international protection (recast).

27 Regulation (EU) No. 604/2013 of the European Parliament and of the Council of 26 June 2013 establishing the criteria and mechanisms for determining the Member State responsible for examining an application for international protection lodged in one of the Member States by a third-country national or a stateless person (recast).

28 Council Directive 2005/85/EC of 1 December 2005 on minimum standards on procedures in Member States for granting and withdrawing refugee status.

29 Council Directive 2004/83/EC of 29 April 2004 on minimum standards for the qualification and status of third country nationals or stateless persons as refugees or as persons who otherwise need international protection and the content of the protection granted. 
children in need of protection in Member States. The handbook highlighted the absence of a uniform approach to guardianship across the EU and the lack of specialised training for guardians on the needs of unaccompanied minors, among other challenges, and proposed recommendations to strengthen national guardianship systems (European Union Agency for Fundamental Rights, 2015).

In addition, the Council adopted two decisions to establish the temporary relocation scheme, which required Member States to commit to relocating 160,000 persons in need of international protection from Italy and Greece and which prioritised the relocation of vulnerable applicants, including unaccompanied minors. ${ }^{30}$ The Irish government participated in both programmes, according unaccompanied minors special priority. The Minister for Justice and Equality reported in May 2017 that 22 unaccompanied minors, including unaccompanied minors as defined by the Greek authorities, had been relocated to Ireland under the Irish Refugee Protection Programme (IRPP). ${ }^{31}$ Under a separate initiative, in 2017 and 2018, the Irish government admitted 41 unaccompanied minors to Ireland who had resided in the former migrant camp in Calais (see Section 2.2.2).

Most recently, in April 2017, the Commission issued a Communication on the protection of children in migration to address protection gaps and needs (European Commission, 2017). The Communication highlighted the need for the early integration of children, through mainstream and targeted measures, and provision of supports and opportunities for continued education and training for children transitioning into further study or the labour market (European Commission, 2017).

Since 2010, the SWTSCSA provides care to unaccompanied minors on the basis of an 'equity of care' principle, according to which all unaccompanied minors receive care on a par with other children in the care system up to the age of 18 . In line with this approach, all unaccompanied minors are assigned a social worker and placed in foster care, supported lodgings or residential units (Quinn et al., 2014).

Research has indicated that unaccompanied minors in Ireland receive a high standard of care in comparison with other EU countries, and positive developments in the care of unaccompanied minors have been welcomed (Arnold and Ní Raghallaigh, 2017; Brindle, 2017). However, while significant improvements have been made to the model of care provided to unaccompanied minors in Ireland, the previous EMN study on unaccompanied minors in 2014 highlighted the lack of a national strategy and oversight of care provision. It also noted the

\footnotetext{
30 Council Decision (EU) 2015/1523 of 14 September 2015 establishing provisional measures in the area of international protection for the benefit of Italy and of Greece.

31 Parliamentary Question 30 May 2017 [25828/17], oireachtasdebates.oireachtas.ie.
} 
potential for variation in the experience of unaccompanied minors reaching the age of 18, particularly in relation to their legal status (Quinn et al., 2014) (see Chapter 4).

\subsection{STRUCTURE OF THE STUDY}

This study builds on the 2014 study and focuses on the situation of unaccompanied minors following a decision on their international protection or immigration status in Ireland. The literature identifies finding a durable solution as the 'ultimate aim' when addressing the future of unaccompanied minors (UN Committee on the Rights of the Child, 2005; Arnold et al., 2015; European Commission, 2017). A durable solution for an unaccompanied minor consists of remaining in the host Member State and local integration on the basis of a secure legal status, or return and reintegration in the country of origin or a third country (the Committee, 2005; European Commission, 2017).

The European Commission underlines the importance of comprehensive data collection on unaccompanied minors as part of the durable solution process (European Commission, 2017). Chapter 2 presents available data on recent trends relating to unaccompanied minors in Ireland and the EU.

The European Commission also states that Member States should establish procedures to help identify durable solutions for each unaccompanied minor to avoid children being left in prolonged periods of limbo as regards their legal status (European Commission, 2017). Chapter 3 maps the pathways to status available to unaccompanied minors once they arrive in Ireland, to inform the discussion in later chapters of the approach to unaccompanied minors in Ireland.

Early integration, as one durable solution, is highlighted as crucial to the child's development into adulthood (European Commission, 2017). Housing, health, education and employment are among the main domains in which such integration takes place (Ager and Strang, 2008; Gusciute et al., 2016). Housing for unaccompanied minors in Ireland can include the type of care arrangement provided to the minor while in the care of Tusla, be it in foster care, supported lodgings or residential accommodation, and the provision of care, including healthcare and social welfare supports, in each setting. Schools have also been identified as one of the most important settings for children in developing relationships supportive of integration into the local community as well as providing skills and competences in support of future employment (Ager and Strang, 2008). Chapters 4 and 5 focus on the domains of integration as applied to the situation of unaccompanied minors in Ireland. Chapter 4 looks at the care of unaccompanied minors, including the care and guardianship arrangements provided for unaccompanied minors, as well as the aftercare supports available to 
unaccompanied minors turning 18 years of age. Chapter 5 focuses on access to education and employment for unaccompanied minors and the provision of healthcare and social welfare assistance.

Return and reintegration in the country of origin is another key durable solution as established by UNHCR (UNHCR, 2017c). While no legislative prohibition of the deportation (forced return) of unaccompanied minors exists in Ireland, and unaccompanied minors can be issued with a negative international protection decision and deportation order on the same basis as all international protection applicants, deportations of unaccompanied minors do not normally take place in Ireland in practice. ${ }^{32}$ Return is normally only facilitated for the purposes of family reunification or where return is otherwise in the best interests of the child and the unaccompanied minor is returning to a family environment. ${ }^{33}$

Article 9 of the CRC states that a child should not be separated from their parents except when it is deemed to be necessary in the best interests of the child. The Committee states that all efforts should be undertaken to reunite an unaccompanied minor with their parents (the Committee, 2005). UNHCR and the Irish Naturalisation and Immigration Service (INIS) noted that, where return and reintegration are not possible, in-country family reunification contributes towards the integration of third-country nationals in Ireland (UNHCR Ireland, 2013; INIS, 2016). Research on children's experience of migration finds that family support is important in facilitating the transition to living in Ireland (Ní Laoire et al., 2009). Chapter 6 addresses family reunification, both in Ireland and in the context of the return of unaccompanied minors to their country of origin.

\subsection{METHODOLOGY}

This study collates data and information on legislation, policies and practices that address the situation of unaccompanied minors who have received a final decision on an application for international protection or other immigration status. This is the first comprehensive study in Ireland to examine practices and integration measures for unaccompanied minors post-status decision.

The report is based on information gathered according to commonly agreed EMN study specifications in preparing the Irish contribution to an EU-wide EMN study on Approaches to Unaccompanied Minors Following Status Determination in the EU plus Norway. As with all EMN studies, a similar report was produced by the 
other EMN National Contact Points, and an EU-wide synthesis report has been compiled (EMN, 2018a).

Desk research was undertaken at the outset, including a review of existing academic and policy-based literature. Interviews were undertaken with officials from the Child and Family Agency, Tusla's Social Work Team for Separated Children Seeking Asylum, the City of Dublin Education and Training Board's Youth and Education Service for Refugees and Migrants and the Immigrant Council of Ireland. Information was also sought through correspondence with the International Organization for Migration, the International Protection Office, the Irish Refugee Protection Programme, the Irish Naturalisation and Immigration Service, the Legal Aid Board, Spirasi and the Department of Children and Youth Affairs.

\subsection{DEFINITIONS AND SCOPE}

The definition of the term 'unaccompanied minor' varies widely in law, policy and literature and is often used interchangeably with the term 'separated child'.

The Committee defines an unaccompanied minor as a child who has been separated from both parents and other relatives and is not being cared for by an adult who, by law or custom, is responsible for doing so (the Committee, 2005). A child is defined in Article 1 of the CRC as every human being below the age of 18 years unless under the law applicable to the child, majority is attained earlier.

On the other hand, a separated child is defined by the Committee as a child who has been separated from both parents, or from their previous legal or customary primary caregiver, but not necessarily from other relatives (the Committee, 2005). The Separated Children in Europe Programme (SCEP) Statement of Good Practice defines separated children as children 'under 18 years of age, outside their country of origin and separated from both parents, or their previous legal, or customary primary caregiver' (SCEP, 2009).

Neither the term 'unaccompanied minor' nor the term 'separated child' is explicitly defined in Irish legislation. Section 14 of the International Protection Act 2015 (2015 Act) is entitled 'unaccompanied child seeking international protection' and provides for the referral to Tusla of persons seeking to make an application for international protection who have not attained the age of 18 years and are not accompanied by an adult who is taking responsibility for their care and protection. This definition includes children who may be alone on arrival in Ireland or who may be accompanied by extended family members or other adults who are not their primary caregiver. As such, the definition is close to that recommended for use by SCEP. 
In contrast, the national service dedicated to the care of unaccompanied children is entitled 'Social Work Team for Separated Children Seeking Asylum' and uses the term 'separated child', which it defines as 'children under eighteen years of age who are outside their country of origin, who have applied for asylum and are separated from their parents or their legal/customary care giver'. ${ }^{34}$

Despite the terminology adopted in legislation and by the Irish government limiting the definition of unaccompanied minors to those seeking international protection, in practice both unaccompanied minors seeking international protection and those who are not seeking international protection are taken into care by Tusla.

For the purpose of this EMN study and in accordance with the study specifications and EU Directives, the term 'unaccompanied minor' is defined as:

a third-country national or stateless person below the age of 18 years, who arrives on the territory of the Member States unaccompanied by the adult responsible for them by law or by the practice of the Member State concerned, and for as long as they are not effectively taken into the care of such a person. It includes a minor who is left unaccompanied after they have entered the territory of the Member States.

As such, the scope of the study includes both unaccompanied minors that seek international protection and those who do not. Both children arriving alone and those arriving with an adult that is not their primary legal caregiver are also included in the study. The scope of the study is limited to unaccompanied minors from non-EEA countries who have received a final decision on their international protection or immigration status. The situation of unaccompanied minors turning 18 is also highlighted throughout the report. In Ireland, Tusla provides care to all unaccompanied minors on an 'equity of care' principle, irrespective of their status, up to the age of 18 . Due to the fact that only a small proportion of unaccompanied minors arriving spontaneously in Ireland are granted a legal status before the age of 18 in Ireland, the study also provides information on implications for unaccompanied minors of a lack of status. The term 'aged-out minor' is used throughout the study to describe unaccompanied minors who have turned 18 years of age.

The reference period of the study is January 2014 to December 2017; 2018 data are provided where available and relevant.

34 Tusla, 'Separated Children Seeking Asylum', https://www.tusla.ie/services/alternative-care/separated-children/. 

Unaccompanied minors in Ireland and the EU: profile, flows and data

Globally, data on unaccompanied minors tend to be limited to those who seek international protection. The United Nations (UN) Committee on the Rights of the Child (the Committee) has stated that this is insufficient for the development of appropriate responses to unaccompanied minors (the Committee, 2005).

At European Union (EU) level, Member States are required to provide data to Eurostat on unaccompanied children seeking international protection as well as unaccompanied minors granted an alternative immigration status in EU Member States. However, the Commission identified shortcomings in data collection among EU Member States on unaccompanied minors who do not seek international protection, noting that information on the specific types of permits issued to unaccompanied minors is not available in some Member States (European Commission, 2010; European Commission, 2017).

In Ireland, the Child and Family Agency, Tusla (Tusla) Social Work Team for Separated Children Seeking Asylum (SWTSCSA) compiles statistics on the number of unaccompanied minors referred to its Dublin-based service and placed in care. The International Protection Office (IPO) collects national data on the number of unaccompanied minors who submit an application for international protection and on the number subsequently granted refugee or subsidiary protection status. No data are collected by IPO on the number of unaccompanied minors who are granted permission to remain under the International Protection Act 2015 (2015 Act). ${ }^{35}$ The Irish Naturalisation and Immigration Service (INIS) does not collect data on the number, if any, of unaccompanied minors who apply for, and are subsequently granted, an alternative immigration status. ${ }^{36}$

This chapter presents statistics on recent trends in migration of unaccompanied minors to the EU and Ireland. It provides an overview of available data obtained from Eurostat, IPO and Tusla.

\subsection{OVERVIEW OF MAIN TRENDS REGARDING UNACCOMPANIED MINORS IN EUROPE}

As noted in Chapter 1, the Council of the EU established a temporary EU relocation scheme in September 2015 to relocate 160,000 people seeking international 
protection from Italy and Greece, in response to the significant increase in persons seeking international protection in the EU. In adopting the scheme, the Council of the EU noted that relocation of vulnerable applicants, including unaccompanied minors, should be prioritised. ${ }^{37}$ As of May 2018, 34,690 people had been relocated from Greece and Italy. Some 546 unaccompanied minors eligible for relocation had been relocated from Greece, while 256 had been relocated from Italy (European Commission, 2018).

Figure 2.1 shows that the number of unaccompanied minors seeking international protection in the EU and Norway increased significantly between 2014 and 2015. In 2015, 99,995 unaccompanied minors sought international protection in the 28 EU Member States and Norway, an increase of 315 per cent from 2014, when the total was 24,090 . The total number of applications from unaccompanied minors in the EU and Norway decreased to 63,515 in 2016 and decreased further in 2017 to 31,570. These figures reflect overall trends in relation to persons seeking international protection arriving in the EU. The increase in persons seeking international protection in $\mathbf{2 0 1 5}$ arose in large part as a result of conflict in Syria, Iraq, Yemen and sub-Saharan Africa (Arnold et al., 2018).

FIGURE 2.1 UNACCOMPANIED MINORS SEEKING INTERNATIONAL PROTECTION IN EU MEMBER STATES AND NORWAY, 2008-2017

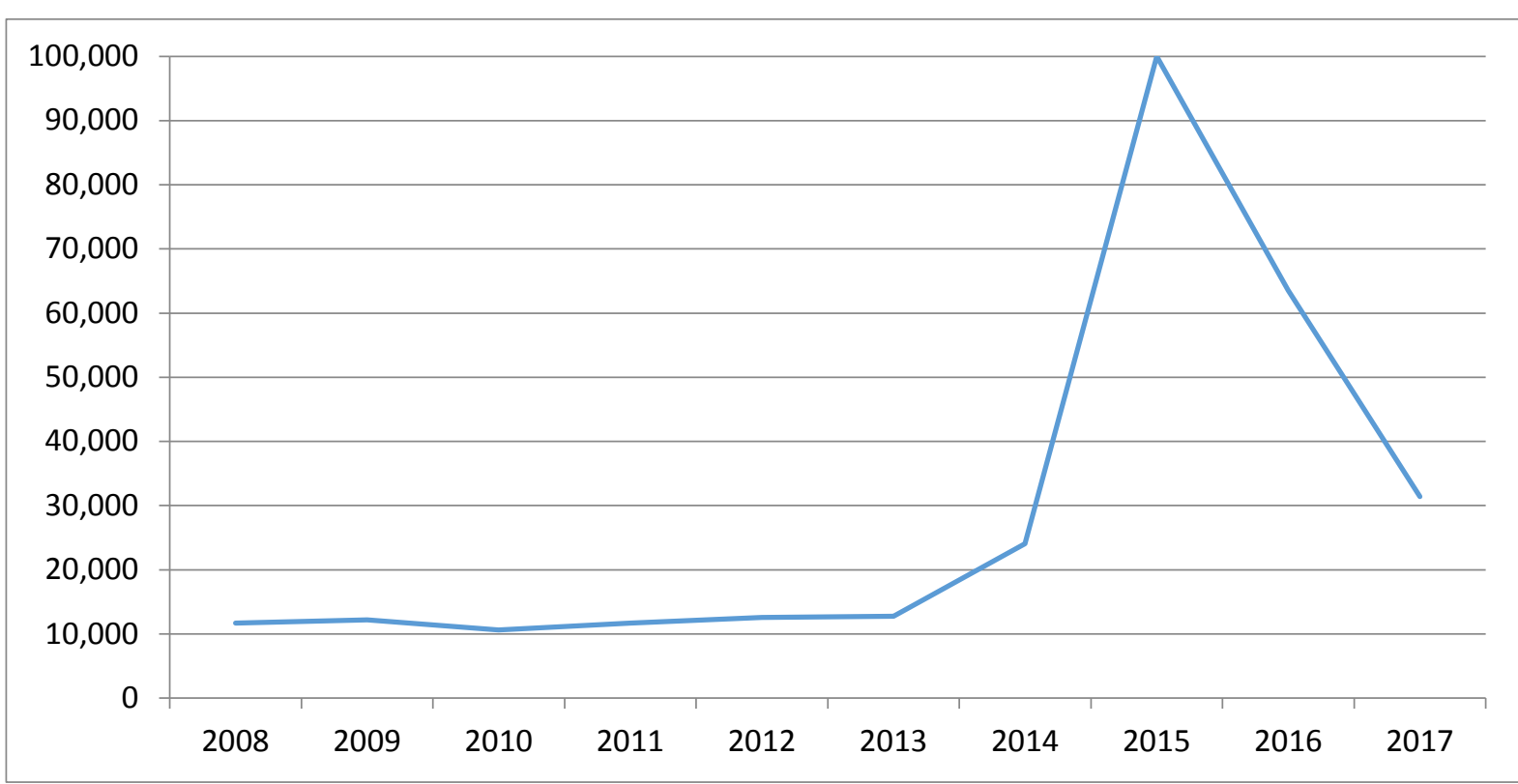

Source: Eurostat (2018b).

Note: Data on Croatia are not included for the period 2008-2011.

37 Council Decision (EU) 2015/1523 of 14 September 2015 establishing provisional measures in the area of international protection for the benefit of Italy and of Greece; Council Decision (EU) 2015/1601 of 22 September 2015 establishing provisional measures in the area of international protection for the benefit of Italy and Greece. 
In 2014, Sweden, Germany, Italy and Austria received the highest number of applications made by unaccompanied minors in the EU and Norway. In 2015, Sweden, Germany, Hungary and Austria received the highest number of applications from unaccompanied minors, while Germany, Italy, Austria and the United Kingdom received the highest number in 2016 (see Figure 2.2).

Figure 2.2 shows that in 2017 the highest number of international protection applications submitted by unaccompanied minors was recorded in Italy $(10,005)$, which comprised 32 per cent of all applications made by unaccompanied minors in the EU and Norway. Some 9,085 applications were submitted by unaccompanied minors in Germany (29 per cent), 2,455 in Greece (8 per cent) and 2,205 in the UK (7 per cent).

Many of these unaccompanied minors arrive in Europe through precarious routes, including by sea. Some 92 per cent of children who arrived in Italy in 2017 were unaccompanied (UNHCR, 2017a). In the same year, around 12 per cent of children arriving in Greece were unaccompanied (UNHCR, 2017b).

In 2014, Ireland received 30 applications for international protection from unaccompanied minors, ranking 20th out of 29 countries in the EU and Norway. Ireland ranked 21st in 2015 and 2016. In 2017, Ireland received 30 applications from unaccompanied minors, representing less than 1 per cent ( 0.09 per cent) of all applications submitted by unaccompanied minors in the EU and Norway and ranking 22nd out of 29 countries (see Figure 2.3). 
FIGURE 2.2 UNACCOMPANIED MINORS SEEKING INTERNATIONAL PROTECTION IN EU MEMBER STATES AND NORWAY, 2014-2017

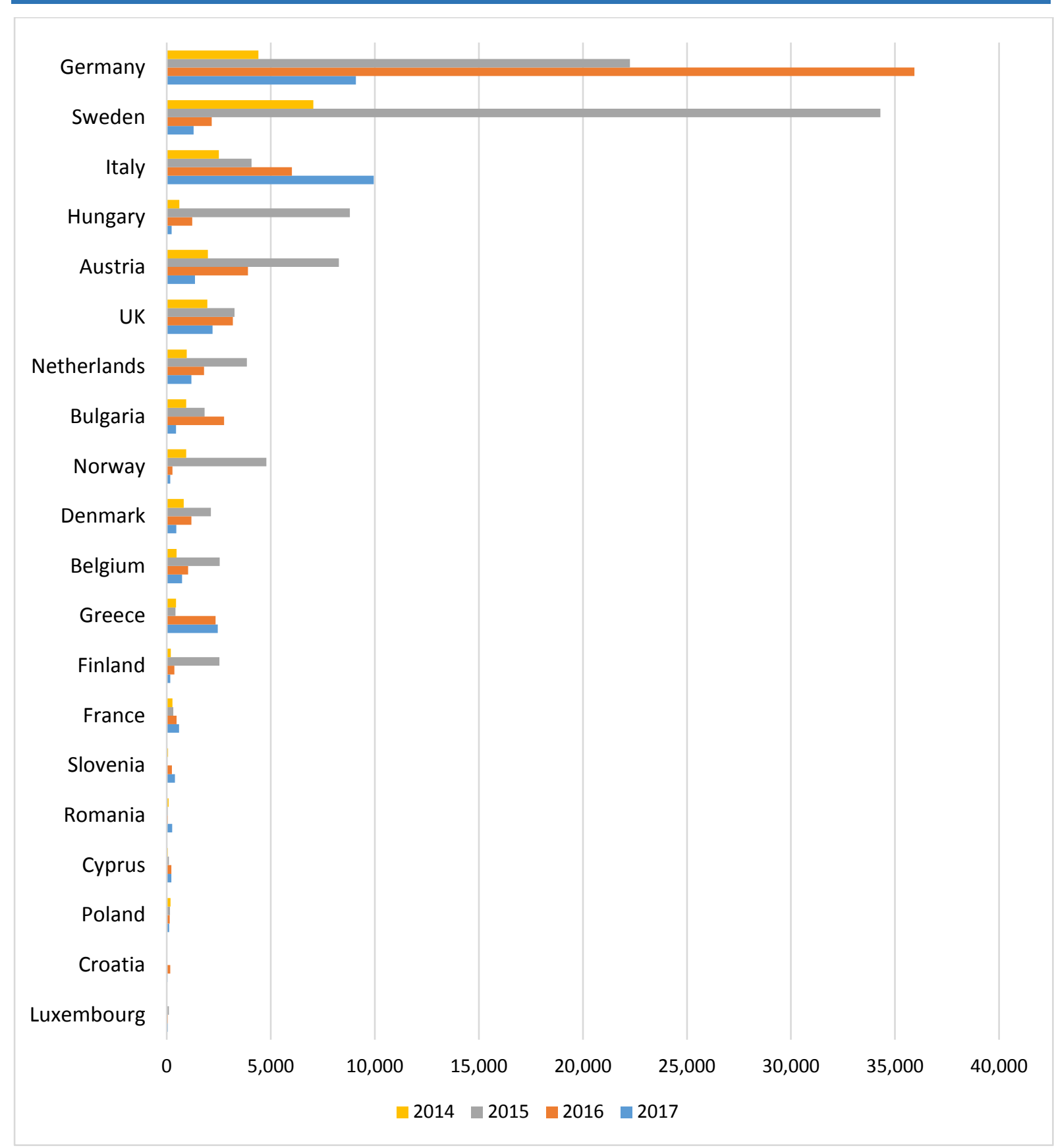

Source: Eurostat (2018b)

Note: $\quad$ Nine EU Member States with fewer than 100 applications in each year between 2014 and 2017 are excluded from the chart: Malta, Portugal, Ireland, Spain, Slovakia, Latvia, Czech Republic, Lithuania and Estonia.

From 2014 to 2016, the majority of applications were submitted by unaccompanied minors from Afghanistan, Syria and Eritrea. In 2017, 17 per cent of applications from unaccompanied minors $(5,385)$ in the EU and Norway were made by unaccompanied minors from Afghanistan, with 10 per cent $(3,160)$ from Eritrea and 8 per cent $(2,580)$ from The Gambia (Eurostat, 2018b). 
Male unaccompanied minors comprised 88 per cent of all unaccompanied minor applicants in the EU and Norway 2017, while 77 per cent of unaccompanied minors who submitted an application were aged 16-17 years (Eurostat, 2018b).

On average, between 2014 and 2017, unaccompanied minors accounted for 18 per cent of all applications for international protection lodged in the EU and Norway by children under the age of 18 (Eurostat, 2018b).

Only data on unaccompanied minors applying for international protection are collected consistently at EU level. Complete data on the number of applicants subsequently granted international protection status are not available. Between 2014 and 2017, figures provided by 20 EU Member States and Norway for the present study show that at least 90,200 unaccompanied minors received a positive decision on an application for international protection or other immigration status. However, it is not possible to determine how many positive decisions were made in respect of applications for international protection due to variations in reporting by EU Member States (EMN, 2018a).

While many unaccompanied minors seek to regularise their status through routes outside the international protection system, data collection in this regard is inconsistent across EU Member States. A greater number of unaccompanied minors overall therefore arrive in the EU annually, with estimates suggesting that the number of unaccompanied minors not seeking international protection may be as high as those seeking international protection (IOM, 2017). Figures provided by six Member States in the EMN Synthesis Report show that at least 48,591 unaccompanied minors arrived in the EU between 2014 and 2017 for reasons other than to seek international protection (EMN, 2018a). A particular issue related to data collection is the varying definition of an unaccompanied minor adopted by EU Member States due to differences in national law and practice, which may lead to inconsistencies in reporting at EU level (European Commission, 2016).

\subsection{OVERVIEW OF MAIN TRENDS REGARDING UNACCOMPANIED MINORS IN IRELAND}

\subsubsection{Referrals to Tusla}

The number of unaccompanied minors referred to the SWTSCSA has declined steeply since its peak in 2001, when 1,085 referrals were reported (Quinn et al., 2014). Total referrals reached their lowest since 2000 in 2012 (Quinn et al., 2014); however, the number of unaccompanied minors taken into care has increased gradually in recent years. Table 2.1 shows an increase in referrals of unaccompanied minors to the SWTSCSA from 97 in 2014 to 175 in 2017. Data include referrals from the Garda National Immigration Bureau (GNIB) of 
unaccompanied minors arriving at air or sea ports or from IPO. Data for 2016 and 2017 also include unaccompanied minors admitted to Ireland under the Irish Refugee Protection Programme (IRPP) and the Calais Special Project (see below).

Table 2.1 also shows the reported outcomes for unaccompanied minors referred to the SWTSCSA since 2014. The majority of unaccompanied minors were placed in care or were reunited with family members following family assessments carried out by SWTSCSA. Of the 175 unaccompanied minors referred to the SWTSCSA in 2017, 111 were taken into care.

A total of 70 unaccompanied minors referred to the SWTSCSA were provided with a family reunification service in 2017 . The majority of unaccompanied minors are reunited with family already in Ireland, while many unaccompanied minors are also reunited with family in the UK. ${ }^{38}$ Unaccompanied minors granted international protection status may apply for family to join them in Ireland in line with their entitlement to family reunification in Ireland under the 2015 Act. Unaccompanied minors can also be reunited with family in the country of origin within the framework of returns, which is less frequent (see Chapter 6). ${ }^{39}$

\begin{tabular}{|c|c|c|c|}
\hline Year & Total Referrals & Placed in Care & $\begin{array}{c}\text { Family Reunification } \\
\text { Service Provided* }\end{array}$ \\
\hline $\mathbf{2 0 1 4}$ & 97 & 86 & 49 \\
\hline $\mathbf{2 0 1 5}$ & 109 & 82 & 32 \\
\hline $\mathbf{2 0 1 6}$ & 126 & 82 & 42 \\
\hline $\mathbf{2 0 1 7}$ & 175 & 111 & 70 \\
\hline
\end{tabular}

Source: Tusla, 2018d, 2018e.

Note: $\quad \mathrm{N} / \mathrm{l}=$ no information available. ${ }^{*}$ There may be double counting of minors placed in care and minors who were provided with a family reunification service and subsequently reunited with family.

Of the unaccompanied minors referred to the SWTSCSA in 2017, 52 were female and 123 were male. ${ }^{40}$ More than 50 per cent of unaccompanied minors referred to the SWTSCSA are aged between 16 and $17 .{ }^{41}$

Richason (2017) noted that between 2010 and 2015, the top five countries of origin were Nigeria, the Democratic Republic of the Congo, Zimbabwe, Afghanistan, and South Africa. The top countries of origin of unaccompanied minors referred to Tusla in 2017 were Afghanistan, Eritrea, Iraq, Syria and Ethiopia (Department of 
Foreign Affairs and Trade, 2017). Unaccompanied minors from Nigeria, Libya, Morocco, Georgia, Iran, Sudan and the Democratic Republic of the Congo were also referred to Tusla (Department of Foreign Affairs and Trade, 2017).

\subsubsection{Irish Refugee Protection Programme}

Unaccompanied minors arriving under the IRPP are also referred to the care of the SWTSCSA. The government established the IRPP on 10 September 2015, in which it committed to accept up to 4,000 persons in line with Ireland's EU relocation and resettlement commitments. In establishing the IRPP, the government stated that the situation of unaccompanied minors would be given special priority and that special arrangements would be put in place to support their needs. ${ }^{42}$ The government subsequently agreed to relocate 20 unaccompanied minors from Greece and Italy under the EU relocation scheme. ${ }^{43}$ The IRPP reported that a total of six unaccompanied minors have been relocated to Ireland from Greece. ${ }^{44}$ However, the Minister for Justice and Equality reported to the Oireachtas in May 2017 that a total of 22 unaccompanied minors, including minors under the Greek definition of an unaccompanied minor, which was stated to be broader than the Irish definition, were relocated from Greece. ${ }^{45}$ No persons seeking international protection, including unaccompanied minors, have been relocated from Italy to date, which the government reports is due to the refusal by Italian authorities to allow security assessment of applicants on its territory by Irish authorities (Arnold et al., 2018). Of the unaccompanied minors reported in government data as having arrived in Ireland, six have been granted refugee status at first instance following an application for international protection being made on their behalf. ${ }^{46}$ Unaccompanied minors are not a feature of the resettlement programme in Ireland (Arnold and Quinn, 2017).

In addition, in November 2016 the government committed to admit up to 200 unaccompanied minors who had resided in the former migrant camp in Calais and expressed a desire to be admitted to Ireland. ${ }^{47}$ These unaccompanied minors were assessed and identified under the Calais Special Project operated by Tusla. Following 13 missions to identify and assess eligible unaccompanied minors (Department of Justice and Equality, 2018), it was decided that programme refugee status would be granted to those accepted under the Calais Special Project on

\footnotetext{
42 Department of Justice and Equality, 'Ireland to accept up to 4,000 persons under Relocation and Resettlement programmes - Fitzgerald', www.justice.ie.

43 Parliamentary Question 4 October 2017 [42127/17], oireachtasdebates.oireachtas.ie.

44 Department 'Irish Justice, Refugee Protection http://www.justice.ie/en/JELR/Pages/Irish_Refugee_Protection_Programme_(IRPP); Parliamentary Question 20 March 2018 [12352/18], oireachtasdebates.oireachtas.ie.

45 Parliamentary Question 30 May 2017 [25828/17], oireachtasdebates.oireachtas.ie.

46 Consultation with SWTSCSA, February 2018.

47 Dáil Éireann, 10 November 2016, 'EU Migration Crisis: Motion', www.justice.ie.
} 
arrival. ${ }^{48} \mathrm{~A}$ total of 41 unaccompanied minors were brought from Calais under the project, ${ }^{49} 39$ of whom were allocated programme refugee status on arrival. A further two were admitted to Ireland as persons seeking international protection. ${ }^{50}$ The Calais Special Project finished its operations on 27 February 2018 when the last unaccompanied minors arrived in Dublin from Calais. ${ }^{51}$

Of those that arrived under the Project, 38 unaccompanied minors are in the care of Tusla while three have been reunited with family members already in Ireland. ${ }^{52}$ All but one of the unaccompanied minors are male, ${ }^{53,54}$ and they are aged between 14 and $17 .{ }^{55}$ Data show that the unaccompanied minors arriving under the Calais Special Project originate from Afghanistan, Eritrea, South Sudan, Ethiopia and Syria (Department of Justice and Equality, 2018).

In June 2018, the Irish government announced that it would relocate 25 persons to Ireland from the Non-Governmental Organisation (NGO) ship Lifeline that docked in Malta after rescuing 234 people in the Mediterranean off the Libyan coast. ${ }^{56}$ Of the 25 persons relocated to Ireland, four were unaccompanied minors who were taken into care by the SWTSCSA and are awaiting a decision on their applications for international protection, which were made by the SWTSCSA on their behalf following their arrival in Ireland. ${ }^{57}$

\subsubsection{Protection applications and grants}

In contrast to the increase in numbers of unaccompanied minors referred to Tusla since 2014, Figure 2.3 shows only a marginal increase in the number of applications for international protection submitted by unaccompanied minors in 2015 and 2016. In 2014, 30 applications were submitted by unaccompanied minors, while 33 were submitted in 2015 and 34 in 2016 (ORAC, 2015, 2016, 2017). Despite a 39 per cent increase in the number of unaccompanied minors referred to Tusla between 2016 and 2017, the number of applications for international protection decreased to 30 in 2017 (Sheridan, 2018). However, the majority of those who were referred to the SWTSCSA via the Calais Special Project were granted programme refugee status and therefore did not need to apply for international protection.

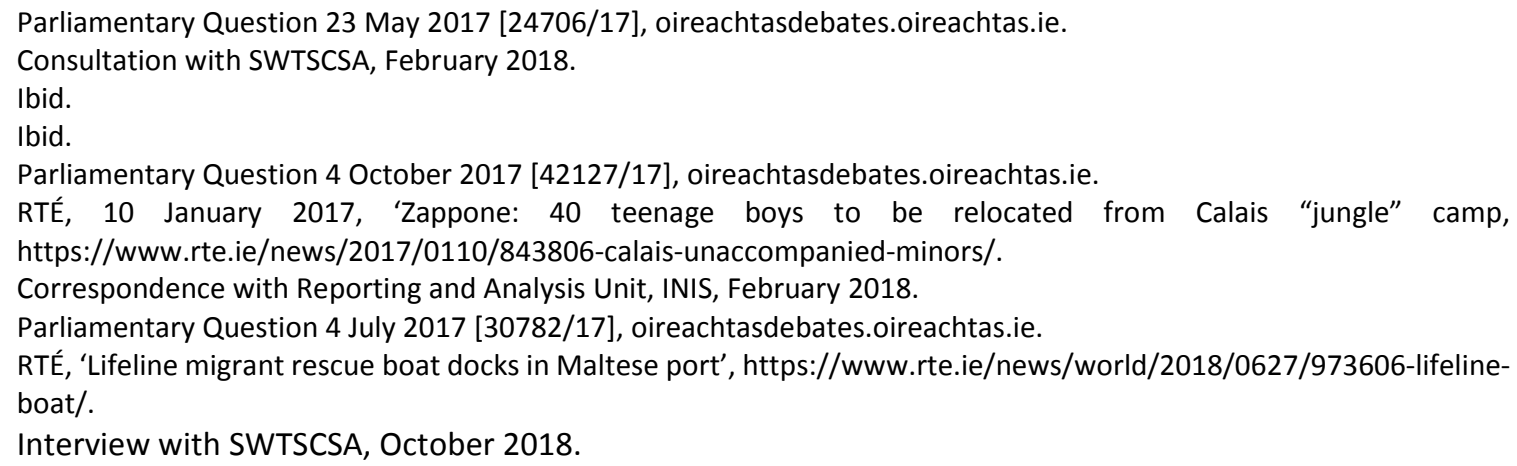


FIGURE 2.3 UNACCOMPANIED MINORS REFERRED TO SWTSCSA AND PLACED IN CARE, AND NUMBER OF INTERNATIONAL PROTECTION APPLICATIONS MADE BY UNACCOMPANIED MINORS, 2014-2017

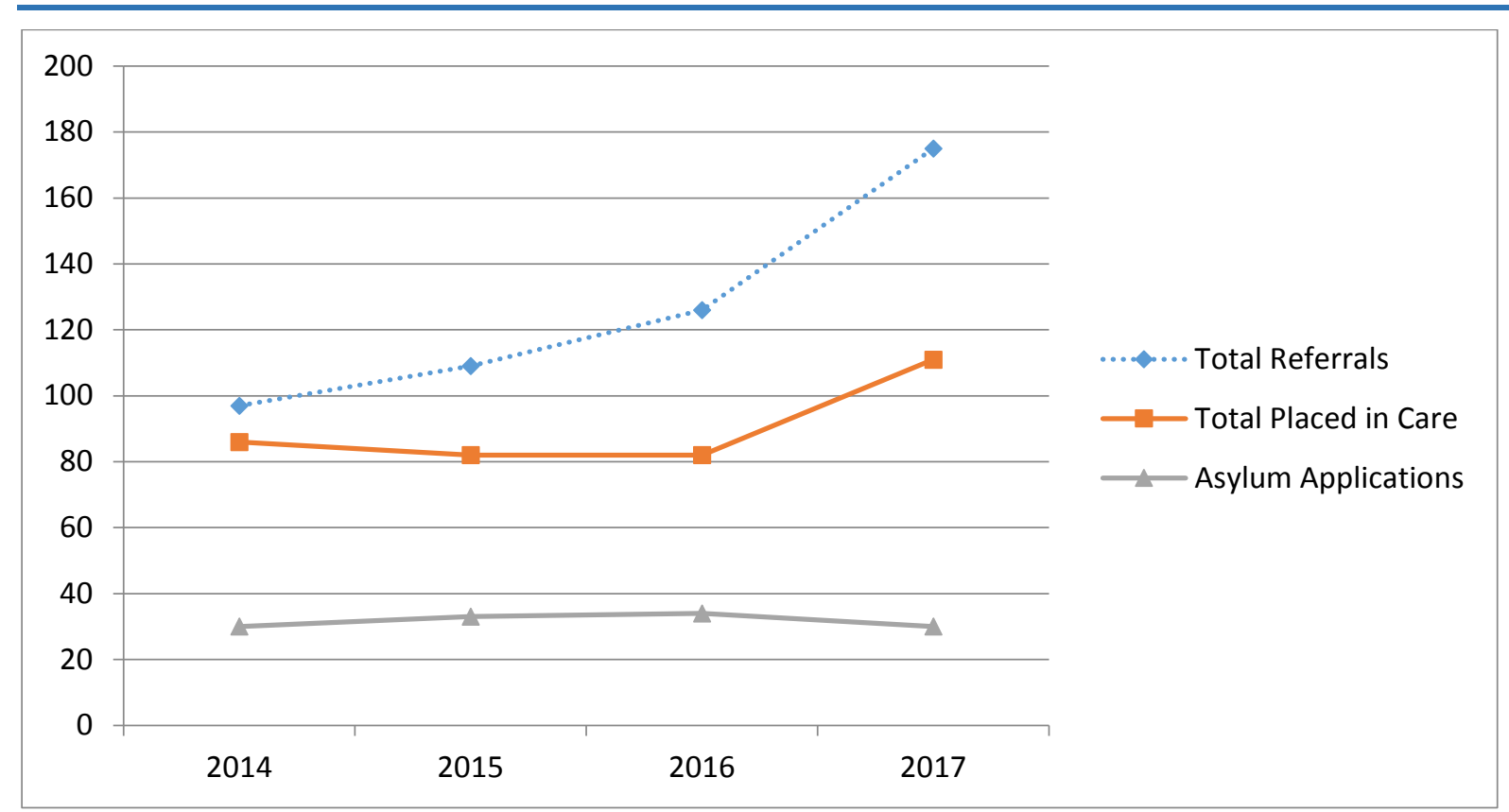

Source: Tusla (2018d, 2018e); ORAC (2015, 2016, 2017); Sheridan (2018).

Note: $\quad$ The year the international protection application is submitted may not correspond to the year the unaccompanied minor was referred to SWTSCSA.

Unaccompanied minors from Albania (10) submitted the highest number of applications for international protection in Ireland in 2017, while applicants from Afghanistan (5) and Iraq (5) submitted the second highest number of applications (Eurostat, 2018b). ${ }^{58}$

As shown in Table 2.2, unaccompanied minors that apply for protection status are predominantly male, with the male to female ratio increasing in 2015 and 2016.

TABLE 2.2 TOTAL NUMBER OF APPLICATIONS FOR INTERNATIONAL PROTECTION IN IRELAND MADE BY UNACCOMPANIED MINORS ACCORDING TO GENDER, 2014-2017

\begin{tabular}{|l|r|r|r|r|}
\hline Year & Male & Female & Total & Male to Female Ratio \\
\hline 2014 & 20 & 10 & 30 & 2.0 \\
\hline 2015 & 29 & 4 & 33 & 7.3 \\
\hline 2016 & 29 & 5 & 34 & 5.8 \\
\hline 2017 & 23 & 7 & 30 & 2.0 \\
\hline Total & 98 & 29 & 127 & 3.4 \\
\hline
\end{tabular}

Source: $\quad$ ORAC (2017); Sheridan (2018).

$58 \quad$ Figures are rounded to the nearest 5. 
Available data show that unaccompanied minors seeking international protection are often close to the age of majority (i.e. 18) when submitting an application for international protection. In 2015 and 2016, only one application for international protection was made by an unaccompanied minor under the age of $14 . .^{59}$ Tusla indicated that most of the unaccompanied minors in their care that make an application for international protection are aged 16 to 17, with most decisions being received after the age of $17 .{ }^{60}$ Only a small number of unaccompanied minors who submit applications for international protection receive a final decision before they reach the age of $18 .{ }^{61}$

Applications for international protection submitted in Ireland annually by unaccompanied minors during this period comprised 1 to 2.5 per cent of all applications for international protection made in Ireland (ORAC, 2015, 2016, 2017; Eurostat, 2018b).

As shown in Table 2.2, between 2014 and 2017, a total of 127 applications for international protection were submitted by unaccompanied minors. Table 2.3 shows that, during this period, 25 unaccompanied minors were granted refugee status, ${ }^{62}$ while 2 were granted subsidiary protection status. ${ }^{63}$

59 Eurostat (2016). 'Almost 90000 unaccompanied minors among asylum seekers registered in the EU in 2015', http://ec.europa.eu/eurostat/documents/2995521/7244677/3-02052016-AP-EN.pdf/; Eurostat (2017). '63300 unaccompanied minors among asylum seekers registered in the EU in 2016' http://ec.europa.eu/eurostat/documents/2995521/8016696/3-11052017-AP-EN.pdf/30ca2206-0db9-4076-a681e069a4bc5290.

60 Interview with SWTSCSA, January 2018

61 Ibid.

62 In the EU context, either a third-country national who, owing to a well-founded fear of persecution for reasons of race, religion, nationality, political opinion or membership of a particular social group, is outside the country of nationality and is unable or, owing to such fear, is unwilling to avail themselves of the protection of that country, or a stateless person, who, being outside of the country of former habitual residence for the same reasons as mentioned above, is unable or, owing to such fear, unwilling to return to it, and to whom Art. 12 (Exclusion) of Directive 2011/95/EU (Recast Qualification Directive) does not apply (EMN, 2018b).

63 A third-country national or a stateless person who does not qualify as a refugee but in respect of whom substantial grounds have been shown for believing that the person concerned, if returned to their country of origin, or in the case of a stateless person, to their country of former habitual residence, would face a real risk of suffering serious harm as defined in Art. 15 of Directive 2011/95/EC (Recast Qualification Directive) and to whom Art. 17(1) and (2) of said Directive do not apply, and is unable, or, owing to such risk, unwilling to avail themselves of the protection of that country (EMN, 2018b). 
NUMBER OF POSITIVE DECISIONS ON APPLICATIONS FOR INTERNATIONAL PROTECTION (REFUGEE STATUS AND SUBSIDIARY PROTECTION STATUS) SUBMITTED BY UNACCOMPANIED MINORS

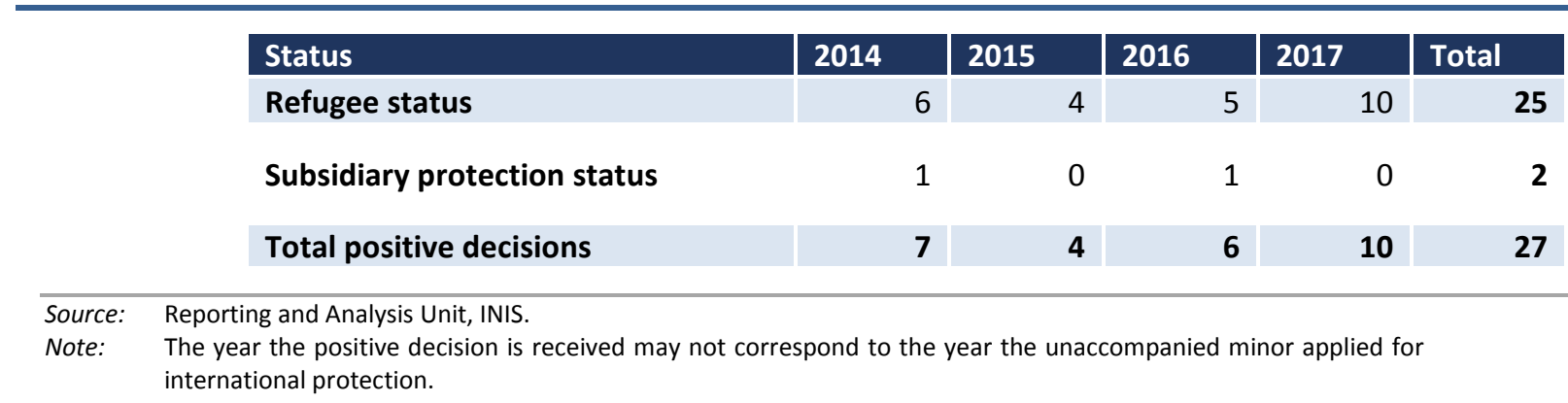

The top five countries of origin of unaccompanied minors granted international protection between 2014 and 2017 were Afghanistan, Syria, Albania, Nigeria and Democratic Republic of Congo. ${ }^{64}$

All but one of the 27 unaccompanied minors granted refugee status or subsidiary protection status between 2014 and 2017 were between 14 and 17 years of age. ${ }^{65}$

Between 2014 and 2017, a further seven unaccompanied minors received a negative decision on their refugee status application, while two received a negative decision on their application for subsidiary protection. ${ }^{66}$ No data are available on whether the unaccompanied minors who received a negative decision on an application for international protection were subsequently granted permission to remain. ${ }^{67}$

\subsubsection{Return}

Unaccompanied minors have not been deported (forcibly returned), following receipt of a negative decision on an application for international protection, in recent years. ${ }^{68}$ Data on the number of aged-out minors who have been deported are not available, as data on deportations do not record whether the individual deported was previously in the care of Tusla. ${ }^{69}$ Data on the deportation of agedout minors was recorded by INIS in the past (Ní Raghallaigh, 2011), as outlined by the government in parliamentary debates in 2005 and 2006. ${ }^{70}$

64 Unaccompanied minors from Bangladesh, Bolivia, Côte d'Ivoire, Ghana, Iraq and the Democratic People's Republic of Korea were also granted international protection during this period.

65 Correspondence with Reporting and Analysis Unit, INIS, February 2018.

66 Ibid.

67 Ibid.

68 Correspondence with Repatriation Division, INIS, October 2018.

69 Parliamentary Question, 19 July 2012 [36892/12], oireachtasdebates.oireachtas.ie.

70 Parliamentary Question, 23 November 2005 [35754/05]; Parliamentary Question, 9 May 2006 [17012/06], oireachtasdebates.oireachtas.ie. 
Some four unaccompanied minors voluntarily returned to their country of origin through the International Organization for Migration's Voluntary Return and Reintegration Programme between 2014 and 2017 (see Section 6.2). ${ }^{71}$

\subsubsection{Challenges arising from data gaps}

Data are not available on the proportion of unaccompanied minors taken into care by Tusla that subsequently apply for international protection. ${ }^{72}$ Data on the number of unaccompanied minors who submit an application for international protection prior to turning 18 years of age and receive a decision after the age of 18 are also not available.

The only available data on the number of unaccompanied minors known to have a protection or immigration status in Ireland are those pertaining to unaccompanied minors granted refugee status and subsidiary protection status, as well as unaccompanied minors arriving under the Calais Special Project, the majority of whom have been granted programme refugee status.

While such data are available, reporting of data on unaccompanied minors arriving in Ireland both within and outside of government-led programmes is inconsistent and varies among government departments. This is reflected in the reporting on unaccompanied minors arriving from Greece through the EU relocation scheme. The IRPP reports that a total of six unaccompanied minors have been relocated to Ireland from Greece. ${ }^{73}$ However, the Minister for Justice and Equality reported to the Oireachtas in May 2017 that a total of 22 unaccompanied minors, including minors under the Greek definition of an unaccompanied minor, which was stated to be broader than the Irish definition, were relocated from Greece. ${ }^{74}$ The government reports that the Greek definition is a child not accompanied by an adult member of the child's immediate family, ${ }^{75}$ while the Irish definition is reported as stricter, ${ }^{76}$ as a child not accompanied by an adult relative (CRA, 2017, 2018). However, the Irish definition reported in the context of relocation contrasts with the broad concept of an unaccompanied minor set out in section 14 of the 2015 Act, and its predecessor the Refugee Act 1996, ${ }^{77}$ which include children that

\footnotetext{
Correspondence with IOM Ireland, February 2018.

Interview with SWTSCSA, October 2018.

Department of Jish Refugee Protection Programme', http://www.justice.ie/en/JELR/Pages/Irish_Refugee_Protection_Programme_(IRPP); Parliamentary Question 20 March 2018 [12352/18], oireachtasdebates.oireachtas.ie.

Parliamentary Question 30 May 2017 [25828/17], oireachtasdebates.oireachtas.ie. Parliamentary Question 14 December 2016 [40430/16], oireachtasdebates.oireachtas.ie. Parliamentary Question 4 October 2017 [42127/17], oireachtasdebates.oireachtas.ie.

Section 8(5) of the Refugee Act 1996 addressed the situation of 'a child under the age of 18 years who has arrived at the frontiers of the State [and] is not in the custody of any person'.
} 
may arrive with an adult relative that is not their custodian or legally appointed guardian.

No data are collected on unaccompanied minors who do not submit an application for international protection. All non-EEA nationals aged 16 and over are required to register with the GNIB. Non-EEA nationals under the age of 16 are currently not required to register. $^{78}$ In 2014, section 35(b) of the Employment Permits (Amendment) Act 2014 provided for the removal of the exemption for those under 16 to register with the GNIB, but this provision has not yet been commenced (Barrett et al., 2017; McGinnity et al., 2018). Despite the registration requirement, which provides an alternative avenue for obtaining an immigration permission outside of the international protection system, the number of unaccompanied minors, if any, who register with the GNIB, and therefore obtain an alternative immigration status, is not available. ${ }^{79}$

Another group of unaccompanied minors that are not accounted for in data are those who are not known to the authorities or referred to the SWTSCSA. Research has indicated that many unaccompanied minors in the care of the SWTSCSA are only referred to their service once within the State's borders and may not be identified on entry to the State (Veale et al., 2003; Kilkelly, 2007). While a joint protocol between Tusla and An Garda Síochána (Irish police) is in place for identification of unaccompanied minors at Dublin Airport and enhanced screening at ports is in operation (Quinn et al., 2014), little information is available on the extent to which unaccompanied minors travelling on their own or with an adult, including victims of trafficking, are identified on entry to the State.

The lack of consistent and comprehensive data collection on unaccompanied minors in Ireland has long been raised in literature as a challenge to the development of appropriate policy responses. Research has identified the current approach to data collection as an issue in urgent need of review (Kilkelly, 2007; Joyce and Quinn, 2009; Quinn et al., 2014). 



\section{Pathways to status for unaccompanied minors}

There is no specific legal status for unaccompanied minors in Ireland. The majority of unaccompanied minors eventually enter the international protection process as a minor or later as an adult. ${ }^{80}$ Children aged over 16 years (or unaccompanied minors under 16 with assistance from their social worker) may alternatively apply for residence permission outside of the international protection system. However, as most unaccompanied minors do not receive a decision on an application for international protection before turning 18 years of age and alternative immigration permissions are rarely applied for, ${ }^{81}$ only a small proportion of unaccompanied minors present in Ireland have an immigration status.

In its 2017 Communication on the protection of children in migration, the European Commission states that ensuring swift and effective access to status determination procedures is one of a series of actions required to address protection gaps faced by children and to prevent children being left in limbo as regards their legal status. The Commission states that clear rules should be established on the legal status of children who are not granted international protection but who will not be returned to their country of origin. The Commission recognises the crucial role played by guardians in safeguarding unaccompanied minors' interests in this regard, including those not applying for international protection (European Commission, 2017).

Practice varies among Member States as to access for unaccompanied minors to the international protection system or other immigration status determination processes. Many EU Member States provide for the granting of a temporary residence permit to unaccompanied minors, including those who seek international protection and those who do not apply for international protection. For example, Italy provides for the granting of a residence permit to all children, including unaccompanied minors, by virtue of their age (EMN, 2018a). In Germany, an unaccompanied minor's guardian undertakes an assessment to determine, along with the minor, whether or not the minor should submit an application for international protection. Guardians are obliged to promptly file an international protection application for the minor if the minor is deemed to be in need of international protection. Should alternative means of securing a residence status for the minor be deemed to be in the minor's best interests, the guardian applies for the minor to obtain a residence permit from the immigration authorities (Tangermann and Hoffmeyer-Zlotnik, 2018). On the other hand, France reports that it does not require unaccompanied minors to hold a residence permit due to 
their age, and instead regards unaccompanied minors as being provided with protection under child welfare law until the age of 18 (EMN, 2018a).

In the National Policy Framework for Children and Young People 2014-2020, the Irish government committed to enacting legislation to 'address in a comprehensive way the interaction of migrant children with the immigration system' (Department of Children and Youth Affairs, 2014). In its review of Ireland's implementation of the United Nations (UN) Convention on the Rights of the Child (CRC), the UN Committee on the Rights of the Child (the Committee) expressed concerns that there are inadequate measures to ensure that children with an irregular migration status and who are in care receive independent legal advice, with the result that such children do not receive timely clarification on their migration status. The Committee recommended that Ireland ensure clear and accessible formal procedures for granting immigration status to children in irregular migration situations (the Committee, 2016). In October 2014, a Working Group to report to government on improvements to the protection process, including Direct Provision and supports to asylum seekers (Working Group on the Protection Process), was established by the Minister for Justice and Equality and the Minister of State for the Department of Justice and Equality (Arnold et al., 2018). In its report, the Working Group on the Protection Process recommended that work be undertaken to clarify access to the international protection process for unaccompanied minors (Working Group on the Protection Process, 2015). The Department of Justice and Equality reported that the recommendation to clarify access to the international protection process in relation to unaccompanied minors had been implemented by Tusla in June 2016 (Department of Justice and Equality, 2017a). Nasc, the Migrant and Refugee Rights Centre (Nasc) (2017) raised concerns regarding the progress made in practice to facilitate access for unaccompanied minors to legal advice and to the international protection process.

This chapter considers the various statuses that may be granted to unaccompanied minors in Ireland. Research in Ireland finds that the ability to plan pathways to adulthood and become independent is reliant on the child's status (Sirriyeh and Ní Raghallaigh, 2018; Mannion, 2016). Thus, while the focus of the study is on unaccompanied minors who already have an immigration status, this chapter includes an overview of the means by which unaccompanied minors can secure an immigration status to provide a context for the discussion in later chapters of the experiences of unaccompanied minors in Ireland during and after the care process. 


\subsection{UNACCOMPANIED MINORS ARRIVING IN IRELAND SEEKING INTERNATIONAL PROTECTION}

\subsubsection{International protection and permission to remain}

Under the International Protection Act 2015 (2015 Act), each international protection applicant is given a permission to enter and reside in Ireland for the purposes of the examination of his or her application. ${ }^{82}$ An unaccompanied minor who submits an application for international protection and receives a positive decision may be granted refugee status or subsidiary protection status by the International Protection Office (IPO) or on appeal by the International Protection Appeals Tribunal (IPAT). ${ }^{83}$ If neither of these statuses is granted, the Minister for Justice and Equality can grant the unaccompanied minor permission to remain in the State, having regard to the applicant's family and personal circumstances and his or her right to respect for private and family life. ${ }^{84}$ Permission to remain is granted by the Minister on a discretionary basis and is deemed to be a permission given under section 4 of the Immigration Act 2004.

An unaccompanied minor granted international protection has most of the same rights and privileges as Irish citizens. Those granted international protection are issued with a Stamp 4 residence permission. The 2015 Act states that beneficiaries of international protection (refugee or subsidiary protection) are entitled to seek and enter employment, to engage in any business, trade or profession as well as education and training, and to receive medical care and social welfare benefits in the same manner as Irish citizens (see Chapter 5 ). ${ }^{85}$ They are also entitled to apply for family reunification within one year of being granted international protection (see Chapter 6).$^{86}$ On grant of international protection, the unaccompanied minor is given permission to reside in the State for a specified period of at least three years, ${ }^{87}$ which may then be renewed. After three years' residence, an unaccompanied minor with refugee status may apply for Irish citizenship through naturalisation. ${ }^{88}$ Those with subsidiary protection status can apply for naturalisation after five years' residence. ${ }^{89}$

International Protection Act 2015, s 16(1).

Ibid., s 47.

International Protection Act 2015, s 49. Section 49(3) states that the Minister also has regard to: '(a) the nature of the applicant's connection with the State, if any, (b) humanitarian considerations, (c) the character and conduct of the applicant both within and (where relevant and ascertainable) outside the State (including any criminal convictions), (d) considerations of national security and public order, and (e) any other considerations of the common good'.

International Protection Act 2015, s 53.

Ibid., s 56.

Ibid., s 54(1).

Irish Nationality and Citizenship Act 1956, as amended, s 16.

Ibid., s 15. 
Rights for persons granted permission to remain are not provided for in legislation. Conditions as to duration of stay or access to employment may vary, subject to Ministerial discretion, having regard to the circumstances of the applicant. ${ }^{90}$ Those granted permission to remain may be issued with a Stamp 4 residence permission allowing them to seek and enter employment, while others may be issued a Stamp 3 residence permission which does not provide for access to the labour market or social welfare benefits (Mannion, 2016). Unaccompanied minors with permission to remain are not entitled to family reunification under the 2015 Act. However, they may apply to the Minister for Justice and Equality for family members to join them in Ireland under the Irish Naturalisation and Immigration Service (INIS) Policy Document on Non-EEA Family Reunification, which is subject to the discretion of the Minister (see Chapter 6 of this report) (INIS, 2016). Similar to those with subsidiary protection status, unaccompanied minors granted permission to remain can apply for naturalisation after five years' residence. ${ }^{91}$

Since the commencement of the 2015 Act, which replaced the Refugee Act 1996 and introduced the single procedure, a decision on all three statuses (refugee status, subsidiary protection status and permission to remain) is issued at the same time.

If an unaccompanied minor receives a negative international protection decision, they have the right to appeal to IPAT. ${ }^{92}$ The permission to remain decision may be reviewed by the Minister simultaneously. If a final negative decision is issued on all three statuses, an unaccompanied minor may be provided with the option to seek voluntary return to their country of origin. ${ }^{93}$ If the unaccompanied minor does not avail of voluntary return, they can be subject to a deportation order (forced return), as is the case with all persons seeking international protection. ${ }^{94} \mathrm{~A}$ deportation order made under section 51 of the 2015 Act is deemed to be a deportation order made under section 3(1) of the Immigration Act 1999 (1999 Act). In accordance with section 3(11) of the 1999 Act, the Minister may by order amend or revoke a deportation order. ${ }^{95}$ An unaccompanied minor may make an application under section 3(11) of the 1999 Act to revoke the deportation order at any time following the issuing of a deportation order. Return, both forced and voluntary, is discussed further in Chapter 6.

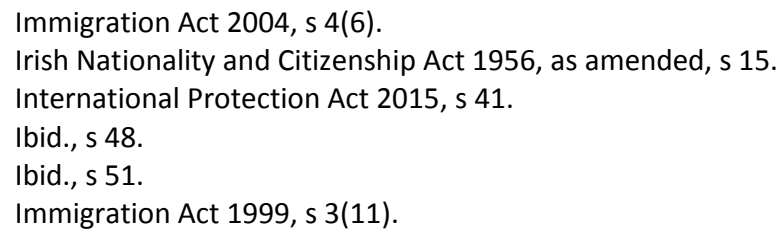




\subsubsection{Access to international protection for spontaneously arriving unaccompanied minors}

In Ireland, most unaccompanied minors eventually enter the international protection process (see Annex 1), ${ }^{96}$ whether an application is made before or after the age of 18. Pursuant to section 15(1) of the 2015 Act, applications for international protection are only accepted from persons aged 18 and over. Section 15(4) of the 2015 Act assigns responsibility to Tusla for the making of an application on behalf of unaccompanied minors, 'where it appears on the basis of information, including legal advice, available to it, that an application for international protection should be made on [their] behalf'. A person who applies for international protection is allowed to remain in the State for the purpose of the examination of their application and is provided with a temporary residence certificate to this end. ${ }^{97}$

Once an application is submitted, section 73(2)(i) of the 2015 Act provides that applications made by unaccompanied minors in the care of Tusla may be prioritised. ${ }^{98}$ The 2015 Act provides that during the international protection interview process, the best interests of the child must be taken into account. ${ }^{99}$ The Legal Aid Board offers legal advice to unaccompanied minors seeking international protection who register with the Board (Quinn et al., 2014). The child's social worker or other person appointed by Tusla to represent the child is allowed to be present at the personal interview with the child. ${ }^{100}$ The child's social worker or representative can make representations on behalf of the minor to support their application where appropriate (Quinn et al., 2014). The interview, and the decision on the child's application, must be conducted by a person who has the necessary knowledge of, and competence to take into account, the special needs of unaccompanied minors. ${ }^{101,102,103}$

However, most unaccompanied minors seeking international protection do not have an application for international protection submitted on their behalf until

Interview with SWTSCSA, January 2018.

International Protection Act 2015, ss 16-17.

The prioritisation of applications relates to the scheduling of interviews, and INIS states that applications accorded priority are scheduled an interview at the earliest possible date having regard to available resources (International Protection Office and UNHCR, 2017).

99 International Protection Act 2015, s 36.

100 Ibid., s 36(a)(ii).

101 Ibid., s 36(b)-(c).

102 To this end, caseworkers at IPO, which considers applications for international protection, have been trained to process applications from unaccompanied minors: see International Protection Office, 'Unaccompanied Minors', http://www.ipo.gov.ie/en/ipo/pages/unaccompanied_minors.

103 All members of the IPAT dealing with appeals from unaccompanied minors have undertaken training on children in the international protection system (IPAT, 2018). IPAT also developed guidelines for appeals involving children (IPAT, 2017). 
they are approaching the age of $18 .{ }^{104}$ The unaccompanied minors that do submit an application for international protection rarely receive a decision prior to reaching the age of majority. ${ }^{105}$

The absence of a national policy or guidelines setting out Tusla's duties, including in respect of submitting applications for international protection on behalf of unaccompanied minors, has been highlighted as a challenge (Mullally, 2011; Arnold, 2013; CRA, 2015b; IRC, 2017a). Stakeholders recommend that legislation or national guidelines clearly define Tusla's duties in respect of submitting applications (Arnold, 2013; CRA, 2015b; IRC, 2017a).

Research shows that social workers vary in their approach to fulfilling their duty regarding the decision to make an application for international protection on behalf of unaccompanied minors in their care. Some social workers delay the making of an application (Quinn et al., 2014; Arnold et al., 2015; Mannion, 2016; Arnold and Ní Raghallaigh, 2017). Reasons put forward for the delay include the view that it is not in the child's best interests and that the child may not be deemed ready for the international protection process (Quinn et al., 2014), as well as the fear that negative decisions on applications would lead to children going missing. ${ }^{106}$ In the previous European Migration Network (EMN) study on unaccompanied minors in Ireland, social workers stated that they did not believe the child had a credible international protection case and therefore decided against submitting an application (Quinn et al., 2014).

This practice of delaying making applications for international protection has met with concern from the Ombudsman for Children's Office (OCO), NonGovernmental Organisations (NGOs) and legal professionals assisting in securing legal status for unaccompanied minors. Stakeholders argue that the decision to make an application being solely at the discretion of Tusla may be contrary to the child's individual right to seek international protection under Article 18 of the Charter of Fundamental Rights of the European Union (Charles, 2009; IRC, 2017a). ${ }^{107}$ The OCO has noted the importance of Tusla's role in determining whether or not an application for international protection should be made; however, it has underlined that the role played by Tusla should not interfere with the right of an unaccompanied minor to seek international protection (Charles, 2009). In this respect, stakeholders highlight Tusla's duty to ensure that the child has access to early and independent legal advice in making the decision whether

Interview with SWTSCSA, January 2018.

Ibid.

Interview with SWTSCSA, January 2018.

Article 18 of the Charter of Fundamental Rights of the European Union guarantees the right to asylum with due respect for the 1951 United Nations Convention Relating to the Status of Refugees and the 1967 Protocol. The Charter applies to EU Member States when implementing EU law. 
or not to apply for international protection (Charles, 2009; Mullally, 2011; Arnold et al., 2015; CRA, 2015b; Working Group on the Protection Process, 2015; Mannion, 2016; IRC, 2017a; Nasc, 2017). This has been reiterated by the Committee, which recommended in its review of Ireland's implementation of the United Nations (UN) Convention on the Rights of the Child (CRC) that Ireland take measures to ensure that children in irregular migration situations are provided with independent legal advice and timely clarification on their migration status (the Committee, 2016). Section 15(4) of the 2015 Act provides that legal advice should form part of Tusla's decision whether to submit an application for international protection. The Social Work Team for Separated Children Seeking Asylum (SWTSCSA) noted that the ongoing practice of delaying access to the international protection process was informed by years of practical experience working with unaccompanied minors. ${ }^{108}$

Research acknowledges that decisions taken by social workers to delay applications are often motivated by the desire not to put children through a potentially adversarial international protection process. However, research also highlights that the lack of status may ultimately lead to variations in the level of access to services, particularly when the child reaches the age of 18 (Horgan et al., 2011; Mullally, 2011; Quinn et al., 2014; Mannion, 2016; Sirriyeh and Ní Raghallaigh, 2018).

\subsubsection{Unaccompanied minors arriving in Ireland through government-led programmes}

In addition to spontaneous arrivals of unaccompanied minors in Ireland, from 2016 the government has commenced programmes to admit unaccompanied minors as part of its commitments under the Irish Refugee Protection Programme (IRPP), including through the EU relocation scheme and the Calais Special Project (see Chapter 2). As previously outlined, most unaccompanied minors admitted under the Calais Special Project were granted programme refugee status on arrival, while unaccompanied minors relocated from Greece were granted refugee status on the basis of an application for international protection submitted on their behalf by the SWTSCSA following arrival in Ireland. Similarly, the four unaccompanied minors relocated to Ireland from Malta following commitments made to accept 25 people rescued by the NGO ship Lifeline are awaiting a decision on their applications for international protection submitted by the SWTSCSA on their behalf following arrival in Ireland. ${ }^{109}$

The decision to grant the majority of unaccompanied minors arriving through the Calais Special Project programme refugee status was made to 'allow them to begin 
their new lives with certainty of their legal status in the country from day one' (Department of Justice and Equality, 2018), and to provide them 'with more security and a sense of stability in traumatic and stressful circumstances'. ${ }^{110}$

A programme refugee is defined in section 59(1) of the 2015 Act as a person to whom permission to enter and remain in the State for resettlement or temporary protection purposes has been granted. Those granted programme refugee status are entitled on arrival in Ireland to rights similar to beneficiaries of international protection. As with persons granted refugee status or subsidiary protection status, programme refugees are entitled to access education and employment and receive medical care and social welfare on the same basis as Irish citizens. ${ }^{111}$ However, unlike those with refugee status, programme refugees may be granted permission to reside in the State for a period of less than three years. ${ }^{112}$ Applications for family reunification from programme refugees are accepted and processed under sections 56 and 57 of the 2015 Act (Arnold and Quinn, 2017).

\subsection{ALTERNATIVE IMMIGRATION STATUSES FOR UNACCOMPANIED MINORS}

Stakeholders argue that when an unaccompanied minor is approaching the age of 18 without an immigration status, social workers may view the international protection process as the only means of regularising his or her status. No mechanism or guidance is provided in legislation or policy addressing unaccompanied minors who do not enter the international protection process (Arnold, 2013).

However, social workers could assist unaccompanied minors aged 16 and over, in respect of whom they decide not to submit an international protection application, to apply to INIS for a residence permission. Currently, all non-EEA nationals aged 16 and over are required by law to register with INIS or the Garda National Immigration Bureau (GNIB) once a residence permission is obtained. ${ }^{113}$ On registering, an Irish Residence Permit is issued, which indicates one of several residence permission stamps that set out the conditions of the holder's immigration permission. Non-EEA nationals who fail to register are guilty of an offence, ${ }^{114}$ and may be issued with a deportation order. ${ }^{115}$ Non-EEA nationals under the age of 16 are currently not required to register. ${ }^{116}$ In 2014, section 35(b) of the Employment Permits (Amendment) Act 2014 provided for the removal of

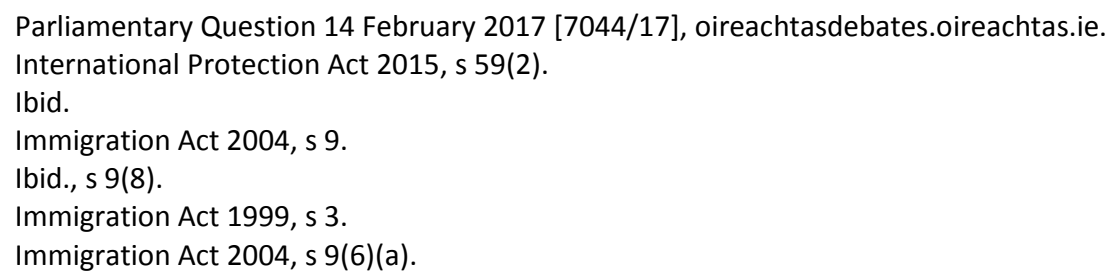


the exemption for those under 16 to register, but this provision has not yet been commenced (Barrett et al., 2017; McGinnity et al., 2018). The Migrant Integration Strategy committed to enable the registration of children under the age of 16 as a matter of urgency by 2018 (Department of Justice and Equality, 2017c). INIS plans to bring children under 16 years of age into the registration system, commencing with 14-16-year-olds by the end of 2019 (INIS, 2018). The commencement of this provision will provide for the residence of children, including unaccompanied minors, to be officially documented (Barrett et al., 2017).

INIS indicated that if Tusla had reason to bring an unaccompanied minor aged 16 or over in its care to the attention of INIS, because he or she was in need of a residence permit, he or she would generally be given Stamp 4 permission, which is one of the most favourable residence permissions available (Quinn et al., 2014). ${ }^{117}$ Stamp 4, which is also granted to beneficiaries of international protection, entitles an unaccompanied minor to access employment and social welfare and is reckonable as residence when applying for naturalisation.

However, INIS stated that it is not common practice for applications to be made for residence permits for unaccompanied minors aged 16 and over and no specific procedure or guidance exists in this regard (Quinn et al., 2014). The Immigrant Council of Ireland (ICI) notes that due to the absence of guidance and a lack of awareness among social workers of the requirement to register and apply for residence permissions, such applications are rarely pursued, and if they are, they are made on an ad hoc basis. ${ }^{118}$ SWTSCSA stated that it has not applied for a residence permission or sought to register unaccompanied minors, including those whom it deems not ready to enter the international protection process, as it does not view registration as necessary or in the minor's best interests and instead relies on the fact that the child is under the care and protection of the Child Care Act 1991, as amended (1991 Act). ${ }^{119}$

ICI (2016) reported that guidance is not provided by INIS to its staff or the GNIB on the application procedure or appropriate immigration permission for children, and $\mathrm{ICl}$ observed that residence permissions granted to children, including unaccompanied minors, when applied for, are inconsistent and often inappropriate to the child's situation. ICI (2018) also highlighted the importance of regard being had to existing issues, such as the lack of awareness as to registration obligations for children aged 16 and over and lack of guidelines on the application

Consultation with IRPP, February 2018.

Interview with Immigrant Council of Ireland, January 2018.

Interview with SWTSCSA, January 2018. 
process and appropriate residence permissions for children, when extending current registration requirements to children under 16.

\subsubsection{Addressing the interaction of children in care with the immigration system}

CRA and ICI have called for clear legislative guidelines on the registration process and the appropriate immigration status for children who are not seeking international protection (CRA, 2015b; Mannion, 2016). ICl argues that Tusla's duty to safeguard and promote the child's welfare extends to the resolution of a child's immigration status in the State (Mannion, 2016). NGOs recommend that Tusla should be required to address the immigration status of unaccompanied minors on taking them into care, and include immigration status in their care plans, to ensure that overall integration objectives can be achieved (Arnold et al., 2015; Cosgrave and Thornton, 2015; Mannion, 2016). In respect of migrant children in care generally, ICl, Migrant Rights Centre of Ireland and Nasc recommend that the child's social worker should write to INIS when the child turns 15 to request that permission to reside is granted to the child (Mannion et al., 2018). As many unaccompanied minors referred to Tusla are aged 16 to 17, CRA and ICl specify that Tusla should apply for an alternative residence permission on behalf of unaccompanied minors in its care should a decision be taken not to submit an application for international protection on their behalf (CRA, 2015b; Mannion, 2016).

In order to ensure that Tusla is able to carry out its role in relation to addressing the immigration status of unaccompanied minors prior to their leaving care, ICl has pointed to the need for increased knowledge and supports among social workers working with unaccompanied minors (Mannion, 2016). There are currently no course requirements for social workers in relation to immigration law and unaccompanied minors (Arnold, 2013; Mannion, 2016). Many social workers and care staff have reported having little knowledge of immigration procedures and requirements and being unaware of the need to assist children in their care in this regard (Mannion, 2016; HIQA, 2018b). Research highlights the need for comprehensive information and training on immigration matters to be provided to social workers (Arnold, 2013; Mannion, 2016).

$\mathrm{ICl}$ further observed the lack of interagency dialogue around addressing the status of unaccompanied minors in the care of Child and Family Agency, Tusla (Tusla). ${ }^{120}$ In this regard, the Irish Refugee Council (IRC) highlighted the need for a more holistic, child-centred inter-agency approach by immigration officials, legal professionals and carers to addressing the immigration status of unaccompanied 
minors (Arnold et al., 2015). ICl noted that good practice in the care of unaccompanied minors is reflected in cases where appropriate applications for international protection or other residence permission are made on the basis of legal advice and issued in a timely manner prior to the age of 18 . ICl supports such practice being mainstreamed in the approach to unaccompanied minors by all stakeholders. ${ }^{121}$

Unless an unaccompanied minor has applied for international protection or has been granted refugee status, programme refugee status, subsidiary protection status, permission to remain or other residence permission, he or she does not have a legal status in the State. ${ }^{122}$ While many eventually enter the international protection process, the fact that other statuses are rarely applied for and that applications are not made until the child is nearing the age of 18 means that in many cases unaccompanied minors may be without a legal status for a number of years. Researchers have highlighted that the lack of a legal status at the age of 18 has an impact on access to employment, education, citizenship and other supports and services, including aftercare (Horgan et al., 2011; Arnold et al., 2015; ICl, 2016; Mannion, 2016; Ní Raghallaigh and Thornton, 2017; Sirriyeh and Ní Raghallaigh, 2018). The implications of the lack of legal status are discussed further in Chapters 4,5 and 6.

\subsection{UNACCOMPANIED MINOR VICTIMS OF TRAFFICKING}

All unaccompanied minors identified as victims of trafficking are taken into Tusla's care by way of a full care order under section 18 of the 1991 Act and as a result are assigned a social worker who is appointed by the court as the legal guardian of the minor (GRETA, 2017).

An unaccompanied minor who is a suspected victim of trafficking can be assisted in applying for international protection or granted a temporary permission to remain in the State for a period of 60 days or longer. They may also be granted a temporary residence permission for a renewable period of six months in cases where the unaccompanied minor victim of trafficking agrees to assist An Garda Síochána (Irish Police) in an investigation in relation to alleged trafficking (Department of Justice and Equality, 2011). After a period of temporary permission to remain or reside in Ireland, unaccompanied minor victims of trafficking can apply for a Stamp 4 residence permission (Department of Justice and Equality, 2015). No up-to-date data on unaccompanied minor victims of trafficking were available at the time of publication. 



\section{CHAPTER 4}

\section{Care}

Under the International Protection Act 2015 (2015 Act), the Child and Family Agency, Tusla (Tusla), is responsible for the care of unaccompanied minors in Ireland. ${ }^{123}$ The Social Work Team for Separated Children Seeking Asylum (SWTSCSA), based in Dublin, provides care to all unaccompanied minors in Ireland referred to Tusla. Care is provided by the SWTSCSA on the basis of an 'equity of care' principle, according to which all unaccompanied minors receive care on a par with other children in the care system up to the age of 18 . No distinction is made in the level of care provided to unaccompanied minors on the basis of their international protection or immigration status. However, the level of aftercare services available to unaccompanied minors may vary depending on the entitlements arising from the child's status on reaching the age of 18.

This chapter outlines the care arrangements for unaccompanied minors in Ireland, providing information on the care provided to unaccompanied minors from their initial referral to Tusla to leaving care at the age of 18 . Section 4.1 introduces Irish law and policy in relation to the care of unaccompanied minors. Section 4.2 provides information on the type of accommodation arrangements available for unaccompanied minors throughout the care process, while Section 4.3 considers the guardianship structures relevant to unaccompanied minors. Section 4.4 then examines aftercare planning and provision for unaccompanied minors.

\subsection{CARE OF UNACCOMPANIED MINORS: LAW AND POLICY}

The 2015 Act is the primary legislation in Ireland that governs the international protection process and assigns responsibility to Tusla for unaccompanied minors seeking international protection. Section 14(1) of the 2015 Act states that

[w] here it appears to an officer [of the Minister or an immigration officer] ... that a person seeking to make an application for international protection, or who is the subject of a preliminary interview, has not attained the age of 18 years and is not accompanied by an adult who is taking responsibility for the care and protection of the person, the officer shall ... notify the Child and Family Agency of that fact.

Pursuant to section 14(2) of the 2015 Act, once an unaccompanied minor is referred to Tusla, ${ }^{124}$ the Child Care Acts 1991 to 2013, Child and Family Agency Act

123 International Protection Act 2015, s 14(2).

124 For information on the referral pathway, see Annex 2. 
2013 and other legislation relating to the care and welfare of children apply. The European Communities (Reception Conditions) Regulations 2018 (2018 Regulations), which were adopted following the government's opt-in to the EU Reception Conditions Directive, ${ }^{125}$ set out further guidelines in respect of unaccompanied minors seeking international protection. The 2018 Regulations state that Tusla must represent and assist the unaccompanied minor in international protection procedures with a view to ensuring the best interests of the child.

Legislation does not explicitly provide for responsibility in respect of unaccompanied minors who do not seek international protection. Child care legislation provides general guidance on the role of Tusla in relation to children in need of care and protection. The Child Care Act 1991, as amended (1991 Act), states that Tusla must promote the welfare of children who are not receiving adequate care and protection, ${ }^{126}$ and sets out Tusla's duty to take children into its care where it appears that a child is in need of care and protection. ${ }^{127}$

Children seeking international protection and in care are recognised in the National Policy Framework for Children and Young People 2014-2020 as being at particular risk and in need of additional support and protection (DCYA, 2014). As part of the Policy Framework, the government has committed to promoting the protection and welfare of all refugee children and children in the international protection system (DCYA, 2014). In addition, national child protection policy states that particular attention should be paid to the welfare and protection of children who are separated from their parents, as well as to child victims of trafficking (DCYA, 2011). A revised National Aftercare Policy was introduced in September 2017 outlining the procedure in relation to aftercare planning for eligible children leaving care at the age of 18 , in which unaccompanied minors leaving care are identified as requiring special consideration (Tusla, 2017b) (discussed further in Section 4.4).

Following the establishment of the Calais Special Project, the Minister for Children and Youth Affairs announced the expansion of Tusla's capacity to meet the needs of unaccompanied minors, including resources of $€ 2.4$ million. ${ }^{128}$ Since the commencement of the Calais Special Project, the number of residential units specifically for unaccompanied minors has increased from four to seven. ${ }^{129}$ The capacities of the SWTSCSA have also expanded, to include six aftercare workers

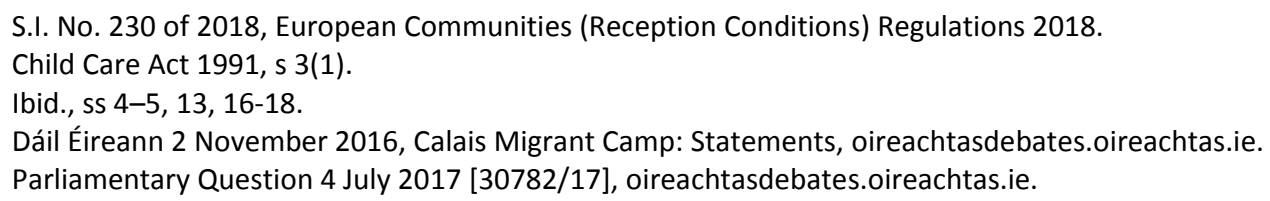


and a social care worker, who provide support in addition to that provided by the unaccompanied minor's social worker in order to address additional needs as they arise. $^{130}$

The SWTSCSA reported in 2017 that the team comprises one principal social worker, four social work team leaders (in the areas of aftercare, children in care, duty and fostering), six aftercare workers, five social workers, one fostering social worker and administrative support. ${ }^{131}$

\subsubsection{Future plans}

The Irish Refugee Protection Programme (IRPP) noted that difficulties were encountered in identifying additional unaccompanied minors that met the terms of the government decision on Calais and the EU relocation schemes in Greece and Italy. ${ }^{132}$ The government is continuing to explore the relocation of additional unaccompanied minors from Greece and Italy in 2018, in order to meet commitments under the IRPP. ${ }^{133}$ The SWTSCSA reported that, in addition to the arrival of the remaining unaccompanied minors under the Calais Special Project and the relocation of four unaccompanied minors from Malta in 2018, it aims to accept 16 more unaccompanied minors from Greece and Italy by the end of 2018. ${ }^{134}$ The SWTSCSA stated that it is prioritising female unaccompanied minors and unaccompanied minors aged 16 and under to ensure the minors' eligibility for aftercare. ${ }^{135}$

Tusla's Corporate Plan 2018-2020 states that Tusla plans to work with the Department of Justice and Equality and other stakeholders to increase its capacity by 40 unaccompanied minors per year (Tusla, 2018a). Tusla also stated it intends to establish an Action Plan with relevant government departments to receive further unaccompanied minors under the IRPP (Tusla, 2018b). In May 2018, the Department of Justice and Equality indicated its intention to relocate up to 60 unaccompanied minors from Italy and Greece before the end of 2019. ${ }^{136}$

\footnotetext{
130 Interview with SWTSCSA, January 2018.

131 SWTSCSA, Presentation: 'Aftercare Service for Separated Children Ireland', 15 September 2017, available at https://www.grkom.se/download/18.63fdd0a015e72a7f709e7dfa/1505386814987/KERETA+Aftercare+Presentation +G\%C3\%96TEBORGSREGIONENS+\%28002\%29+\%5BKompatibilitetsl\%C3\%A4ge\%5D.pdf.

132 Interview with IRPP, February 2018.

133 Ibid.

134 Interview with SWTSCSA, October 2018.

135 Ibid.

136 Parliamentary Question, 23 May 2018 [22377/18], oireachtasdebates.oireachtas.ie.
} 


\subsection{ACCOMMODATION}

On referral to the SWTSCSA, unaccompanied minors over 12 years of age, regardless of their status, are placed in one of four short-term and medium-term intake residential units for periods ranging from six to 24 months when taken into the care of Tusla. ${ }^{137}$ During this period, Tusla carries out an intake assessment with the unaccompanied minor to determine their needs, including a medical examination and an educational assessment. On this basis, a care plan is developed for all unaccompanied minors, setting out the most appropriate care arrangement (Quinn et al., 2014). In line with the equity of care approach, all unaccompanied minors are assigned a social worker and placed in foster care, supported lodgings or residential units (Quinn et al., 2014).

Research has indicated that unaccompanied minors in Ireland receive a high standard of care in comparison with other EU countries, and positive developments in the care of unaccompanied minors have been welcomed (Arnold and Ní Raghallaigh, 2017; Brindle, 2017). In an activity report produced at the end of December 2017, the SWTSCSA reported that all unaccompanied minors in the State had been allocated a social worker and had an up-to-date care plan (Tusla, 2018c).

Of the 80 unaccompanied minors in the care of the SWTSCSA at the end of December 2017, 35 were reported as residing in residential care, 19 in foster care and 26 in other care placements, which include supported lodgings (Tusla, 2018c). ${ }^{138}$

\subsubsection{Residential units}

Following an initial period spent in one of the four residential intake units, unaccompanied minors may be placed in one of three long-term residential units or in foster care (see Section 4.2.2). These units are registered children's homes dedicated specifically to unaccompanied minors. ${ }^{139}$

The residential units must be staffed with qualified social care workers (Tusla, 2017f), and all staff are required to receive training in line with Children First National Guidance for the Protection and Welfare of Children (DCYA, 2011). All units are subject to inspections by the Health Information and Quality Authority (HIQA) against the National Standards for Children's Residential Centres

137 Interview with SWTSCSA, January 2018.

138 Other care placements may include: children at home under a care order; detention centre/prison; youth homeless facilities; other residential centres, e.g., therapeutic, disability, residential assessment, designated mother and baby units (Tusla, 2018d).

139 Interview with SWTSCSA, January 2018. 
(Department of Health and Children, 2001; Quinn et al., 2014). The Report of the Commission to Inquire into Child Abuse (Ryan Report) recommended that reviews of legislation and policies in relation to children in care be carried out at regular intervals (Department of Health and Children, 2009). The National Standards for Children's Residential Centres were last updated in 2001. ${ }^{140}$

Recent HIQA inspections of two residential centres for unaccompanied minors reported that several aspects of care provision in the centres were not in compliance with the National Standards for Children's Residential Centres (HIQA, 2017, 2018a). HIQA reported in 2017 and 2018 that some of the children's care plans varied in quality or were incomplete, and not all unaccompanied minors had up-to-date care plans on file. It was further reported that minors did not have consistent and sufficient aftercare plans in place, despite the fact that the majority of children being cared for were 17 years old (HIQA, 2017, 2018a).

While the children living in both centres inspected by HIQA spoke positively of their care and were assisted in participating in activities in the community, inspectors found that the quality of life was mixed, some of the factors negatively affecting care and integration being specifically related to the child's experience as an unaccompanied minor. Both children and staff reported uncertainty around children's care and accommodation needs on reaching the age of 18 , and centres did not have policies that reflected key service needs for unaccompanied minors.

In particular, it was found that the provision of therapeutic or specialised services to respond to the children's emotional needs and experience of trauma in both centres was inadequate or absent. HIQA (2018a) also highlighted that some unaccompanied minors in one of the centres were precluded from traveling in order to participate in a school trip or sports event in which one of the unaccompanied minors was due to compete, despite all having refugee status. In one of the centres based outside of Dublin, unaccompanied minors did not receive regular visits from their appointed SWTSCSA social worker as required by the Child Care Regulations 1995 (HIQA, 2017a). Staff in one of the centres also reported that further training on issues relevant to the children for which they were providing care, including the international protection system and family reunification, was required, but had not been planned at the time of the inspection (HIQA, 2018b). Staff in both centres had not all received mandatory Children First training (HIQA, 2017, 2018a, 2018b).

140 A public consultation on the draft National Standards for Children's Residential Centres is underway. See: Health Information and Quality Authority, 'Public Consultation on the Draft Standards for Children's Residential Centres', https://www.hiqa.ie/reports-and-publications/consultation/public-consultation-draft-standards-childrensresidential. 


\subsubsection{Foster care}

Unaccompanied minors under 12 years of age are placed directly in foster care on referral to Tusla. Following an initial period spent in residential intake units, most unaccompanied minors over the age of 12 are also placed in foster care (Arnold and Ní Raghallaigh, 2017). Foster care placements are arranged by Tusla and private foster agencies. Private foster agencies provide training to foster carers on unaccompanied minors (Quinn et al., 2014). Foster carers may also be assigned a social worker to provide support and guidance (Quinn et al., 2014). Foster care is governed by the 1991 Act and the Child Care (Placement of Children in Foster Care) Regulations 1995. Foster care is further subject to the National Standards for Foster Care, which provide guidelines on the provision of foster care services and are used by HIQA to measure the quality of foster care services (Department of Health and Children, 2003). Similarly to standards relating to residential care, foster care standards have not been updated since 2003 .

Studies carried out with unaccompanied minors and carers found that unaccompanied minors had positive experiences living in foster care, which assisted them to integrate into family and community life (Ní Raghallaigh, 2013; Horgan and Ní Raghallaigh, 2017). Research suggests that foster carers are best placed to support unaccompanied minors, particularly during the transition to adulthood (Sirriyeh and Ní Raghallaigh, 2018). Sirriyeh and Ní Raghallaigh (2018) also highlight the role foster carers can play in advocating for unaccompanied minors, including in relation to their education.

Research finds that the transition from initial residential care during the intake period to foster care poses a challenge to unaccompanied minors, including adjusting to a different environment (Quinn et al., 2014). Some stakeholders are critical of the practice of moving unaccompanied minors to foster care placements following periods spent in residential intake units. Some minors may be moved far from where they were initially housed, resulting in disruption to integration into local communities and relationships built with other young people and care staff (Ní Raghallaigh, 2013; Quinn et al., 2014; Arnold et al., 2015). Challenges with recruiting foster carers, such as matching the needs of the unaccompanied minor to appropriate carers, have also been reported (Horgan and Ní Raghallaigh, 2017).

\subsubsection{Supported lodgings}

Supported lodgings are one of the primary care arrangements provided to unaccompanied minors. This is a form of family care in which children aged 15 and over receive less support from carers than in other forms of family-based care, with the aim of supporting the child's increased independence (Quinn et al., 2014). Arnold and Ní Raghallaigh (2017) highlighted the importance of supported lodgings in ensuring unaccompanied minors' independence. As with foster carers, 
supported lodgings placements are arranged by Tusla and private foster agencies. Providers of supported lodgings are assessed and approved by Foster Care Committees (Tusla, 2017h). The SWTSCSA stated that supported lodgings adhere to National Standards for Foster Care. ${ }^{141}$ Concerns as to the use of supported lodgings have been expressed in the past (CRA, 2012; Ní Raghallaigh, 2013) as supported lodgings are not the subject of national standards or subject to HIQA inspections (HSE, 2012).

Varying levels of training for foster carers and supported lodgings carers have also been reported (Quinn et al., 2014). Research conducted with foster and supported lodgings carers found that supported lodgings carers received little training in comparison with most foster carers, who receive significant training prior to care placements (Ní Raghallaigh, 2013). The need for adequate training for all carers, including training that is culturally conscious, has been highlighted in research (Ní Raghallaigh, 2013; Ní Raghallaigh and Sirriyeh, 2015; Horgan and Ní Raghallaigh, 2017).

\subsection{APPOINTMENT OF A REPRESENTATIVE}

In June 2018, the government opted in to the recast Reception Conditions Directive, which was transposed into national law with the adoption of the European Communities (Reception Conditions) Regulations 2018 (2018 Regulations). ${ }^{142}$ Pursuant to article 24 of the Directive, Member States must take measures to ensure that a person or organisation represents and assists the unaccompanied minor to enable him or her to benefit from the rights provided for in the Directive. Article 2 defines a representative as 'a person or an organisation appointed by the competent bodies in order to assist and represent an unaccompanied minor in procedures provided for in this Directive with a view to ensuring the best interests of the child and exercising legal capacity for the minor where necessary'.

\subsubsection{Tusla}

In line with the Reception Conditions Directive, 2018 Regulations provide for the appointment of a Tusla employee or other individual to perform the functions of a representative. ${ }^{143}$

The 2018 Regulations apply only to an unaccompanied minor who has submitted an application for international protection or has given an indication that he or she wishes to make an application for international protection, is requesting not to be

\footnotetext{
Interview with SWTSCSA, October 2018.

S.I. No. 230 of 2018, European Communities (Reception Conditions) Regulations 2018.

Ibid., Regulation 10.
} 
expelled or returned to a territory where there is a serious risk that he or she would be subjected to the death penalty, torture or other inhuman or degrading treatment or punishment, or fears or faces persecution or serious harm if returned to his or her country of origin. In practice, every unaccompanied minor is appointed a social worker who performs the functions of a representative.

Tusla's ability to exercise legal capacity for the minor where necessary depends on the section of the 1991 Act utilised by Tusla to take the unaccompanied minor into its care. Typically, the SWTSCSA takes unaccompanied minors into care on the basis of section 4 of the 1991 Act (Quinn et al., 2014). Section 4 provides that Tusla may take into 'voluntary care' a child that requires care that is unlikely to be received otherwise. Under section 4, parental consent to the child being taken into care must be provided. ${ }^{144}$

This may have implications for the child's care. For example, social workers caring for children under section 4 are statutorily obliged to have regard to the wishes of the parent or person in loco parentis in providing care to the child. ${ }^{145}$ In practice, this means that the SWTSCSA is required to seek consent from parents in the country of origin or third country concerning key decisions affecting the child in relation to their health and education, such as consent for travel outside the jurisdiction and engagement in after-school activities (Corbett, 2018). If the SWTSCSA is not in contact with the family, it must seek a court order to dispense with parental consent. For example, if the child is under the age of 16, the SWTSCSA must go to court in order to dispense with parental consent for medical procedures (Quinn et al., 2014; Arnold and Sarsfield Collins, 2011; Arnold, 2013). Researchers have argued that the application of this section is problematic in the case of unaccompanied minors as the parents or guardians of an unaccompanied minor may not be in the State or contactable in order to provide their consent (Arnold and Kelly, 2012; Corbett, 2018). The SWTSCSA noted that the implications are minimal. ${ }^{146}$

Following the inspection of care facilities provided to unaccompanied minors seeking international protection in January 2018, HIQA raised the issue of the application of section 4 to the situation of unaccompanied minors (HIQA, 2018a). The inspection found that there were no copies of a court order or of parental consent to the child's admission into voluntary care in some of the children's case files, contrary to the Child Care (Placement of Children in Residential Care) Regulations 1995, which require proof of parental consent to be included in a child's case file on placement in residential care. HIQA (2018a) also highlighted that admission into care under section 4 did not take into consideration significant

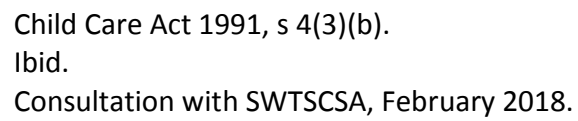


components of the unaccompanied minor's care and was a source of uncertainty for care staff, including in relation to providing consent for participation in school activities, such as school trips and sports events. In April 2018, the residential centre reported that additional documentation had subsequently been included on file to support the children's care status (HIQA, 2018a).

In contrast, in cases where Tusla takes the child into its care on the basis of a full care order granted by the court under section 18 of the 1991 Act, Tusla has 'the like control over the child as if it were his parent' and is entitled to make all decisions concerning the welfare of the child until the child reaches the age of 18. ${ }^{147}$ Utilising section 18 of the 1991 Act requires Tusla to go to the district court. However, applications for a care order have been made infrequently in practice (Arnold and Kelly, 2012; Arnold, 2013; Horgan and Ní Raghallaigh, 2017). The SWTSCSA noted that applying for a care order may not always be appropriate where family reunification is being pursued. If it appears that long-term care arrangements will be needed for an unaccompanied minor, the SWTSCSA has stated that it will seek a care order (Quinn et al., 2014). The SWTSCSA noted that the practice of utilising section 4 of the 1991 Act arose from legal advice received early in the development of its service. ${ }^{148}$ However, the pursuance of care orders is becoming more common. ${ }^{149}$ The SWTSCSA added that there is a shift towards care orders, noting that Emergency Care Orders ${ }^{150}$ and Interim Care Orders ${ }^{151}$ have been applied for in court for unaccompanied minors; applications to court for an order in respect of children aged 15 and under are made in general; applications to the court in respect of children aged 16 and 17 are made on a case-by-case basis; and vulnerability and age are factors in the decision to make an order to the court. $^{152}$

Corbett (2018) reports that guidance provided to social workers by Tusla in 2017 on voluntary consent for admission to care states that voluntary care 'should not be sought if reunification is seen not to be possible', in which case, 'steps must be taken to seek the appropriate permanency placement for the child'. Researchers recommend that, while the use of section 4 provides a quick and inexpensive means to admit children into care, Tusla should be required to apply to the court for a care order under section 18, in respect of a child in voluntary care, in cases where a parent or guardian is unidentifiable or uncontactable (Arnold and Kelly, 2012; Corbett, 2018).

Child Care Act 1991, s 18(2).

Interview with SWTSCSA, October 2018.

Ibid.

Child Care Act 1991, as amended, s 13.

Ibid., s 17.

Interview with SWTSCSA, October 2018. 


\subsubsection{Guardian ad litem}

Provision is also made in Irish law for the appointment of a guardian ad litem in respect of care proceedings where the court is satisfied that it is necessary in the best interests of the child. A guardian ad litem is an independent representative, typically with a social work background, who is appointed by the courts to represent a child in court proceedings, ensuring their voice is heard, and to advise the court on the best interests of the child. ${ }^{153} \mathrm{~A}$ guardian ad litem is not legally responsible for the child. Section 26 of the 1991 Act provides for the appointment of a guardian ad litem in the course of care proceedings, such as where the child is taken into care under section 18 of the 1991 Act. Researchers recommend therefore that care orders under section 18 of the 1991 Act be utilised to take unaccompanied minors into care to provide for the possibility to appoint a guardian ad litem (Arnold and Kelly, 2012; Arnold et al., 2015; Arnold and Ní Raghallaigh, 2017).

The appointment of guardians ad litem to children, including unaccompanied minors, in Ireland is carried out in an ad hoc and inconsistent manner and no guidance is available on their appointment, qualifications or role (Phelan, 2015). Guardians ad litem are rarely appointed to unaccompanied minors in the care of Tusla (Arnold and Kelly, 2012; Mannion, 2016). The CRA and the Oireachtas Special Rapporteur on Child Protection have advocated for the appointment of guardians ad litem to all unaccompanied minors in the care of Tusla (CRA, 2015a, 2015b; Shannon, 2016). In contrast, the Department of Justice and Equality has previously stated that the guardian ad litem only addresses the needs of the child in relation to court proceedings and Tusla's role in acting in the best interests of the child mitigates the need for a legal guardian (Department of Justice, Equality and Law Reform, 2009). Reform of the guardian ad litem arrangements in Ireland is currently being undertaken, with a view to clearly setting out the role and appointment of a guardian ad litem in legislation and providing for the establishment of a national guardian ad litem service. ${ }^{154}$

NGOs and researchers have alternatively recommended that an independent guardian be appointed to each unaccompanied minor when taken into their care, separate to guardians ad litem, which would include a role beyond the courts, particularly to address the minor's immigration status (Quinn et al., 2014; Charles, 2009; Abunimah and Blower, 2010; Arnold and Sarsfield Collins, 2011; Arnold and Kelly, 2012; Horgan et al., 2012; Arnold, 2013; Cosgrave and Thornton, 2015; Mannion, 2016). Research suggests that factors such as the burden of the decisionmaking process as well as a lack of comprehensive expertise and awareness among

153 Child Care Act 1991, s 26.

154 See: Department of Children and Youth Affairs, 'Reform of Guardian ad litem arrangements in child care proceedings', https://www.dcya.gov.ie/docs/Reform_of_Guardian_ad_litem_arrangements_in_child_care_proce/3969.htm. 
Tusla social workers in relation to immigration procedures has been found to impact on Tusla's decision whether or not to apply for an international protection or other immigration status for the minor, and highlights the need for an independent legal guardian (Horgan et al., 2012; Arnold, 2013; Mannion, 2016). Researchers also highlight Tusla's involvement as a State institution in the application process as giving rise to a conflict of interest and raising concerns as to whether the child's best interests are adequately taken into account (Mullally, 2011; Arnold and Sarsfield Collins, 2011; Arnold et al., 2014; Shannon, 2016). The SWTSCSA however commented that an independent guardianship system would result in an additional relationship with an adult, which would distract from the relationship with the unaccompanied minor's allocated social worker trained in responding to the needs of children. ${ }^{155}$

\subsection{AFTERCARE: UNACCOMPANIED MINORS TURNING 18}

As outlined in Section 2.2, most unaccompanied minors referred to the SWTSCSA are aged between 16 and 17 . These children therefore require specific supports in preparation for the transition to adulthood. The National Aftercare Policy for Alternative Care states that aftercare services are support services that build on and support the work already undertaken in preparing young people for adulthood and leaving care (Tusla, 2017a). It identifies unaccompanied minors seeking international protection as requiring particular support in aftercare planning (Tusla, 2017b).

The level of support provided to young people leaving care depends on the child's identified needs and the resources in place as well as the legal status of the child (Quinn et al., 2014). As noted previously, the vast majority of unaccompanied minors do not have an immigration status by the age of 18 . See Box 1 for specific information on aftercare for unaccompanied minors who do not have an immigration status.

Aftercare arrangements for all children leaving care at the age of 18 are provided for in legislation. Section 45 of the 1991 Act places a statutory duty on Tusla to undertake a needs assessment of eligible children to determine the supports and services required on leaving care. Where any need is identified, Tusla is required to prepare an aftercare plan for the child. Eligible children are those who have been in the care of the State for at least 12 months between the ages of 13 and $18 .{ }^{156}$ As previously reported, more than 50 per cent of unaccompanied minors referred to the SWTSCSA are aged between 16 and $17 .{ }^{157}$ Some unaccompanied minors may

Consultation with SWTSCSA, February 2018.

Child Care Act 1991, as amended, s 45A(1).

Interview with SWTSCSA, October 2018. 
therefore not meet the eligibility requirements for aftercare. As at 15 September 2017, the SWTSCSA reported that it had 80 aftercare cases allocated to aftercare workers. ${ }^{158}$

If a need is identified, an aftercare worker, who is an employee of Tusla working with the SWTSCSA, assists the child in preparing an aftercare plan, along with the child's social worker and other relevant stakeholders. The aftercare plan sets out key supports or services that may be required by the child in his or her transition to adulthood in areas including education, health, accommodation and financial assistance. Social workers and care staff also assist the unaccompanied minor in practice and develop his or her independence ahead of the transition to adulthood and leaving care. Staff in residential centres have reportedly provided assistance to children in opening a bank account, participating in shopping and cooking (HIQA, 2018a).

When the minor turns 18 and leaves care, an aftercare worker may be allocated to the aged-out minor to provide support and guidance in all aspects of their life according to their aftercare plan, including accessing education, training and employment, personal and social wellbeing, family tracing/reunification and other supports and services to facilitate their ongoing integration into the community (Tusla, 2017a). Aftercare support is provided up to the age of 21 and can be extended to the age of 23 if education or training continues. ${ }^{159}$ An aftercare dropin service is also available for both aged-out minors in aftercare and those who were previously in care, and is not subject to an age limit (Tusla, 2017e). Young people leaving care may also be referred to one of 21 inter-agency aftercare steering committees which have been set up in local areas across Ireland. Aftercare steering committees provide a forum to support the planning, implementing and monitoring of aftercare provision for young people leaving care. The committee includes public and voluntary service providers who provide a service to care leavers (Tusla, 2017g).

An aftercare plan can include support in transitioning to independent accommodation and securing suitable accommodation. As part of aftercare planning, housing needs are identified in collaboration with relevant stakeholders, including local housing authorities, and the aftercare worker (Tusla, 2017b). Unaccompanied minors who are living in foster care or supported lodgings and who receive a positive decision on their international protection application before reaching the age of 18 can either move from care to independent living or remain in their care arrangement until the age of 21 . The care arrangement can be 
extended to the age of 23 if education or training continues. In 2014 a Joint Working Protocol was agreed in order to provide a guide to housing authorities and Tusla in assessing and progressing the housing and support needs of young people leaving care (Department of Planning, Housing and Local Government, 2014). Local housing authority representatives are also represented on aftercare steering committees and provide support in respect of children identified as being at risk of becoming homeless. The SWTSCSA currently works with an Approved Housing Body to identify suitable accommodation for care leavers at risk of homelessness under the Capital Assistance Scheme administered by local authorities. ${ }^{160}$

An Individual Financial Support Plan is included in aftercare planning to assess the financial needs of children leaving care. Unaccompanied young people over the age of 18 who have been granted a status and are in education/training are entitled to receive the Standardised National Aftercare Allowance (for more information see Section 5.4) (Tusla, 2015, 2017c).

Aftercare services are also provided by NGOs, such as Crosscare, which operates an aftercare service for young people who have lived in care and are transitioning to independent living. This service is provided on behalf of Tusla under a service level agreement. Tusla co-ordinates and oversees the service. ${ }^{161}$ The service offers programmes, such as literacy and life skills, provision of a link worker to develop strategies for personal development, and a house-share arrangement for eligible young people aged 18-25 who have lived in care, with some support provided by aftercare service staff. ${ }^{162}$ Some aged-out minors who have transitioned from care and obtained status are reported to have availed of the house-share arrangement along with other young people, including young Irish people, who have left care (Freyne, 2017).

HIQA has reported that aftercare planning for unaccompanied minors in residential centres can be inconsistent (HIQA, 2018a, 2018b). HIQA has further noted variation among some residential care staff in their understanding of the eligibility of unaccompanied minors in their care for aftercare support. HIQA noted this as a concern given unaccompanied minors' particular vulnerabilities (HIQA, 2018b).

160 An Approved Housing Body is a non-profit organisation that provides affordable rented housing for people who cannot afford to pay private sector rents or buy their own homes; or for particular groups, such as older people or homeless people. See Department of Housing, Planning and Local Government, 'Approved Housing Bodies (AHBs)', https://www.housing.gov.ie/housing/social-housing/voluntary-and-cooperative-housing/approved-housing-bodiesAHBs.

161 Correspondence with SWTSCSA, October 2018.

162 Crosscare, 'Crosscare Aftercare Service', http://www.crosscare.ie/index.php/after-care. 
Following inspection of one residential centre for unaccompanied minors in January 2018, HIQA (2018a) reported that a sufficient aftercare plan was not in place for six unaccompanied minors, all of whom were 17 years of age, had refugee status and had been placed in the residential centre in March 2017. HIQA noted that care plans focused predominantly on addressing current needs and settling into a new environment. However, it stated that aftercare planning for children nearing the age of majority requires equal focus and should run in tandem with the child's immediate care needs (HIQA, 2018a). The SWTSCSA noted that referrals to the aftercare service may not be made for a short period of time following entry into care, as preparing for entry into care and leaving care at the same time may be confusing for the child. ${ }^{163}$ Following the HIQA inspection, the residential centre reported in April 2018 that aftercare needs assessments had been completed and that an aftercare worker would be allocated to all unaccompanied minors in the centre by 31 May 2018 (HIQA, 2018a).

\section{Box 1 Unaccompanied minors turning 18 without status}

Unaccompanied minors who do not have an immigration status at the age of 18 but who meet the eligibility criteria set out in section 45 of the 1991 Act are entitled to avail of aftercare in the same manner as all eligible children in care. However, aged-out minors who do not have international protection or another immigration status at the age of 18 and are in full-time education are not eligible for the Standardised National Aftercare Allowance (Tusla, 2017b).

In the case of unaccompanied minors who are eligible for an aftercare service and are turning 18 without an immigration status, National Aftercare Policy states that efforts will be made to ensure the aftercare service provides support to social workers to work with the young person in securing their status (Tusla, 2017b).

The SWTSCSA undertakes parallel planning in respect of eligible unaccompanied minors turning 18 without an immigration status. ${ }^{164}$ The SWTSCSA stated that the child's aftercare plan can be drawn up to reflect the supports available in more than one scenario, including where: the minor receives status, is reunited with family, (voluntarily) returns to their country of origin, is still awaiting a decision on their application for international protection, or enters into the international protection process when they have turned $18 .{ }^{165}$ Aftercare plans can be reviewed to reflect any changes that occur in relation to the child's immigration status. ${ }^{166}$

A HIQA inspection of one of the residential units dedicated to unaccompanied minors carried out in 2018 reported that, in situations where children were awaiting confirmation of their immigration status, parallel planning was absent. As a result, HIQA observed that children were uncertain about

Consultation with SWTSCSA, October 2018.

Ibid.

Interview with SWTSCSA, January 2018.

Consultation with SWTSCSA, October 2018. 
their future and their preparation for the transition to adulthood and leaving care was compromised (HIQA, 2018b).

Unaccompanied minors who have submitted an international protection application and have not received a decision on their status prior to turning 18 years of age, or who submit an international protection application on turning 18, are transferred from care to Direct Provision reception centres for adults seeking international protection. ${ }^{167}$

Prior to transferring aged-out minors to Direct Provision reception centres, Reception and Integration Agency (RIA) and Tusla jointly prepare a plan for the unaccompanied minor and identify a suitable reception centre, taking into account the needs and circumstances of the unaccompanied minor (Working Group on the Protection Process, 2015). In cases where an aged-out minor is deemed by Tusla to be particularly vulnerable, the period spent in care can be extended beyond 18 years of age (RIA, 2011). Aged-out minors are often not transferred from care to Direct Provision within an academic year so as to avoid disruption to their studies (Quinn et al., 2014). Research finds that in some cases aged-out minors awaiting a decision on their application for international protection have been provided with continued informal support from foster carers (Sirriyeh and Ní Raghallaigh, 2018). In one case, a foster family continued to provide accommodation to an agedout minor without financial assistance so the minor would not have to move to a Direct Provision reception centre (Sirriyeh and Ní Raghallaigh, 2018).

Research notes the disparities between the experience of aged-out minors who have received international protection status and those who are awaiting a status determination while residing in Direct Provision reception centres (Quinn et al., 2014). While efforts have been made in recent years to improve conditions (Working Group on the Protection Process, 2015; Department of Justice and Equality, 2017a, 2017b), living standards for persons seeking international protection in Direct Provision reception centres have been widely criticised (Smyth, 2014; Ní Raghallaigh et al., 2016; CRA, 2017; Ní Raghallaigh and Thornton, 2017). Aged-out minors who are transferred to Direct Provision on turning 18 and in full-time education or training are not eligible for the Standardised National Aftercare Allowance (Tusla, 2017b). As with other persons seeking international protection in Direct Provision, they are currently entitled to a weekly allowance of $€ 21.60$ from the Department of Employment Affairs and Social Protection (see Section 5.4, Box 4).

Research has highlighted the negative impact of Direct Provision reception centres on the wellbeing of aged-out minors (Ní Raghallaigh, 2013; Arnold et al., 2015). Difficulties in aftercare provision within the Direct Provision system have been reported in research, including where agedout minors are transferred to reception centres around the country, whereas aftercare workers are often based in Dublin (Ní Raghallaigh, 2013). Research states that transferring aged-out minors without an immigration status to Direct Provision places constraints on aged-out minors and aftercare workers to explore accommodation, educational or other supports for aged-out minors beyond those provided within the Direct Provision system (Ní Raghallaigh and Thornton, 2017).

167 Direct Provision is the system in which international protection applicants are accommodated and given full board in reception centres operated by the Reception and Integration Agency, while waiting for a decision on their application for international protection. 
Aged-out minors who reside in Direct Provision centres and are subsequently granted protection or leave to remain may face difficulties reported by persons seeking international protection in accessing accommodation, employment and mainstream services and supports on leaving the centres, which may affect their capacity to integrate into society (Working Group on the Protection Process, 2015; UNHCR Ireland, 2013; Ní Raghallaigh et al., 2016).

Research has shown the need for a coherent pathway of care for unaccompanied minors that ensures consistency and equity in the care provided during care and aftercare (Mannion, 2016; Horgan and Ní Raghallaigh, 2017). Researchers note that the uncertainty linked to the international protection system hinders the ability of carers and the child to plan for the transition to adulthood (Sirriyeh and Ní Raghallaigh, 2018). The international protection process and the move to Direct Provision on turning 18 have been identified as sources of stress for unaccompanied minors, which impact on integration into the education system (see Section 4.5) and into care placements, including, in particular, foster placements (Ní Raghallaigh, 2013; Arnold et al., 2015). It has therefore been recommended by some stakeholders that aged-out minors be given the option of remaining in their care placement beyond the age of 18 or be placed in alternative forms of independent living until their application for international protection is assessed (IRC, 2012; Mannion, 2016; Nasc, 2017). However, the SWTSCSA noted that this would take up valuable beds in foster families for vulnerable children in need. The SWTSCSA further observed that this proposal contradicts current government policy which prohibits adults seeking international protection from accessing most public funds. ${ }^{168}$ 


\section{CHAPTER 5}

\section{Access to education and employment, social welfare and healthcare}

Education is a fundamental right under Article 42 of the Constitution of Ireland, which applies to all resident children, regardless of their legal status in the State. All unaccompanied minors are entitled to primary and secondary education in Ireland. However, unlike ordinarily resident Irish children, unaccompanied minors are not automatically entitled to access free third-level education. Section 5.1 outlines the measures in place to support unaccompanied minors' access to mainstream education, and Section 5.2 examines access to third-level education and alternative education routes.

Unaccompanied minor beneficiaries of international protection or with a Stamp 4 permission to remain are entitled to seek and enter employment, subject to conditions set out in the Protection of Young Persons (Employment) Act 1996 applicable to all young people in Ireland. Access to employment is discussed in Section 5.3.

A discussion of social welfare entitlements and access to healthcare follows in Sections 5.4 and 5.5 .

\subsection{ACCESSING MAINSTREAM EDUCATION}

Education is compulsory for children under the Education (Welfare) Act 2000, which requires that children attend school up to the age of 16 , or for a minimum of three years of secondary education, whichever is the later. The education of children, including unaccompanied minors, between the ages of 16 and 18 is not legislated for. The Education Act 1998 places an obligation on primary and secondary schools to ensure that the educational needs of all students are identified and provided for. ${ }^{169}$ Under the National Policy Framework for Children and Young People 2014-2020, the government commits to strengthening inclusion measures and reinvigorating efforts to improve educational outcomes and integration for migrant children in general (Department of Children and Youth Affairs, 2014).

In respect of unaccompanied minors seeking international protection, the European Communities (Reception Conditions) Regulations 2018 (2018 Regulations) provide for 'access to primary and post-primary education in the like 
manner and to the like extent in all respects as a minor who is an Irish citizen'. ${ }^{170}$ In order to facilitate a minor's access to and participation in the education system, the State must provide support services and language supports to minors where necessary. ${ }^{171}$

On their being taken into care by the Child and Family Agency, Tusla (Tusla) Social Work Team for Separated Children Seeking Asylum (SWTSCSA) carries out a clinical intake assessment with unaccompanied minors to determine their needs in areas including education. On this basis, a care plan is developed for all unaccompanied minors, which includes input regarding an educational plan for the child (Quinn et al., 2014).

\subsubsection{The Youth and Education Service for Refugees and Migrants}

The SWTSCSA in Dublin usually refers the child to the City of Dublin Education and Training Board (CDETB)'s Youth and Education Service for Refugees and Migrants (YES) (formerly the Separated Children's Service) for an assessment prior to their entry into mainstream education (Quinn et al., 2014). YES provides a range of educational and outreach supports to unaccompanied minors in the Dublin area to support them to integrate into the Irish education system and Irish society in general. It is funded by the Department of Education and Skills, the Department of Children and Youth Affairs, SOLAS and, from 2017 to 2019, by the Dormant Accounts Fund, and its implementation is supported by the City of Dublin Youth Service Board. ${ }^{172}$ YES assesses the minor's educational background and English language skills on the basis of its own Preliminary Needs Assessment Tool, which includes a self-assessment checklist for the child that is available in six languages. ${ }^{173}$ Based on the assessment, the unaccompanied minor may then be placed in the YES Migrant Access Programme (MAP), which is a transition programme to prepare migrant children for mainstream education or training in Ireland. An agreement between YES and SWTSCSA provides access to the MAP for all unaccompanied minors in the care of the SWTSCSA in the Dublin area. ${ }^{174}$ Unaccompanied minors are placed in a group that corresponds to their level of English. ${ }^{175}$

MAP operates an ongoing enrolment system from September to July for 42 weeks per year, so that unaccompanied minors can join at any time during the academic

S.I. No. 230 of 2018, European Communities (Reception Conditions) Regulations 2018, Regulation 17(1). Ibid., Regulation 17(2).

See https://separatedchildrensservice.wordpress.com/. It also receives funding through the EU Asylum, Migration and Integration Fund.

Interview with Youth and Education Service for Refugees and Migrants, CDETB, January 2018.

Ibid.

Ibid. 
year. ${ }^{176}$ MAP consists of 20 hours of classes per week and focuses on four core modules: English, Mathematics, IT and Life-Skills. Additional after-school activities are offered in other subject areas such as outdoor education, arts and crafts, and cooking (Quinn et al., 2014). MAP also runs a language exchange class with Irish students in a secondary school in the Dublin area, which gives migrant children the opportunity to meet indigenous peers, have a conversation and play games, ${ }^{177,178}$ and has worked with Scouting Ireland to provide joint activities for migrant students and Irish students. ${ }^{179}$

MAP was initially established to provide supports to unaccompanied minors while they resided for a short period in residential intake units; however, the length of time an unaccompanied minor spends in residential units can vary. YES indicated that some unaccompanied minors continue to participate in the MAP after moving out of residential care if they are still located in the Dublin area. In addition, the length of time an unaccompanied minor spends in the MAP depends on their level of English and educational background and needs. ${ }^{180}$ In recent years, the educational profile of unaccompanied minors has shifted, with more children arriving in Ireland with very little formal education, poor literacy and low levels of English, which results in longer periods spent in the MAP (Brindle, 2017). On completion of the MAP, YES works closely with the SWTSCSA in providing a report and recommendation on the child's progress, which feeds into the child/young person's overall care plan. ${ }^{181}$ When he or she is ready, the unaccompanied minor transitions mainly to mainstream second-level education. Some unaccompanied minors transfer to other training options or, if they have turned 18 , onto programmes offered through the adult and community education sector. ${ }^{182}$

In addition to MAP, YES offers after-school and in-school services and supports in Dublin to migrant children in mainstream education, such as the School Support Programme, including an afterschool Study Buddy Homework Club, and afterschool and holiday revision and exam preparation camps. YES also provides information and support for schools with a large number of migrant students. A youth support service is available for young people seeking international protection, refugees and migrants, in which youth workers provide advice and support in relation to school placement, education, social welfare, accommodation, health and other specialist services. ${ }^{183}$

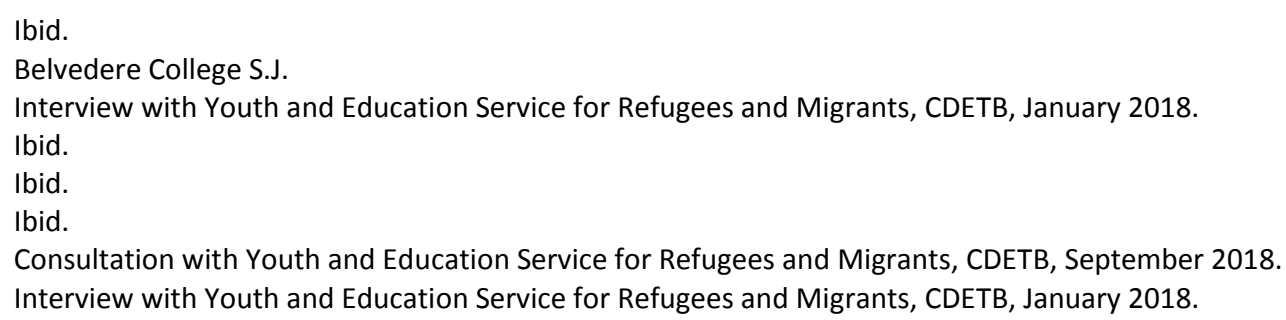


The supports provided to unaccompanied minors through YES are regarded highly by State service providers and Non-Governmental Organisations (NGOs) (Quinn et al., 2014). However, the service is only available to minors in the Dublin area and similar supports are not available for unaccompanied minors in other areas around the country. When accommodating unaccompanied minors in residential intake units outside of Dublin, the SWTSCSA has indicated that it endeavours to place minors with a higher level of English to ensure the minor is capable of entering mainstream education. ${ }^{184}$

\subsubsection{Supports in mainstream education}

Once in mainstream education, unaccompanied minors may access Englishlanguage tuition, which is the main national support available to migrant children in general in Irish schools (Rodríguez-Izquierdo and Darmody, 2017). In most cases, students are withdrawn from regular classes to attend English language tuition (Smyth et al., 2009). In addition, unaccompanied minors in mainstream schools have access to general social and academic guidance supports and other learning supports that may be available in the school (Quinn et al., 2014). The supports are generally provided as part of a mainstream approach that targets all migrant children with English as an additional language or children with additional educational needs (Darmody and Arnold, 2018).

In December 2017, the Department of Education and Skills launched Languages Connect, Ireland's Strategy for Foreign Languages in Education 2017-2026, which recognises the lack of adequate support for languages of immigrant communities in Ireland (Department of Education and Skills, 2017). The Department's PostPrimary Languages Initiative is working on developing short courses in some home languages, which will be offered as part of the Junior Cycle Programme (the first three years of secondary school) in addition to the four Junior Cycle languages French, German, Italian and Spanish - that are currently offered. Certain languages are currently available as part of the Senior Cycle Leaving Certificate Examination, including French and Arabic. ${ }^{185}$

Little information is available on the experiences of unaccompanied minors in adjusting to the Irish education system and the impact of educational supports on the integration and educational performance of unaccompanied minors. The need for further research in this area has been highlighted (UNHCR Ireland, 2013; Arnold et al., 2015; Faas et al., 2015; Arnold and Ní Raghallaigh, 2017). Research on unaccompanied minors in Ireland shows how young people attach high importance to education, including as a source of stability and a means of fostering self-esteem and of encouraging integration (Mintern and Dorney, 2006; Charles, 2009; Arnold 
et al., 2015). Education is viewed as part of a durable solution by stakeholders working with unaccompanied minors in Ireland (Arnold et al., 2015).

The main challenge for children, including unaccompanied minors, in the Irish education system identified in research relates to linguistic skills (Faas et al., 2015; HIQA, 2018a). A recent study on supports provided to migrant children in general in secondary schools found that schools are relatively unprepared for new arrivals (Faas et al., 2015). Some schools have targeted supports in place for migrant children, such as buddy systems for assisting integration and group activities (Faas et al., 2015). Such supports vary depending on each school, including available resources and staff. In some schools, it has been reported that an individual teacher is assigned responsibility for looking after newly arrived migrant students (Faas et al., 2015). Access to supports may also be affected by transfers to residential or foster care in areas outside Dublin, which may not have a similar level of supports available to unaccompanied minors, such as access to tailored language programmes or services provided by YES (Arnold and Sarsfield Collins, 2011). However, the SWTSCSA noted that every placement is considered on a caseby-case basis and there are times when the quality of the care placement will take precedence over the continuation of education at a particular school or the distance between the foster placement and the school. ${ }^{186}$

Concerns have been expressed in research as to the provision of adequate multicultural training to teachers to enable them to provide support specifically for migrant children (Faas et al., 2015). While there is no specific policy to support teachers who teach students with a migrant background nor provision for intercultural training as part of teacher training in Ireland, higher education institutions are beginning to include diversity training and intercultural education in initial teacher education (Faas et al., 2015; Rodrígquez-Izquierdo and Darmody, 2017). Research in this area has called for increased resources and pre-service and in-service training for teachers aimed at assisting schools in meeting the needs of migrant students (Faas et al., 2015; Rodrígquez-Izquierdo and Darmody, 2017). Despite these challenges, recent studies show that schools have developed various approaches and adapted school policies in order to address the needs of migrant children (Faas et al., 2015).

While many unaccompanied minors may be capable of entering mainstream education without difficulty, many of the unaccompanied minors arriving recently in Ireland have low education levels and low levels of English. ${ }^{187}$ Some unaccompanied minors had previously reported that the move to mainstream

186 Interview with SWTSCSA, October 2018.

187 Interview with Youth and Education Service for Refugees and Migrants, CDETB, January 2018. 
schools took place too soon, when they felt they did not have sufficient linguistic capabilities (Charles, 2009). YES indicated that many children are moved into mainstream education at A2 level on the Common European Framework of References for Languages ${ }^{188}$ scale, with insufficient linguistic capabilities for the mainstream curriculum. YES therefore highlighted the need to provide access to alternative education routes for unaccompanied minors aged 16 to 23 years. YES noted that such alternative routes could take the form of vocational education programmes and training programmes offered by Education and Training Boards ${ }^{189}$ - Community Training Centres ${ }^{190}$ and Youthreach ${ }^{191}$ being existing services that could be adapted to respond to the needs of this group - which incorporate second-level qualifications and English language supports. ${ }^{192}$

\subsection{ACCESSING THIRD-LEVEL EDUCATION AND OTHER ROUTES}

Further education is identified as a core requirement for young people leaving care in National Aftercare Policy and is a priority in the provision of aftercare services (Tusla, 2017a). Research on access to education after 18 years of age has highlighted the importance of education in the aftercare of children (Arnold et al., 2015; Mannion, 2016), in ensuring:

- access to job opportunities (Mannion, 2016);

- the development of life-skills, including if the child returns to their country of origin (Arnold et al., 2015); ${ }^{193}$

- children's mental health and well-being (Mannion, 2016).

However, unlike primary and secondary education, unaccompanied minors both with and without an immigration status are not automatically entitled to access free third-level education on the same basis as Irish citizens and may face difficulties in accessing further education due to high international tuition fees for non-EEA applicants and other barriers relating to their status.

Support in respect of further education is available from Tusla for unaccompanied minors who secure an immigration status prior to turning 18; however, most

See Council of Europe, 'Common European Framework of References for Languages: Learning, teaching, assessment', www.coe.int.

Education and Training Boards are statutory authorities that manage and operate second-level schools, further education colleges and a range of adult and further education centres delivering education and training programmes. For further information, see: https://www.etbi.ie/.

Community Training Centres provide training, educational and employment related services for young people. For more information, see: www.iacto.ie/learners/ctcs/.

191 Youthreach is an education, training and work experience programme led by the Department of Education and Skills for early school leavers aged $15-20$. For more information, see: www.youthreach.ie.

192 Interview with Youth and Education Service for Refugees and Migrants, CDETB, January 2018.

193 Ibid. 
unaccompanied minors do not have an immigration status secured by the time they turn 18 (see Box 2 for information on unaccompanied minors who do not have a status at the age of 18 ).

\subsubsection{Access to aftercare support}

Unaccompanied minors who are granted status before turning 18 and who pursue third-level education or training may remain in their care arrangement until completion of their education. They can also continue to access aftercare supports, including an allocated aftercare worker, up to the age of 23 if in full-time education or training (Tusla, 2017a). As mentioned in Section 4.4, unaccompanied minors who pursue third-level education or further training may be entitled to receive a weekly Aftercare Allowance as part of their aftercare financial plan. The purpose of the Aftercare Allowance is to cover day-to-day costs to support young people who are pursuing further education or training (Tusla, 2017c) (see Section 5.4 for further information). As part of aftercare policy, Tusla also covers fees for Post Leaving Certificate (PLC) courses (Tusla, 2017c). ${ }^{194}$ Unaccompanied minors who are accessing aftercare supports from Tusla and pursuing an undergraduate or PLC course may also receive assistance from an aftercare worker in submitting an application for a student grant (Tusla, 2017c).

\subsubsection{Access to financial support}

Unaccompanied minors with refugee status and subsidiary protection status may be entitled to free third-level education under the Free Fees Initiative led by the Department of Education and Skills and administered by Student Universal Support Ireland (SUSI). ${ }^{195}$ In addition, they may be entitled to receive a maintenance grant from SUSI for day-to-day living costs during the academic year. ${ }^{196}$

However, a residency requirement stipulates that applicants must have been legally resident in Ireland for at least three years to avail of this support. As previously stated, most unaccompanied minors are in their late teens on arrival (Working Group on the Protection Process, 2015), and do not have their immigration status resolved by the time they turn 18. ${ }^{197}$ Many unaccompanied minors may therefore be precluded from receiving the grant as they are unlikely to have spent the required number of years in the Irish State with a legal immigration status.

\footnotetext{
194 PLC courses are full-time programmes offered to students who have completed their Leaving Certificate and adults returning to education. PLC courses offer Level 5 and 6 qualifications aimed at developing vocational and technological skills.

195 Higher Education Authority, 'Free Fees Initiative', http://hea.ie/funding-governance-performance/funding/studentfinance/course-fees/.

196 https://susi.ie.

197 Interview with SWTSCSA, January 2018.
} 
In addition, eligibility for the Free Fees Initiative and for a SUSI grant is limited to persons granted permission to remain only in certain circumstances. In respect of children who have submitted an application for international protection, only persons granted permission to remain following a decision not to deport under section 3 of the Immigration Act 1999 are currently eligible. However, young people may be granted permission to remain without a deportation order being issued (Mannion, 2016). In particular, as international protection applicants may be granted permission to remain under the International Protection Act 2015 (2015 Act) prior to the issuing of a deportation order (see Section 6.2), it is unclear whether the eligibility requirements include those granted permission to remain under the 2015 Act. Some unaccompanied minors have also reported being ineligible for such grants due to being granted permission to remain on discretionary or exceptional grounds (Empowering People in Care, 2016; Mannion, 2016).

The Immigrant Council of Ireland (ICI) states that reforms are needed to ensure migrant children in the care of the State and migrant care leavers meet the eligibility criteria for SUSI grants in order to access further education, including through revision of funding requirements to broaden the categories of eligibility for children leaving care (Mannion, 2016).

\subsubsection{Access to alternative support}

Alternative sources of financial support have been introduced in recent years to support access of migrants to third-level education. A number of universities, including the National University of Ireland, Galway; Dublin City University; the University of Limerick; University College Cork; and University College Dublin, have introduced a limited number of scholarship schemes for persons with international protection status and international protection applicants. Athlone Institute of Technology launched the Sanctuary Scholarship Programme in 2018, offering six places on its third-level access programme and three undergraduate scholarships, which are open to current and former unaccompanied minors in the care of Tusla, in addition to current and former residents of the Lissywollen Direct Provision centre. ${ }^{198}$ These programmes have been welcomed by civil society as providing additional opportunities for young people of a migrant background, refugees and persons seeking international protection to access further education (Mannion, 2016).

198 Athlone Institute of Technology, 'Humanitarian work and spirit of inclusion rewarded as AIT is awarded the first College of Sanctuary in Ireland', https://www.ait.ie/news-and-events/news/humanitarian-work-and-spirit-of-inclusionrewarded-as-ait-is-awarded-the-fi. 
NGOs such as the Irish Refugee Council (IRC), the Dún Laoghaire Refugee Project, Doras Luimní and Nasc, the Migrant and Refugee Rights Centre (Nasc), with funding from the general public and organisations such as Community Foundation Ireland, have also provided grants to young people seeking international protection or with international protection status to access further or third-level education after secondary-school. The One Foundation has also provided support specifically for unaccompanied minors to access third-level education. A Scholarship Fund, which covered the cost of third-level programmes and included a living allowance, was awarded to 43 unaccompanied minors up to the end of 2013 (The One Foundation, 2014).

\section{Box 2 Access to third-level education for unaccompanied minors without status}

Unaccompanied minors who do not have an immigration status by the age of 18 and who wish to pursue an undergraduate or PLC course are not eligible for free fees or for a student grant; these are only available for individuals with a particular type of immigration status.

In 2015 the government introduced the Pilot Student Support Scheme to provide financial support to persons seeking international protection who have obtained their Leaving Certificate and have been accepted to an approved PLC or undergraduate course. ${ }^{199}$ In order to benefit from financial support, persons seeking international protection must have been part of the international protection process for five years and must have spent a minimum of five years in the Irish school system. The Pilot Student Support Scheme was welcomed by ICl as a positive development for young people still in the international protection system (Mannion, 2016).

However, only a small number of people seeking international protection have reportedly been able to avail of the Support Scheme due to the requirement that an applicant must have resided in Ireland for five years and spent five years in the Irish school system (McGuire and Pollak, 2016; Murray, 2017). ${ }^{200}$ Access for unaccompanied minors in particular may be limited, as the majority of unaccompanied minors are in their late teens on arrival in the State, and are therefore unlikely to have spent the required number of years in the school system. Unaccompanied minors that have spent more than five years in the Irish school system may nevertheless be ineligible for supports due to the fact that in practice, most unaccompanied minors have not had an international protection application submitted on their behalf by the time they turn 18 years of age. ${ }^{201}$ The eligibility requirements have met with criticism; the Irish Human Rights and Equality Commission (IHREC) stated that the requirement that an applicant must have spent five years in secondary school is onerous and should be revised (IHREC, 2017a). IRC recommends that the residency requirement be reduced to three years, in line with SUSI requirements, and that the requirement that an applicant

\footnotetext{
199 Department of Education and Skills, 'Pilot Support Scheme 2017', https://www.education.ie/en/Learners/Services/Pilot-Support-Scheme/.

200 Two out of 39 students that applied in 2015 were reported as having met the criteria in 2015; two students out of 15 that applied in 2016 benefited from the scheme; while only one out of five applicants was deemed eligible in 2017 (Fletcher, 2018).

201 Interview with SWTSCSA, January 2018.
} 
must have spent five years in secondary school be reduced to two years (Murray, 2016; Fletcher, 2018; IRC, 2018).

Unaccompanied minors without a status but who have applied for international protection are eligible to apply for a number of the university scholarships, and have also benefited from NGO funding, as previously outlined for unaccompanied minors who have been granted a status. While such community initiatives have been welcomed, ICI highlights the need for broader funding mechanisms and to address the situation of those who are in limbo as regards their immigration status (Mannion, 2016).

Research has shown that children in the care of the state who have not secured an immigration status before turning 18 have reported difficulties in accessing third-level education due to the high fees and restricted access to financial support as a result of a lack of immigration status (Mannion, 2016). Such limitations have led to unaccompanied minors reporting a lack of motivation to succeed in secondary school and feelings of exclusion from peers (Ní Raghallaigh, 2013).

\subsection{ACCESS TO EMPLOYMENT}

Pursuant to section 53(a) of the 2015 Act, beneficiaries of international protection are entitled to seek and enter employment. They are granted a Stamp 4 residence permission, which entitles the holder to access employment and does not require the holder to obtain a work permit in order to do so.

Similarly, unaccompanied minors granted temporary residence permission under the Administrative Immigration Arrangements for the Protection of Victims of Human Trafficking are granted Stamp 4 permission and are entitled to access employment (Department of Justice and Equality, 2011; Quinn et al., 2014).

Stamp 4 permission may also be granted to unaccompanied minors who are not beneficiaries of international protection.

However, cases have been reported whereby children have been granted immigration permissions that do not take account of the child's individual circumstances and preclude access to employment, such as a Stamp 3 immigration permission (Mannion, 2016). ICl recommends that immigration permission granted to children, including unaccompanied minors, allow them to take up work on an equal basis with Irish citizens (Mannion, 2016). 


\subsubsection{Access to employment for unaccompanied minors under 18}

Unaccompanied minors with a legal status that permits them to seek employment are subject to the same provisions as Irish nationals. The Protection of Young Persons (Employment) Act 1996 governs the rights of young workers in Ireland and sets minimum age limits for employment and maximum working hours. Only children aged 16 and over can be employed in full-time regular work. ${ }^{202}$ Children aged 14 and 15 may be employed subject to certain conditions, such as for work as part of approved work experience programmes. ${ }^{203}$

Tusla reported that in practice unaccompanied minors are not encouraged to seek employment before the age of 18 while in its care. However, this is determined on an individual basis and, in some cases, Tusla has assisted unaccompanied minors in pursuing part-time work. ${ }^{204}$

\subsubsection{Access to employment for aged-out minors}

Tusla identified employment in national aftercare policy as one of the most important requirements for young people leaving care (Tusla, 2017b). Needs in relation to employment therefore form part of the aftercare plan of eligible unaccompanied minors leaving the care of the State. ${ }^{205}$ Aftercare workers can provide assistance to aged-out minors in preparing CVs, developing interview skills and other aspects of seeking employment. ${ }^{206}$

Aged-out minors with a legal status that permits them to seek employment can also access mainstream employment support services provided by the Department of Employment Affairs and Social Protection to assist the integration of unemployed persons into the Irish labour market. Local Intreo offices provide services that include assistance and advice on employment, training and personal development, self-service information facilities, access to information on job vacancies and information on income supports provided by the Department of Employment Affairs and Social Protection (Gusciute et al., 2016). ${ }^{207}$

Aged-out minors may also access employment-related supports provided by Business in the Community Ireland, the business network, through the Employment for People from Immigrant Communities programme, which is funded

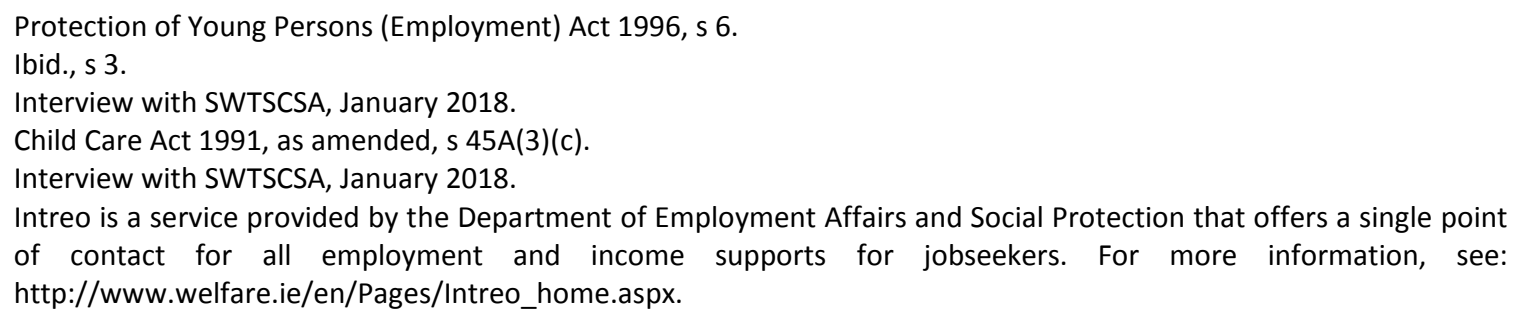


by the Office for the Promotion of Migrant Integration within the Department of Justice and the European Social Fund (Gusciute et al., 2016). The programme seeks to assist immigrants and refugees with Stamp 4 permission in the Dublin area who have an intermediate to high level of English in integrating into Irish society through pre-employment training, individual supports, assistance with work experience opportunities, advice on social welfare and IT access. ${ }^{208}$

The Migrant Access Programme run by YES provides a life-skills module to unaccompanied minors referred to its service, which supports the development of basic skills, including those relevant to future employment. YES youth workers also provide an outreach and drop-in service, which can provide unaccompanied and aged-out minors with supports including career guidance, CV workshops and referrals to other services providing employability programmes. ${ }^{209}$

YES engaged young people from minority ethnic and migrant backgrounds in implementing the $110 \%$ Project, which was funded by the Dormant Accounts Fund of the Department of Children and Youth Affairs under the Youth Employability Initiative, and aimed to raise awareness about the barriers faced by young migrants in seeking employment. The project produced an awareness-raising video and leaflets including information on the barriers identified by young people. ${ }^{210}$ Racism and discrimination, limited social networks, lack of recognition of prior learning or foreign qualifications and immigration status were identified as potential barriers to training and employment (CDETB Youth and Education Service for Refugees and Migrants, 2018).

\section{Box 3 Access to employment for unaccompanied minors without status}

Prior to 2018, persons seeking international protection, including unaccompanied minors, were prohibited from seeking employment. However, in June 2018, the government opted in to the EU Reception Conditions Directive and made provision in national law for access to the labour market for persons seeking international protection, subject to certain conditions. ${ }^{211}$ Unaccompanied minors who have submitted an application for international protection, and have not received a first-instance decision after nine months, are entitled to seek and enter employment on the basis of a labour market access permission granted by the Minister, subject to the provisions of the Protection of Young Persons (Employment) Act 1996. ${ }^{212}$ Unaccompanied minors with a labour market access permission may also avail of vocational training. ${ }^{213}$

208 Business in the Community Ireland, 'Are you a Jobseeker?', https://www.bitc.ie/business-actionprogrammes/business-action-on-employment/are-you-a-jobseeker/.

209 Interview with Youth and Education Service for Refugees and Migrants, CDETB, January 2018.

210 Ibid.

211 S.I. No. 230 of 2018, European Communities (Reception Conditions) Regulations, Regulation 11.

212 Ibid., Regulation 16

213 Ibid., Regulation 11. 
Unaccompanied minors who do not meet the above conditions as persons seeking international protection or who do not hold an international protection status, permission to remain, temporary residence permission by virtue of their status as victims of trafficking, or other immigration status permitting employment cannot take up employment (Quinn et al., 2014). Research has highlighted how the lack of an immigration status, or an inappropriate immigration permission being granted, can affect migrant children's eligibility to seek employment, which impacts negatively on their future employment prospects (Mannion, 2016).

\subsection{ACCESS TO SOCIAL WELFARE}

Similarly to Irish citizens under the aged of 18 , unaccompanied minors are not entitled to social welfare/assistance prior to the age of 18 , regardless of their legal status (Quinn et al., 2014). However, Tusla provides a weekly Foster Care Allowance to foster carers of children in care, including unaccompanied minors. Foster carers may also receive various additional financial supports provided by the State to families with children.

Under section 53(b) of the 2015 Act, beneficiaries of international protection, including unaccompanied minors, are entitled to receive social benefits on the same basis as Irish citizens. Unaccompanied minors who are granted Stamp 4 permission are also entitled to access social welfare on reaching the age of 18 . See Box 4 for information on unaccompanied minors who do not have an immigration status by 18 years of age.

Unaccompanied young people over the age of 18 who have a legal status are entitled to receive Jobseeker's Allowance if no longer in education and unemployed after reaching the age of 18 . Similarly to Irish citizens over the age of 18 , if unaccompanied minors with a legal status are aged over 18 and in full-time education, they may not receive social welfare (Quinn et al., 2014). However, like Irish citizens, unaccompanied minors who receive a status decision before they reach the age of 18 , have a Stamp 4 permission to remain and are in receipt of social welfare may be able to access Back to Education Allowance (BTEA) if commencing second- or third-level courses. In order to qualify for BTEA, the unaccompanied minor must be aged 18, out of formal education for at least two years and in receipt of social welfare payments such as Jobseeker's Allowance for at least three months if pursuing a second-level course or nine months if pursuing a third-level course. ${ }^{214}$

In addition, unaccompanied young people over the age of 18 who have been granted a status and are in education/training are entitled to the Standardised

214 Department of Employment Affairs and Social Protection, 'Back to Education Allowance', https://www.welfare.ie/en/Pages/353_Back-to-Education-Allowance.aspx. 
National Aftercare Allowance on reaching the age of 18. The allowance consists of an amount of up to $€ 300$ per week, which is determined taking into consideration any other social welfare payments or education grants being received. The allowance, which was introduced in 2015 by Tusla as part of its aftercare policy for all eligible children leaving care, is provided up to the age of 21 and can be extended to the age of 23 if education or training continues. For those still in a care arrangement after the age of 18 , the allowance is paid to the foster carer or provider of supported accommodation, while those who reside in private accommodation receive the allowance directly. On leaving care, the aged-out minor is required to submit progress updates at the end of each academic term to the aftercare worker in order to continue receiving the weekly allowance. An aftercare grant is also provided as a once-off payment to children turning 18 and leaving care in order to assist with expenses in securing and moving to private accommodation. This consists of one month's rent and deposit as well as a setting up home allowance of $€ 300$ (Tusla, 2017c).

\section{Box 4 Access to social welfare for aged-out minors without status}

In order to access social welfare, all applicants must satisfy the Habitual Residence Condition which requires individuals to have a legal right to reside in the State. Non-EEA nationals, including unaccompanied minors, who do not have a residence permission in Ireland are not considered to have a right to reside and are therefore not entitled to access social welfare.

$\mathrm{ICl}$ highlights that delays in addressing a child's immigration status can preclude access to social welfare supports. Children who spent time in the care of the State before turning 18 have reported being unable to access social welfare because their immigration status had not been secured during their time in care (Mannion, 2016).

As a result, $\mathrm{ICl}$ observed that aged-out minors have encountered difficulties in integrating into Irish society (Mannion, 2016). The lack of legal status precludes individuals from receiving the Housing Assistance Payment for social housing and rent allowance, with the result that some aged-out minors may face significant difficulties in accessing affordable housing (Mannion, 2016).

In particular, aged-out minors who are transferred to Direct Provision on turning 18 are not eligible for the Standardised National Aftercare Allowance (Tusla, 2017b), which forms part of national aftercare policy for eligible children leaving care and in full-time education, or for other social welfare supports. ${ }^{215}$ Persons seeking international protection in Direct Provision are currently eligible for a weekly allowance of $€ 21.60$ from the Department of Employment Affairs and Social Protection (Tusla, 2017b). The government announced in October 2018 that the weekly allowance will increase to $€ 38.80$ in 2019. ${ }^{216}$ Research indicates that financial barriers arising from the weekly allowance provided to persons seeking international protection and lack of access to transportation

215 With the exception of the Exceptional Needs Payment for once-off, immediate needs and the Back to School Clothing and Footwear Allowance.

216 Government of Ireland, Budget 2019: Expenditure Report, available at https://www.gov.ie/en/campaigns/0941370210-budget-2019/. 
pose a challenge to aged-out minors pursuing further education and a barrier to integration (Arnold and Sarsfield Collins, 2011; Foreman and Ní Raghallaigh, 2015; Working Group on the Protection Process, 2015; Ní Raghallaigh and Thornton, 2017).

$\mathrm{ICI}$ highlights the need for policy-makers to consider the ways in which immigration permission is granted to children and the impact this has on children's access to services. In particular, it is recommended that children in care be assisted in applying for permission to reside to ensure they can access social welfare, housing and financial support on the same basis as Irish citizens (Mannion, 2016). The Irish Human Rights and Equality Commission (IHREC) has also recommended the revision of the Habitual Residency Condition to ensure it is not discriminatory towards children seeking international protection and children of a migrant background (IHREC, 2015b).

\subsection{ACCESS TO HEALTHCARE}

All unaccompanied minors have access to the public healthcare system in Ireland.

Unaccompanied minors in the care of Tusla are entitled to a medical card issued by the Health Service Executive (HSE), which provides for access to public health services free of charge (Quinn et al., 2014). This includes basic medical care, including through a General Practitioner (GP) and access to prescription medication free of charge, as well as emergency treatment.

All unaccompanied minors who are referred to Tusla undergo a medical assessment as part of their needs assessment, with referral to specialist services where necessary. A general screening appointment with a GP is organised for unaccompanied minors on being taken into care (Quinn et al., 2014).

The medical card also provides for access to specialised services for victims of torture, sexual violence or other conflict-related trauma. On identification and referral to Tusla, child victims of trafficking have access to assessment and treatment services for sexual assault, full medical screening and psychological and counselling services (Department of Justice and Equality, 2012). Health and Information Quality Authority (HIQA) however reported in January 2018 that, while medical screening was provided on admission, a comprehensive assessment of emotional needs was absent from some of the care plans of unaccompanied minors in residential care, and therapeutic needs of all children were not adequately assessed and addressed through referrals to specialist services (HIQA, 2018a).

Practitioners note that services to respond to the unique needs presented by individuals, including children, in the context of migration are not routinely available in the Irish health system (Royal College of Physicians of Ireland, 2016; 
College of Psychiatrists of Ireland, 2017). Spirasi, an NGO providing rehabilitation services for victims of torture or inhuman treatment, is the only organisation in Ireland providing rehabilitation services for victims of torture on behalf of the State; it provides intake assessments, therapeutic services, psychosocial support and medical legal reports on referral from the client's GP. ${ }^{217}$ A Remit Panel, comprising the director and senior staff, reviews all referrals made to the service to determine eligibility for support. ${ }^{218}$ Spirasi's family therapy service, which was established in 2015, offers a structured and specialised service to families and unaccompanied minors. ${ }^{219}$

As the sole provider of such services, Spirasi has highlighted how the service is limited in its ability to provide for all individuals in need of specialised services due to resource constraints and the fact that the service is based in Dublin, which poses a barrier to accessing the service for those living outside of Dublin (Spirasi, 2017). In particular, Spirasi has expressed concern at the lack of specialised rehabilitative services and therapeutic support for child and adolescent victims of torture in Ireland (Spirasi, 2017). Spirasi has recommended that legislation be enacted to establish concrete mechanisms and programmes for the provision of holistic rehabilitation to victims of torture and ill-treatment, including in particular for child and adolescent survivors of torture (Spirasi, 2017). Research on unaccompanied minors has recommended that provision be made for comprehensive and culturally appropriate mental health screening for all unaccompanied minors in Ireland (Abunimah and Blower, 2010).

Research finds that covering costs for medical expenses that are not covered by the unaccompanied minor's medical card can pose a challenge to social workers caring for unaccompanied minors (Quinn et al., 2014). Research also highlights that social workers can face difficulties in obtaining Personal Public Service Numbers (PPSNs) for unaccompanied minors who have not submitted, or received a decision on, an application for international protection, and those who have not applied for an alternative immigration status or registered with the Irish Naturalisation and Immigration Service (INIS) (Quinn et al., 2014). PPSNs are required to access public services including healthcare.

In practice, timely access to a medical care is dependent on the basis on which an unaccompanied minor is in the care of Tusla. Research has highlighted how social workers, residential care staff and foster carers caring for children under section 4 of the Child Care Act 1991 are precluded from giving consent for medical procedures on behalf of children under the age of 16 . In cases where consent from the child's parent or guardian cannot be obtained, social workers must go to court

Spirasi, 'Spirasi Client Services', http://spirasi.ie/healthcare-professionals/sub-healthcare/.

Correspondence with Spirasi, February 2018.

Ibid. 
in order to obtain permission to give such consent, which is time-consuming and costly (Arnold and Sarsfield Collins, 2011; Arnold, 2013; Quinn et al., 2014; Corbett, 2018).

As previously outlined, unaccompanied minors who have submitted an international protection application and have not received a decision on their status prior to turning 18 years of age, or who submit an international protection application on turning 18, are transferred to Direct Provision reception centres. As with all persons seeking international protection residing in a Direct Provision reception centre, aged-out minors are still entitled to a medical card. In some cases, foster families are reported to have continued to provide accommodation to aged-out minors so they do not have to be transferred to a Direct Provision reception centre (Sirriyeh and Ní Raghallaigh, 2018). However, in such cases, they will not be automatically entitled to basic supports, including a medical card, provided to residents of Direct Provision reception centres (Tusla, 2017b). 



\section{CHAPTER 6}

\section{Family reunification in Ireland and returning to family in the country of origin}

In-country family reunification or return and reunification with family in the country of origin are two of several durable solutions for unaccompanied minors (the Committee, 2005; European Commission, 2017). The United Nations (UN) Committee on the Rights of the Child (the Committee) stated that family reunification is a key part of the durable solutions process and all efforts should be made to reunite an unaccompanied minor with his or her parents where this is in the best interests of the child. It noted that where family reunification in the country of origin is not possible, it should be prioritised in the host country (the Committee, 2005). Family reunification in the host country is widely perceived as having a positive impact on integration (Becker et al., 2012; Hinds, 2018). However, stakeholders also report that the arrival of family members may present challenges for the sponsor and family, such as accessing appropriate accommodation, public services and employment, and a lack of post-arrival supports (Becker et al., 2012).

Data on the proportion of unaccompanied minors referred to the Child and Family Agency, Tusla (Tusla) who are reunited with family are not available. ${ }^{220}$ Data on the number of unaccompanied minors reunited with family in Ireland, in a third country or in the child's country of origin are also not available. ${ }^{221}$ The Social Work Team for Separated Children Seeking Asylum (SWTSCSA) only collates data on the number of family reunification services provided. It does not break down outcomes of the provision of such a service; for example, if and where the minor was reunited with family. ${ }^{222}$ The majority of children referred to the SWTSCSA and reunited with family are reunited with family members already in Ireland or in the UK (Ní Raghallaigh, 2013; Quinn et al., 2014). ${ }^{223}$ In some cases, unaccompanied minors are reunited with family after being granted international protection and applying for family reunification under the International Protection Act 2015 (2015 Act). A smaller number of unaccompanied minors reunite with family through voluntary return to their country of origin. While no legislative prohibition exists for the deportation (forced return) of unaccompanied minors, and unaccompanied minors can be issued with a negative international protection decision and deportation order on the same basis as all persons seeking international protection, deportations of unaccompanied minors do not normally take place in practice. 
Section 6.1 focuses on family reunification of unaccompanied minors in Ireland and in the country of origin. Section 6.1.1 discusses the voluntary return of unaccompanied minors to their families in their country of origin. Section 6.1.2 outlines the avenues through which unaccompanied minors with an immigration status can apply for their family members to join them in Ireland. Deportation of unaccompanied minors is discussed in Section 6.2.

\subsection{FAMILY REUNIFICATION OF UNACCOMPANIED MINORS}

Section 3 of the Child Care Act 1991, as amended (1991 Act), states that in respect of children in its care, Tusla must have regard to the principle that it is in the best interests of a child to be brought up in their own family. Furthermore, where an unaccompanied minor has been taken into the care of Tusla, section 4(4) of the 1991 Act provides that Tusla must endeavour to reunite the child with their parents where this appears to be in the best interests of the child. In line with the European Union (EU) Reception Conditions Directive, Tusla must endeavour to trace an unaccompanied minor's family. 224

Much of the work the SWTSCSA carries out is in relation to reuniting unaccompanied minors with their families. ${ }^{225}$ On referral to Tusla, the SWTSCSA carries out an intake assessment with the unaccompanied minor to identify needs in areas including reuniting with family who may be in Ireland, a third country or the country of origin through voluntary return. If reuniting the child with family is identified as being in the child's best interests, the SWTSCSA conducts a reunification assessment, including an assessment of parentage or guardianship and risks to the child. Once contact is established with the family, the SWTSCSA carries out interviews with the child and their parents to assess parentage or guardianship. Tusla may also use DNA testing in the family assessment process (Quinn et al., 2014).

\subsubsection{Family tracing}

Family tracing may take place to locate and establish contact with the child's family, if they are residing in the country of origin or a third country. Family tracing services provided in Ireland by the Irish Red Cross Restoring Family Links Unit may be utilised by Tusla, on referral by the child's social worker (Arnold et al., 2015). The social worker and the unaccompanied minor provide details of the minor's background to the Irish Red Cross to assist in family tracing. The Irish Red Cross and Irish Refugee Council (IRC) have recommended that the child is given the opportunity to speak with the Irish Red Cross on their own to further improve the tracing process (Arnold and Sarsfield Collins, 2013; Arnold et al., 2015). 
Additionally, the Irish Red Cross expressed concern at the lack of co-ordination between government departments on developments relating to unaccompanied minors in care and in the international protection process, which affects its capacity to conduct family tracing investigations and communicate results to unaccompanied minors who may have moved out of Dublin or moved on from care (Horgan et al., 2012).

Child care legislation was adopted prior to the enactment of legislation in the area of international protection and the particular situation of unaccompanied minors is not addressed in child care legislation (Mullally, 2011). Researchers argue that efforts to reunite the child with their parents must be carried out in line with the State's obligation to protect the identity of the child where the child has submitted an application for international protection (Arnold and Kelly, 2012). ${ }^{226}$ In line with the EU Reception Conditions Directive, the European Communities (Reception Conditions) Regulations 2018 (2018 Regulations) set out this obligation further in respect of unaccompanied minors, stating that where there may be a threat to the life or integrity of the unaccompanied minor or their family, Tusla must ensure the processing of information relating to the minor is carried out in a confidential manner so as not to jeopardise their safety. IRC recommended that social workers go through the Irish Red Cross in any efforts to establish contact with the unaccompanied minor's family, as the child may be at risk of harm from their family or communities in their country of origin (Arnold and Sarsfield Collins, 2011).

\subsubsection{Voluntary return: reuniting with family in the country of origin}

Where reunification with family in the country of origin is deemed to be in the best interests of the child, an unaccompanied minor may be assisted by the SWTSCSA to voluntarily return to their country of origin. Irish legislation does not provide specifically for voluntary return. However, section 48 of the 2015 Act provides persons seeking international protection, including unaccompanied minors, who receive a negative decision on an application for international protection with the option to voluntarily return to their country of origin. ${ }^{227}$ The SWTSCSA may also assist unaccompanied minors who have not submitted an application for international protection or other status to voluntarily return to their country of origin.

\section{IOM Voluntary Assisted Return and Reintegration Programme (VARRP)}

The International Organization for Migration (IOM) is the UN Migration Agency and in Ireland operates a programme providing assisted voluntary return and reintegration services to persons seeking international protection and irregular migrants, including unaccompanied minors. The Department of Justice and 
Equality in conjunction with IOM has provided for the voluntary return of unaccompanied minors in Ireland since 2001 through IOM's Voluntary Assisted Return and Reintegration Programme (VARRP). IOM also provides support for the Voluntary Assisted Return and reintegration of aged-out young people between the ages of 18 and $21 .{ }^{228}$

A small number of unaccompanied minors have availed of voluntary return and reintegration through the VARRP from 2014 to 2017, with one voluntarily returning in 2014, two in 2015 and one in 2016. ${ }^{229}$ No unaccompanied minors availed of the VARRP in 2017. ${ }^{230}$

If a decision is made by Tusla in conjunction with the unaccompanied minor to seek voluntary return, Tusla refers the unaccompanied minor to IOM. Unaccompanied minors may also self-refer or be referred by another organisation, in which case IOM links the child with the relevant social work team in both Ireland and the country of origin (Quinn et al., 2014). Once a referral to IOM is made, IOM establishes contact with the family/legal guardian in the country of origin. A family assessment can also be facilitated by IOM in the country of origin at the request of Tusla. This is done through liaising with local social work teams or, in the absence of developed social services, a qualified IOM staff member will conduct the assessment. ${ }^{231}$ Tusla often engages the assistance of International Social Services and other services where necessary to provide information on safety and risks in the country of origin (Quinn et al., 2014). Local government agencies in the country of return may also be consulted (Quinn et al., 2014). IOM can facilitate a DNA test to verify relationships if necessary. ${ }^{232}$ DNA results are sent to a hospital in Ireland for analysis. ${ }^{233}$

On the basis of family and country of origin assessments, Tusla decides whether or not voluntary return is in the best interests of the child (Quinn et al., 2014). Research identifies assessing the best interests of the child in light of the situation in the country of origin as a challenge in implementing voluntary return of unaccompanied minors in Ireland. In particular, the lack of clear guidance for social workers around the process of voluntary return has been highlighted (Quinn et al., 2014; Arnold et al., 2015). IRC recommended that more guidance be provided to social workers and others working with unaccompanied minors in relation to best interests assessments and reunification in the context of return (Arnold et al., 2015). In relation to the voluntary return of victims of trafficking, the Group of

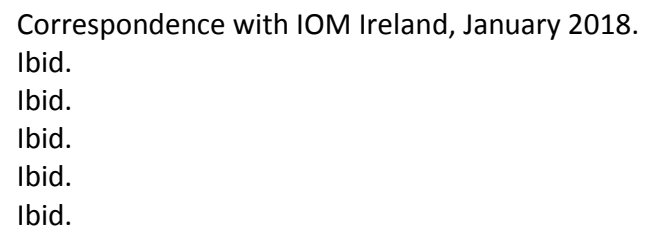


Experts on Action Against Trafficking in Human Beings recommended that Ireland continue to develop co-operation with countries of origin to ensure comprehensive risk and security assessments and the safe return and effective reintegration of victims (GRETA, 2017).

\section{Return under the VARRP}

If a decision is made that it is in the best interests of the child to return to his or her country of origin, then IOM forwards the application for assisted voluntary return and reintegration for approval to the Department of Justice and Equality (Quinn, 2010). Once it is approved, IOM assists in obtaining travel documents where required, conducts fitness to travel checks where necessary, covers the costs of travel to and from airports and a flight ticket, and provides assistance at the airport during departure, transit and arrival (Quinn et al., 2014). All unaccompanied minors are escorted to their country of origin. If possible, the unaccompanied minor is escorted by two social workers (one funded by Tusla and the other by IOM) or one social worker and another appropriate escort identified by Tusla and IOM (such as a guardian ad litem or IOM operational staff member) (Quinn, 2010). The social worker may travel to the family's home to ensure the child's reunification with their family and may also arrange follow-up visits in the days following arrival (Quinn et al., 2014).

The majority of unaccompanied minors who are voluntarily returned to the country of origin are returned to family environments. While Ireland does not operate a policy of returning unaccompanied minors to alternative care facilities, IOM can, in certain circumstances, assist the unaccompanied minor to return to their country of origin when there is no supporting family or guardian to receive them. A small number of returns from Ireland assisted by IOM in particularly vulnerable cases have been to non-State specialist care accommodation centres. In such cases IOM liaises with the relevant government authority in the country of return to determine what services and supports, including residential centres or foster care, are available to the minor. This information is then shared with the social worker in Ireland, who makes a best-interests determination as to whether the child should remain in Irish State care or be returned to the care of the State in the country of return. ${ }^{234}$ Where a suitable care arrangement is unavailable, the minor can remain in the care of Tusla in Ireland (Quinn et al., 2014). As noted above, the SWTSCSA stated that Tusla does not generally pursue a residence permission for children outside of the international protection system, viewing the fact that the child is in the care of the State as sufficient protection for the child (see Section 3.2). ${ }^{235}$ 


\section{Reintegration and monitoring under the VARRP}

Reintegration assistance is also offered to unaccompanied minors under the VARRP. A return and reintegration plan that highlights the immediate, mediumterm and long-term needs of the child on return is drawn up by IOM in conjunction with the young person's social worker and the local IOM office in the country of return as well as the family and other partner agencies where applicable. ${ }^{236} \mathrm{IOM}$ and local partners in the unaccompanied minor's country of origin can provide reintegration assistance, such as assisting the child in entering the local education system by way of providing school fees, uniforms or books, or attending training courses. ${ }^{237}$

IOM provides a non-cash grant of $€ 600$ to each unaccompanied minor returning under the VARRP programme, which is administered on return by IOM or partner agencies for the child's educational purposes or the family's income generation. Monitoring takes place three to six months following provision of the grant by local IOM staff in conjunction with the family of the returned minor (Quinn et al., 2014). A comprehensive monitoring form developed by IOM Ireland is completed by the minor's family members and IOM staff, the outcome of which is reported to IOM Ireland and the social work team in Ireland. More regular monitoring can also be conducted by local IOM staff or social work agencies, including by way of telephone call or home visits, if specifically requested, on the basis of which information is provided to the social work team in Ireland.

The frequency and extent of monitoring carried out depends on the capacity of the local IOM office or care team to carry out monitoring activities as well as the requirements of the social work team in Ireland (Quinn et al., 2014). The effect of resources and logistics on the capacity of local IOM staff or social workers to carry out regular post-return monitoring of the minor has been identified as a challenge in this context (Quinn et al., 2014).

\subsubsection{Family reunification: reuniting with family in Ireland}

Family reunification in Ireland is recognised by the government as contributing to the integration of migrants in Ireland (INIS, 2016).

Data on the outcomes of family reunification applications are not disaggregated by sponsor type, therefore data on the number of applications submitted by unaccompanied minors are not gathered by the Irish Naturalisation and Immigration Service (INIS). ${ }^{238}$ The Children's Rights Alliance (CRA) highlighted the

Correspondence with IOM Ireland, January 2018.

Ibid.

Parliamentary Question 30 January 2018 [4665/18], oireachtasdebates.oireachtas.ie. 
lack of data on family reunification as a significant issue in Ireland (Cosgrave and Thornton, 2015).

\section{Family reunification for unaccompanied minors under the 2015 Act}

As previously outlined, an unaccompanied minor granted international protection or who is granted programme refugee status on arrival in Ireland is entitled to apply for family reunification within one year of being granted status. ${ }^{239}$ Such unaccompanied minors are entitled to apply for family reunification with nuclear family members: section 56(9)(c) of the 2015 Act states that eligible family members of the unaccompanied minor are his or her parents and the parents' children under the age of 18 .

The 2015 Act introduced changes to previous legislation providing for family reunification under the Refugee Act 1996. Section 56(9) of the 2015 Act defines 'family member' in relation to the child sponsor as parents and their unmarried children under the age of 18. The Refugee Act 1996 entitled beneficiaries of international protection to apply for family reunification of a dependent member of their family at the discretion of the Minister, including grandparents and siblings as well as guardians that were dependent on the applicant. This has not been included in the 2015 Act. An application can still be made for reunification with extended family members subject to ministerial discretion; however, such applications can now only be made through general administrative procedures governed by the INIS Policy Document on Non-EEA Family Reunification (discussed below) (INIS, 2016).

Family reunification entitlements for unaccompanied minors under the 2015 Act are also more limited in scope than those under the EU Family Reunification Directive, to which Ireland has not opted in, and which provides for a broader definition of family for unaccompanied minors. The Directive includes provision for family reunification of first-degree relatives in the direct ascending line of an unaccompanied minor and legal guardians or any other member of the family where the unaccompanied minor has no family in the direct ascending line or where they cannot be traced. ${ }^{240}$ Furthermore, conditions related to dependency on the sponsor applicable to adult applicants do not apply in the case of unaccompanied minors. ${ }^{241}$ Over half of EU Member States have applied provisions of the Directive allowing for a wider definition of family members for unaccompanied minors (EMN, 2017b).

International Protection Act 2015, ss 56-57.

Council Directive 2003/86/EC of 22 September 2003 on the right to family reunification, article 10(3).

Ibid., article 10(3)(a). 
The strict application of the definition of family members in Ireland and the changes brought about by the 2015 Act have been met with concern from the UN Refugee Agency Ireland (UNHCR), the Council of Europe, Irish Human Rights and Equality Commission (IHREC) and NGOs (Nasc, 2016; Arnold and Quinn, 2017; Council of Europe Commissioner for Human Rights, 2017; Oxfam, 2017; Hinds, 2018; IHREC, 2018). Oxfam stated that changes introduced by the 2015 Act have made it more difficult for refugee families, particularly family members outside of the nuclear family, to be brought together (Oxfam, 2017; Hinds, 2018). Crosscare emphasised the importance of family reunification with extended family as sponsors may rely on them to provide additional family support, including care (Quinn et al., 2014). Irish NGOs, UNHCR and IHREC therefore recommended that the government amend legislation to provide for family reunification for a wider range of family members to apply for family reunification (IRMC, 2017; Oxfam, 2017; Hinds, 2018; IHREC, 2018). A Private Members' Bill that seeks to amend the 2015 Act to expand the definition of eligible family members was introduced in 2017 and is currently under consideration. ${ }^{242}$

\section{Family reunification for unaccompanied minors turning 18 years of age}

Unaccompanied young people beneficiaries of international protection who submit applications for family reunification after turning 18 years old may face further difficulties in making successful applications for family reunification as they are no longer considered to be children at the time of application (Cosgrave and Thornton, 2015). This issue is particularly important among unaccompanied minors who arrive in Ireland independent of government-led programmes, such as the Irish Refugee Protection Programme (IRPP) or Calais Special Project. As discussed above, the majority of unaccompanied young people arriving spontaneously to seek international protection do not have an application for international protection submitted on their behalf until they are nearing the age of $18,{ }^{243}$ and often do not receive a decision before the age of $18 .{ }^{244}$ Section 56(9) of the 2015 Act provides that beneficiaries of international protection over the age of 18 are entitled to reunification with their spouse and their children under the age of 18 . Unaccompanied minors may therefore no longer be entitled to reunification with their parents and siblings, on whom they may still be dependent, after turning 18 years of age.

In April 2018, the Court of Justice of the EU ruled in A and S v State Secretary of Security and Justice that an unaccompanied minor who lodges an application for international protection before the age of 18 but reaches the age of majority

\footnotetext{
242 International Protection (Family Reunification) (Amendment) Bill 2017, available at https://data.oireachtas.ie/ie/oireachtas/bill/2017/101/eng/ver_b/b101b17s.pdf. Interview with SWTSCSA, January 2018. Ibid.
} 
before being granted international protection must be regarded as a 'minor' in assessing entitlements for family reunification. ${ }^{245}$ The judgment is not binding in Ireland as Ireland has not opted in to the EU Family Reunification Directive, which determines the conditions under which family reunification is granted in all other EU Member States apart from the UK.

In these circumstances, the vulnerability provisions of the 2015 Act may apply. Pursuant to section 58 of the 2015 Act, due regard must be had to the specific situation of vulnerable persons, including persons under the age of 18 years, in the application of sections 56 and 57 of the 2015 Act relating to family reunification. While no standard practice has been established concerning its application, NGOs report that applications made on behalf of aged-out minors have been successful in cases where legal representations have been made on the basis of section 58 of the 2015 Act and the $A$ and S case (IRC, 2017b). ${ }^{246}$

In order to ensure that unaccompanied minors access their right to family reunification on being granted international protection, NGOs highlight the importance of addressing the lodging of an application for international protection as soon as possible once the child is referred to Tusla (Arnold et al., 2015). It is further recommended that applications for family reunification made by unaccompanied minors are prioritised and that reunification takes place with the least possible delay to minimise the harm caused by separation from parents and family (Cosgrave and Thornton, 2015). To address the impact that aging-out may have on unaccompanied young people's entitlements, some EU Member States report that efforts are made to prioritise applications from unaccompanied minors nearing the age of majority. In some cases an unaccompanied minor who turns 18 before a decision is made on their application may receive a positive decision if their application was delayed for reasons beyond their control (EMN, 2018a).

The Immigrant Council of Ireland (ICI) observed that the issues relating to applications for family reunification made by aged-out minors are not addressed in the International Protection (Family Reunification) Bill 2017 as currently drafted. $^{247}$

\section{Family reunification for unaccompanied minors with permission to remain}

Unaccompanied young people who are granted permission to remain or other residence permission have no entitlement to family reunification; however, they may apply for family reunification for family members and dependants under the

Case C-550/16 A and S v Staatssecretaris van Veiligheid en Justitie [2018] EU:C:2018:248.

Catherine Cosgrave (2018). Presentation at 'Perilous Passage: Child Refugee Symposium', Children's Rights Alliance, 5 April.

Correspondence with Immigrant Council of Ireland, September 2018. 
general administrative mechanism for non-EEA nationals set out in the INIS Policy Document on Non-EEA Family Reunification (INIS, 2016). Unaccompanied minor beneficiaries of international protection may also apply for reunification with extended family members through this mechanism.

Applications for family reunification made through this route are subject to the discretion of the Minister for Justice and Equality. NGOs have argued that the lack of a legislative entitlement to reunification and the reliance on Ministerial discretion may result in inconsistencies in decision-making (Arnold and Quinn, 2017). Family reunification through this mechanism is also subject to the requirement that the family member is dependent on the sponsor. In order to meet the dependency requirement, the family member must be supported financially by the sponsor on a continuous basis to the extent that the absence of such support makes independent life unsustainable and there must be evidence of social dependency between the sponsor and the family member. This requirement can be waived on humanitarian grounds (INIS, 2016). While NGOs note that the discretionary nature of decision-making under this mechanism may benefit the applicant in such cases, NGOs have observed that waiving the requirement is difficult in practice (Arnold and Quinn, 2017).

\section{Assistance in submitting applications for family reunification}

Access to tailored legal services and information is also identified as a challenge faced by persons seeking international protection in the family reunification process, and may create obstacles for unaccompanied minors applying for family reunification (Becker et al., 2012; Arnold and Quinn, 2017). Unaccompanied minors and aged-out minors may apply to the Legal Aid Board for legal advice and legal aid if necessary in connection with family reunification issues, once they have been granted refugee or subsidiary protection status. ${ }^{248} \mathrm{~A}$ number of NGOs, including Crosscare, Doras Luimní, ICI, IRC and Nasc, the Migrant and Refugee Rights Centre (Nasc), and UNHCR provide persons seeking international protection assistance with family reunification applications, which unaccompanied minors may avail of (Arnold and Quinn, 2017). While the SWTSCSA may assist the child in submitting an application for family reunification under the 2015 Act, the SWTSCSA often refers unaccompanied minors to ICl or IRC for legal assistance with the application process. ${ }^{249}$ IRC, Nasc and Oxfam have called on the government to introduce legal aid for family reunification applicants by increasing funding from the Department of Justice to the Legal Aid Board (Hinds, 2018). 


\section{Challenges after family reunification}

Notwithstanding the importance of family reunification, research has observed a number of challenges associated with the arrival of families in Ireland following family reunification (Arnold and Quinn, 2017). Research highlights that ongoing support from social workers following reunification should be provided, as reunification can occur following significant periods of separation from family members and can place unaccompanied minors in vulnerable situations, including being at risk of trafficking and exploitation (Horgan et al., 2012; Arnold et al., 2015). Future reunification with family may also impact on the young person's experience in settling into a family environment within their care arrangement, and applicants may have to deal with a sense of dual belonging to their home country and Ireland (Arnold et al., 2015; Becker et al., 2012). Research has highlighted the need for more knowledge around the integration experiences of unaccompanied minors, including the impact of family reunification on young people and their families (UNHCR Ireland, 2013; Arnold and Ní Raghallaigh, 2017).

The SWTSCSA noted a lack of supports in place for families of unaccompanied minors who arrived in Ireland following a successful application for family reunification. ${ }^{250}$ It stated that social workers may face difficulties in allocating sufficient resources to supporting such families, noting in particular the housing crisis and administrative barriers as preventing access to housing and supports on arrival. ${ }^{251}$ The IRPP stated that it has been providing support in arranging housing for families reuniting in Ireland. ${ }^{252} \mathrm{ICI}$ recommended greater coordination between the Department of Justice and Equality and the SWTSCSA in respect of family reunification for unaccompanied minors (see also Mannion, 2016; Crosscare, 2018)..$^{253}$

\subsection{DEPORTATION (FORCED RETURN)}

Unaccompanied minors who receive a negative decision on an application for international protection can be subject to a deportation order (forced return), as is the case with all persons seeking international protection. ${ }^{254} \mathrm{~A}$ deportation order may also be issued to an unaccompanied minor who has not been assisted in applying for a residence permission after turning 16 years of age and who therefore has no permission to reside in the State.

Section 3 of the Immigration Act 1999 (1999 Act) sets out the Minister's power to make deportation orders. Section 3(4) of the 1999 Act provides that when the 
Minister proposes to make a deportation order, the person concerned will be notified by way of a ' 15 day letter', which sets out three options: to make representations to the Minister as to why the applicant should be given leave to remain in the State; to leave the State voluntarily within a short period; or to consent to the making of a deportation order within 15 working days. Pursuant to section 3(6), in considering the issuing of a deportation order, the Minister must have regard to the following:

(a) the age of the person;

(b) the duration of residence in the State of the person;

(c) the family and domestic circumstances of the person;

(d) the nature of the person's connection with the State, if any;

(e) the employment (including self-employment) record of the person;

(f) the employment (including self-employment) prospects of the person;

(g) the character and conduct of the person both within and (where relevant and ascertainable) outside the State (including any criminal convictions);

(h) humanitarian considerations;

(i) any representations duly made by or on behalf of the person;

(j) the common good;

(k) considerations of national security and public policy.

The 1999 Act does not require the best interests of the child to be taken into account before a deportation order is issued. The omission of such a requirement was the subject of a legal challenge in the case of Dos Santos $v$ Minister for Justice and Equality ${ }^{255}$ but the Court of Appeal confirmed that the Minister for Justice is not obliged to treat as a primary consideration the best interests of the child or, as alternatively put, to expressly decide whether deportation is consistent with the best interests of the child. ${ }^{256}$ In addition, there is no statutory obligation on the Minister to ensure that the child will be returned to a member of the child's family or adequate reception facilities in the country of origin (Cosgrave and Thornton, 2015). Ireland differs in this respect from other EU Member States (EMN, 2018a). The EU Return Directive, to which all EU Member States, with the exception of Ireland and the UK, have opted in, requires that the best interests of the child be a

\footnotetext{
255 Dos Santos \& Ors v Minister for Justice and Equality \& Ors [2015] IECA 210.

256 The case concerned a Brazilian family, consisting of five children and their parents, who were residing in Ireland unlawfully and in respect of whom deportation orders had been issued.
} 
primary consideration in the return process. ${ }^{257}$ The Directive also requires that the authorities be satisfied that the child will be returned to a family member, nominated guardian or adequate reception facilities in the State of return. ${ }^{258}$

The provisions of the 1999 Act applied to unaccompanied minors who had submitted an application for international protection under the Refugee Act 1996, which was in force up to end 2016. However, since the coming into force of the 2015 Act, the procedure around deportation of an international protection applicant has changed. Section 51 of the 2015 Act provides for the making of a deportation order following the receipt of a final negative decision on an application for international protection, subject to the prohibition of refoulement. ${ }^{259}$ While such deportation orders are deemed to be a deportation order made under section 3(1) of the 1999 Act, the issuing of a 15 day letter and assessment no longer apply to international protection applicants. ${ }^{260}$ As a result, the option for an international protection applicant to make representations to the Minister as to why the applicant should be given leave to remain in the State has been removed.

However, section 3(11) of the 1999 Act still applies to deportation orders issued under section 51 of the 2015 Act and provides that the Minister may by order amend or revoke a deportation order. ${ }^{261}$ An unaccompanied minor may make an application under section 3(11) of the 1999 Act to revoke the deportation order at any time following the issuing of a deportation order. An unaccompanied minor may alternatively seek to set aside a deportation order via judicial review, which deals with the procedures followed rather than the merits of the individual case.

While no legislative prohibition exists for the deportation of children, including unaccompanied minors, and unaccompanied minors can be issued with a negative decision and deportation order on the same basis as all persons seeking international protection, deportations of unaccompanied minors do not normally take place in practice. ${ }^{262}$ This is due in part to the fact that most unaccompanied minors do not receive a final decision on their application for international protection before reaching the age of 18. INIS indicated however that deportations

257 Directive 2008/115/EC of the European Parliament and of the Council of 16 December 2008 on common standards and procedures in Member States for returning illegally staying third-country nationals, article 5(a).

258 Ibid., article 10(2).

259 International Protection Act 2015, s 50. In line with the principle of non-refoulement set out in the 1951 United Nations Convention relating to the Status of Refugees, the prohibition of refoulement states that a person shall not be expelled or returned in any manner whatsoever to the frontier of a territory where, in the opinion of the Minister - (a) the life or freedom of the person would be threatened for reasons of race, religion, nationality, membership of a particular social group or political opinion, or (b) there is a serious risk that the person would be subjected to the death penalty, torture or other inhuman or degrading treatment or punishment.

International Protection Act 2015, s 51(4).

Immigration Act 1999, s 3(11).

Consultation with Repatriation Division, INIS, February 2018. 
of unaccompanied minors may take place in certain circumstances, for example where the minor will be sent back to family. ${ }^{263}$ Where an unaccompanied minor is issued with a deportation order, care staff accompany the child back to the country of origin or third country. ${ }^{264}$ The Working Group on the Protection Process recommended maintaining the practice of not deporting unaccompanied minors (Working Group on the Protection Process, 2015). ${ }^{265}$

In some cases where an unaccompanied minor has reached the final stages of the international protection process, while the Minister may agree to the issuing of a final negative decision on an application for international protection, the decision may not be issued formally to the minor on behalf of the Minister until the minor has reached the age of $18 .{ }^{266}$ The return of aged-out minors who receive a negative decision on their application for international protection after turning the age of 18 is dealt with on a case-by-case basis by INIS, as is the case with other persons seeking international protection (Quinn et al., 2014). Data on the number of agedout minors who have been deported are not available as data on deportations do not record whether the individual deported was previously in the care of Tusla. ${ }^{267}$ Ní Raghallaigh (2011) notes that INIS recorded and reported on deportations of aged-out minors in the past, as outlined by the government in parliamentary debates in 2005 and 2006. ${ }^{268}$

Research shows that the uncertainty surrounding the international protection process, including due to the delay in submitting applications and receiving a decision on status, raises fears of being deported among unaccompanied minors (Ní Raghallaigh, 2013). Horgan et al. (2012) observed that the possibility of deportation on reaching adulthood undermines unaccompanied minors' sense of security and identity. Concerns have been expressed that 'it could be clinically unsound for a child to receive a negative decision regarding their status with the implication of being deported following their 18th birthday' with the result that 'this could lead to them going underground, leaving school or engaging in selfdestructive behaviours' (Working Group on the Protection Process, 2015).

\section{Ibid.}

Ibid.

In October 2014, a Working Group to report to government on improvements to the protection process, including Direct Provision and supports to asylum seekers, was established by the Minister for Justice and Equality and the Minister of State for the Department of Justice and Equality. See Arnold et al. (2018).

267 Parliamentary Question, 19 July 2012 [36892/12], oireachtasdebates.oireachtas.ie.

268 Parliamentary Question, 23 November 2005 [35754/05]; Parliamentary Question, 9 May 2006 [17012/06], oireachtasdebates.oireachtas.ie. 


\section{CONCLUSIONS}

This study examines the policies and practices on unaccompanied minors following a status decision in Ireland. It does not examine status determination procedures; rather it looks at what happens once an international protection or immigration decision is made. Principally, it considers two potential outcomes for unaccompanied minors in Ireland: a positive decision for immigration permission or international protection and subsequent integration in-country, and forced or voluntary return.

EU law does not foresee transitional rules or refer to the situation when unaccompanied minors turn 18. This is left largely to the discretion of the Member States. The situation of unaccompanied minors turning 18 is highlighted in particular throughout this report, which also presents information on implications arising from a lack of status. The study therefore provides useful information for policy makers at EU level and in Ireland.

An estimated 45,500 unaccompanied minors lodged international protection applications globally in 2017, representing a 33 per cent increase since 2014 $(34,300)$. In 2017 , over 650,000 people lodged an application for international protection in the EU, 31,395 of whom were unaccompanied minors, constituting more than a 30 per cent increase since 2014. The number of unaccompanied minors recorded in Ireland is low compared to other EU Member States. However, consistent with EU and international trends, this number has increased since 2014. In 2017, 175 unaccompanied minors were referred to the Child and Family Agency, Tusla (Tusla) Social Work Team for Separated Children Seeking Asylum (SWTSCSA) in Dublin, up from 97 in 2014. Unaccompanied minors referred to the SWTSCSA include unaccompanied minors arriving spontaneously in Ireland and those arriving through government-led programmes.

Despite a 39 per cent increase in the number of unaccompanied minors referred to Tusla between 2016 and 2017, the number of applications for international protection decreased from 34 in 2016 to 30 in 2017. Between 2014 and 2017, a total of 97 applications for international protection were submitted by unaccompanied minors. During this period, 25 unaccompanied minors were granted refugee status, while two were granted subsidiary protection status. A further seven unaccompanied minors received a negative refugee status decision, and two received a negative subsidiary protection decision. Some 22 unaccompanied minors had been relocated from Greece as of May 2017 under the Irish Refugee Protection Programme (IRPP). A total of 41 unaccompanied minors were brought from Calais under the Calais Special Project. Many of these 
unaccompanied minors were granted programme refugee status on arrival, while others were granted refugee status following submission of an application for international protection shortly after arriving in Ireland.

\section{PATHWAYS TO STATUS FOR UNACCOMPANIED MINORS}

Most unaccompanied minors eventually enter the international protection process as a minor or later as an adult. However, as most unaccompanied minors do not receive a decision on an application for international protection before turning 18 years of age, and alternative immigration permissions are rarely applied for, only a small proportion of unaccompanied minors present in Ireland have an immigration status.

Social workers may choose to delay the making of an application on behalf of the unaccompanied minor because it is not in the child's best interests, because the child was deemed not ready for the international protection process, or because the social worker fears that a negative decision could lead to children going missing. However, research has shown that this practice of delaying applications for international protection may negatively impact on the enjoyment of rights, including family reunification, access to employment, education, citizenship and other supports and services. While the unaccompanied minor is under the age of 18 , other immigration pathways are rarely pursued. As many unaccompanied minors referred to Tusla are aged 16 to 17 , the Children's Rights Alliance (CRA) and Immigrant Council of Ireland (ICI) specify that Tusla should apply for an alternative residence permission on behalf of unaccompanied minors in its care should a decision be taken not to submit an application for international protection on their behalf.

\section{CARE OF UNACCOMPANIED MINORS}

Research indicates that unaccompanied minors in Ireland receive a high standard of care in comparison to other EU countries, and positive developments in their care have been welcomed. Since 2010, the SWTSCSA provides care to unaccompanied minors on the basis of an 'equity of care' principle, according to which all unaccompanied minors receive care on a par with other children in the care system up to the age of 18 . In line with this approach, all unaccompanied minors are assigned a social worker and placed in foster care, supported lodgings or residential units.

Once an unaccompanied minor is placed in care, the SWTSCSA develops a care plan on the basis of an intake assessment. Inspections of residential centres for unaccompanied minors carried out by the Health Information and Quality Authority (HIQA), however, found that the children's care plans varied in quality or 
were incomplete and not all unaccompanied minors had up-to-date care plans on file. In one of the centres based outside of Dublin, unaccompanied minors did not receive regular visits from their appointed SWTSCSA social worker as required by the Child Care Regulations 1995.

\section{APPOINTMENT OF A REPRESENTATIVE}

In June 2018, the government opted in to the recast Reception Conditions Directive, which was transposed into national law with the adoption of the European Communities (Reception Conditions) Regulations 2018 (2018 Regulations). The 2018 Regulations provide for the appointment of a Tusla employee or other individual to perform the functions of a representative in line with the Directive. Among the functions of a representative is the exercise of legal capacity for an unaccompanied minor, where necessary. The SWTSCSA's ability to exercise legal capacity for the minor, where necessary, depends on the section of the Child Care Act 1991, as amended (1991 Act) utilised by the SWTSCSA to take the unaccompanied minor into its care.

Section 4 of the 1991 Act is most frequently invoked by the SWTSCSA to take unaccompanied minors into care. However, under section 4 the SWTSCSA is obliged to have regard to the wishes of the child's parent or guardian in relation to provision of care, including key decisions affecting the child in relation to their health and education, such as engagement in after-school activities and travel outside the jurisdiction. Researchers have argued that the application of this section is problematic in the case of unaccompanied minors, as the parents or guardians of an unaccompanied minor may not be in the State or contactable in order to provide their consent.

Following the inspection of care facilities provided to unaccompanied minors in January 2018, HIQA found that there were no copies of a court order or of parental consent to the child's admission into voluntary care in some of the children's case files, contrary to the Child Care (Placement of Children in Residential Care) Regulations 1995. HIQA also highlighted that admission into care under section 4 did not take into consideration significant components of the unaccompanied minor's care and was a source of uncertainty for care staff, such as in relation to providing consent for school activities or applying for citizenship on behalf of the child. The SWTSCSA notes that the implications are minimal.

In contrast, in cases where Tusla takes the child into its care on the basis of a full care order granted by the court under section 18, Tusla has 'the like control over the child as if it were his parent' and is entitled to make all decisions concerning the welfare of the child. However, applications for a care order have been made infrequently in practice. Researchers recommend that, while the use of section 4 
provides a quick and inexpensive means to admit children into care, Tusla should be required to apply to the court for a care order under section 18 , in respect of a child in voluntary care, in cases where a parent or guardian is unidentifiable or uncontactable. The SWTSCSA stated that the pursuance of care orders is becoming more common, with vulnerability and age being factors in the decision to make an order to the court.

\section{AFTERCARE}

Section 45 of the 1991 Act places a statutory duty on Tusla to undertake a needs assessment of eligible children leaving care to determine the supports and services required by children on leaving care. The provision of aftercare is at the discretion of Tusla. Eligible children are those who have been in the care of the State for at least 12 months between the ages of 13 and 18 . As more than 50 per cent of unaccompanied minors referred to the SWTSCSA are aged between 16 and 17, some unaccompanied minors may not meet the eligibility requirements for aftercare.

HIQA have highlighted that aftercare planning for unaccompanied minors in residential centres is inconsistent, and noted uncertainty among some residential care staff as to the eligibility of unaccompanied minors in their care for aftercare support. The level of aftercare support available depends on whether or not the child has secured a legal status before the age of 18 .

\section{ACCESS TO MAINSTREAM EDUCATION}

All unaccompanied minors, regardless of their status, are entitled to primary and secondary education in Ireland. The SWTSCSA in Dublin usually refers the child to the City of Dublin Education and Training Board (CDETB)'s Youth and Education Service for Refugees and Migrants (YES) for an assessment prior to their entry into mainstream education.

While many unaccompanied minors may be capable of entering mainstream education without difficulty, YES highlighted the need to provide access to alternative education routes for unaccompanied minors aged 16 to 23 years, due to the fact that many of the unaccompanied minors that have been arriving more recently in Ireland have low education levels and low levels of English.

\section{ACCESS TO THIRD-LEVEL EDUCATION}

Unlike ordinarily resident Irish children, unaccompanied young people are not automatically entitled to access free third-level education. Unaccompanied young people may be precluded from accessing the government Free Fees Initiative as 
the majority are in their late teens on arrival. They often do not have their immigration status resolved by the time they turn 18 , and are therefore unlikely to have spent the required number of years in the Irish State with a legal immigration status.

\section{ACCESS TO EMPLOYMENT}

Unaccompanied minors with a legal status that permits them to seek employment are subject to the same provisions as Irish nationals. The SWTSCSA noted that unaccompanied minors in its care are not normally encouraged to seek employment before the age of 18 . Aged-out minors may access mainstream employment support services. The SWTSCSA noted that aftercare workers also support unaccompanied minors to prepare for the labour market by helping to prepare CVs and developing interview skills. YES also provides a Life-Skills module, which includes skills relevant to future employment, and CV support and career guidance through its outreach work and drop-in service.

Through the $110 \%$ Project, YES engaged young people from minority ethnic and migrant community backgrounds to identify key challenges they face in accessing training and employment. The key barriers identified were racism, discrimination, limited social networks, lack of recognition of qualifications from their country of origin and status as an immigrant.

\section{ACCESS TO SOCIAL WELFARE}

Under section 53(b) of the International Protection Act 2015 (2015 Act), beneficiaries of international protection, including unaccompanied minors, are entitled to receive social benefits on the same basis as Irish citizens.

Similarly to Irish citizens under the age of 18 , unaccompanied minors are not entitled to social welfare/assistance prior to the age of 18, regardless of their legal status. However, Tusla provides a weekly Foster Care Allowance to foster carers of children in care, including unaccompanied minors.

Unaccompanied young people over the age of 18 who have been granted a status and are in education/training are entitled to the Standardised National Aftercare Allowance. This consists of an amount of up to $€ 300$ per week and is provided up to the age of 21 . It can be extended to the age of 23 if education or training continues.

Aged-out minors who are transferred to Direct Provision on turning 18 are not eligible for the Standardised National Aftercare Allowance. Persons seeking 
international protection in Direct Provision are currently entitled to a weekly allowance of $€ 21.60$.

\section{ACCESS TO HEALTHCARE}

All unaccompanied minors have access to the public healthcare system in Ireland. However, HIQA reported in January 2018 that, while medical screening was provided on admission, a comprehensive assessment of emotional needs was absent from some of the care plans of unaccompanied minors in residential care, and therapeutic needs of all children were not adequately assessed and addressed through referrals to specialist services. Spirasi has expressed concern at the lack of specialised rehabilitative services and therapeutic support for child and adolescent victims of torture in Ireland.

\section{FAMILY REUNIFICATION IN IRELAND AND RETURNING TO FAMILY IN THE COUNTRY OF ORIGIN}

On referral to Tusla, the SWTSCSA carries out an intake assessment with the unaccompanied minor to identify needs in areas including reuniting with family who may be in Ireland or reuniting with family in the country of origin through voluntary return.

Under the 2015 Act, unaccompanied minors are entitled to reunification with their parents and the parents' children under the age of 18. Unlike the Refugee Act 1996, beneficiaries of international protection are no longer entitled to apply for family reunification of a dependent member of their family at the discretion of the Minister. The strict application of the definition of family members in Ireland and the changes brought about by the 2015 Act have been met with concern from UN Refugee Agency (UNHCR), the Council of Europe, Irish Human Rights and Equality Commission (IHREC) and Non-Governmental Organisations (NGOs). Family reunification entitlements for unaccompanied minors under the 2015 Act are also more limited in scope than those under the EU Family Reunification Directive, to which Ireland has not opted in, and which provides for a broader definition of family for unaccompanied minors. The Directive includes provision for family reunification of first-degree relatives in the direct ascending line of an unaccompanied minor and legal guardians or any other member of the family where the unaccompanied minor has no family in the direct ascending line or where they cannot be traced.

Unaccompanied minor beneficiaries of international protection who submit applications for family reunification after turning 18 years old may face further difficulties in making successful applications for family reunification as they are no longer considered to be children at the time of application. In April 2018, the Court 
of Justice of the EU ruled that an unaccompanied minor who lodges an application for international protection before the age of 18 , but reaches the age of majority before being granted international protection, must be regarded as a 'minor' in assessing entitlements for family reunification. The judgment is not binding in Ireland as Ireland has not opted in to the EU Family Reunification Directive, which determines the conditions under which family reunification is granted in EU Member States apart from the UK.

Unaccompanied minors who are granted permission to remain or other residence permission have no entitlement to family reunification; however, they may apply for family reunification for family members and dependants under the Irish Naturalisation and Immigration Service (INIS) Policy Document on Non-EEA Family Reunification, subject to the discretion of the Minister for Justice and Equality.

Research has observed a number of challenges associated with arrival of families in Ireland following family reunification, including accessing suitable housing and other integration supports.

\section{RETURN}

While no legislative prohibition exists for the deportation of unaccompanied minors, and unaccompanied minors can be issued with a negative decision and deportation order on the same basis as all persons seeking international protection, deportations of unaccompanied minors do not normally take place in practice. INIS indicated, however, that deportations of unaccompanied minors may take place in certain circumstances. In some cases, where an unaccompanied minor has reached the final stages of the international protection process, while the Minister may agree to the issuing of a final negative decision on an application for international protection, the decision may not be issued formally to the minor on behalf of the Minister until the minor has reached the age of 18 .

Research shows that the uncertainty surrounding the international protection process, including due to the delay in submitting applications and receiving a decision on status, raises fears of being deported among unaccompanied minors. The possibility of deportation on reaching adulthood is reported to undermine unaccompanied minors' sense of security and identity.

\section{DATA NEEDS}

The EU Action Plan on Unaccompanied Minors 2010-2014 identified shortcomings in data collection among EU Member States, noting in particular the lack of reliable data on unaccompanied minors who do not seek international protection. In Ireland no data are collected on the number, if any, of unaccompanied minors who 
have applied for, and are subsequently granted, an alternative immigration status, including permission to remain under the 2015 Act. In addition, no disaggregated data are available on the number of unaccompanied minors who have been reunited with family in Ireland, in a third country or in the child's country of origin. 


\section{REFERENCES}

Abunimah, A. and S. Blower (2010). 'The circumstances and needs of separated children seeking asylum in Ireland', Child Care in Practice, Vol. 16, No. 2, pp. 129-146.

Ager, A. and A. Strang (2008). 'Understanding Integration: a conceptual framework', Journal of Refugee Studies, Vol. 21, No. 2, pp. 166-191.

Arnold, S. (2013). Implementing the Core Standards for guardians of separated children in Europe. Country Assessment: Ireland, Dublin: Irish Refugee Council.

Arnold, S., M. Goeman, and K. Fournier (2014). 'The role of the guardian in determining the best interest of the separated child seeking asylum in Europe: a comparative analysis of systems of guardianship in Belgium, Ireland and the Netherlands', European Journal of Migration and Law, Vol. 16, pp. 467-504.

Arnold, S. and J. Kelly (2012). 'Irish child care law and the role of the Health Service Executive in safeguarding separated children seeking asylum', Irish Law Times, Vol. 30, pp. 178-183.

Arnold, S. and M. Ní Raghallaigh (2017). 'Unaccompanied minors in Ireland: current law, policy and practice', Social Work and Society, Vol. 15, No. 1.

Arnold, S., M. Ní Raghallaigh, M. Conaty, E. O’Keeffe, and N. Roe (2015). Durable solutions for separated children in Europe: national report Ireland, Dublin: Irish Refugee Council.

Arnold, S. and E. Quinn (2017). Family reunification of non-EU nationals in Ireland, European Migration Network, Research Series No. 62, Dublin: The Economic and Social Research Institute.

Arnold, S., C. Ryan, and E. Quinn (2018). Ireland's response to recent trends in international protection applications, European Migration Network, Research Series No. 72, Dublin: The Economic and Social Research Institute.

Arnold, S. and L. Sarsfield Collins (2011). Closing a protection gap: national report 20102011, Dublin: Irish Refugee Council.

Barrett, A., F. McGinnity, and E. Quinn (eds) (2017). Monitoring report on integration 2016, Dublin: Economic and Social Research Institute.

Becker, H., C. Cosgrave and M. Labor (2012). Family reunification: a barrier or facilitator of integration? Ireland country report, Dublin: Immigrant Council of Ireland.

Bhabha, J. (2001). 'Minors or aliens? Inconsistent state intervention and separated child asylum-seekers', European Journal of Migration and Law, Vol. 3, pp. 283-314.

Bhabha, J. (2014). 'Moving children: lacunae in contemporary human rights protections for migrant children and adolescents', Revue européenne des migrations internationales, Vol. 30, No. 1, pp. 35-57. 
Brindle, D. (2017). 'Young migrants in Ireland are treated as children, not asylum seekers', The Guardian, https://www.theguardian.com/social-carenetwork/2017/oct/02/child-first-approach-irelands-programme-for-youngmigrants-international-model.

CDETB Youth and Education Service for Refugees and Migrants (2018). 110\%: The Experience of Young People from Migrant Backgrounds in and around Employment, http://cdetbcdu.ie/wp-content/uploads/2018/03/11025-A2-Brochure-FORPRINT-FINAL.pdf.

Charles, K. (2009). Separated children living in Ireland: a report by the Ombudsman for Children's Office, Dublin: Ombudsman for Children's Office.

Child and Family Agency, Tusla (Tusla) (2015). Guidance document for the implementation of the standardised aftercare allowance, Dublin: Tusla.

Child and Family Agency, Tusla (Tusla) (2017a). National aftercare policy for alternative care, Dublin: Tusla.

Child and Family Agency, Tusla (Tusla) (2017b). Complex needs in aftercare, Dublin: Tusla.

Child and Family Agency, Tusla (Tusla) (2017c). Financial support in aftercare, Dublin: Tusla.

Child and Family Agency, Tusla (Tusla) (2017d). Roles and responsibilities in aftercare, Dublin: Tusla.

Child and Family Agency, Tusla (Tusla) (2017e). Drop in services clinic, Dublin: Tusla.

Child and Family Agency, Tusla (Tusla) (2017f). Children's residential centres, Dublin: Tusla.

Child and Family Agency, Tusla (Tusla) (2017g). Steering committees, Dublin: Tusla.

Child and Family Agency, Tusla (Tusla) (2017h). Foster care committees - policy, procedures and best practice guidance, Dublin: Tusla, http://www.ifca.ie/files/6214/9579/2133/Foster_Care_Committees_2017_Policy _Guidance.pdf.

Child and Family Agency, Tusla (Tusla) (2018a). Corporate plan 2018-2020, Dublin: Tusla.

Child and Family Agency, Tusla (Tusla) (2018b). Business plan 2018, Dublin: Tusla.

Child and Family Agency, Tusla (Tusla) (2018c). Quarterly service performance and activity report: quarter 4 2017, Dublin: Tusla.

Child and Family Agency, Tusla (Tusla) (2018d). Annual review on the adequacy of child care and family support services available 2016, Dublin: Tusla.

Child and Family Agency, Tusla (Tusla) (2018e). 2017 Annual Report, Dublin: Tusla.

Children's Rights Alliance (CRA) (2012). Recommendations by the Children's Rights Alliance in relation to child trafficking to the OSCE Special Representative and Coordinator for Combating Trafficking in Human Beings, Dublin: Children's Rights Alliance.

Children's Rights Alliance (CRA) (2015a). Are we there yet? Parallel report to Ireland's Third and Fourth Combined Report under the UN Convention on the Rights of the Child, Dublin: Children's Rights Alliance. 
Children's Rights Alliance (CRA) (2015b). Initial submission on the general scheme of the International Protection Bill 2015, Dublin: Children's Rights Alliance.

Children's Rights Alliance (CRA) (2016). Report Card 2016, Dublin: Children's Rights Alliance.

Children's Rights Alliance (CRA) (2017). Report Card 2017, Dublin: Children's Rights Alliance.

Children's Rights Alliance (CRA) (2018). Report Card 2018, Dublin: Children's Rights Alliance.

Coakley, L. (2015). Strengthening information \& outreach for assisted voluntary return in Ireland, Dublin: International Organization for Migration Ireland.

College of Psychiatrists of Ireland (2017). The mental health service requirements in Ireland for Asylum seekers, refugees and migrants from conflict zones: position paper, www.irishpsychiatry.ie.

Corbett, M. (2018). 'Children in voluntary care: an essential provision but one in need of reform', Irish Journal of Family Law, Vol. 21, No. 1, pp. 9-16.

Cosgrave, C. and L. Thornton (2015). 'Immigration and asylum law', Making rights real for children: a children's rights audit of Irish law, Dublin: Children's Rights Alliance.

Council of Europe Commissioner for Human Rights (2017). Realising the right to family reunification of refugees in Europe, Strasbourg: Council of Europe.

Crosscare (2018). Reunified refugee families and homelessness: submission to the Minister for Justice and Equality, Dublin: Crosscare.

Darmody, M. and S. Arnold (2018, manuscript in preparation). 'Refugee children and young people in Ireland: policies and practices', in Educational Policies and Practices of English-speaking Refugee Resettlement Countries, Rotterdam: Sense Publishers.

Department of Children and Youth Affairs (DCYA) (2011). Children first: national guidance for the protection and welfare of children, Dublin: Department of Children and Youth Affairs.

Department of Children and Youth Affairs (DCYA) (2014). Better outcomes, brighter futures: the national policy framework for children and young people, 2014-2020, Dublin: Department of Children and Youth Affairs.

Department of Education and Skills (2017). Languages connect: Ireland's strategy for foreign languages in education 2017-2026, Dublin: Department of Education and Skills.

Department of Foreign Affairs and Trade (2017). 'Oversight Group of Ireland's Second National Action Plan on Women, Peace and Security (2015-2018): Eleventh Meeting, 6th March, 2017, Department of Foreign Affairs and Trade, Iveagh House, Minutes: Formal Meeting', https://www.dfa.ie/media/dfa/ourrolepolicies/peaceandsecurity/EleventhMeeting-Formal-Minutes-Final.pdf.

Department of Health and Children (2001). National Standards for Children's Residential Centres, Dublin: Government of Ireland. 
Department of Health and Children (2003). National Standards for Foster Care, Dublin: Government of Ireland.

Department of Health and Children (2009). Report of the Commission to Inquire into Child Abuse, 2009: Implementation Plan, https://www.dcya.gov.ie/documents/publications/implementation_plan_from_r yan_commission_report.pdf.

Department of Justice and Equality (2011). Administrative immigration arrangements for the protection of victims of human trafficking, Dublin: Department of Justice and Equality.

Department of Justice and Equality (2012). Services for victims of child trafficking, Dublin: Department of Justice and Equality, www.blueblindfold.gov.ie.

Department of Justice and Equality (2015). Trafficking in human beings in Ireland: annual report 2015, Dublin: Department of Justice and Equality.

Department of Justice and Equality (2016). Second National Action Plan to Prevent and Combat Human Trafficking in Ireland, Dublin: Department of Justice and Equality.

Department of Justice and Equality (2017a). Second audit of progress on improvements to the protection process, Dublin: Department of Justice and Equality, http://www.justice.ie/en/JELR/WG_Report_2nd_Progress_Table_2017.pdf/Files/ WG_Report_2nd_Progress_Table_2017.pdf.

Department of Justice and Equality (2017b). Report of the Working Group to Report to Government on Improvements to the Protection Process, including Direct Provision and Supports for Asylum Seekers: 3rd and final progress report on the implementation of the report's recommendations, June 2017, http://www.justice.ie/en/JELR/3rd_WG_Progress_Report__July_2017.pdf/Files/3rd_WG_Progress_Report_-_July_2017.pdf.

Department of Justice and Equality (2017c). The Migrant Integration Strategy: A Blueprint for the Future,

http://www.justice.ie/en/JELR/Migrant_Integration_Strategy_English.pdf/Files/M igrant_Integration_Strategy_English.pdf.

Department of Justice and Equality (2018). Speech by Minister of State David Stanton, T.D., at 'Perilous Passage: Child Refugee Symposium' hosted by the Children's Rights Alliance, Chartered Accountants House, Dublin 2, 5 April 2018, http://www.justice.ie/en/JELR/Pages/SP18000116.

Department of Justice, Equality and Law Reform (2009). National Action Plan to Prevent and Combat Trafficking of Human Beings in Ireland 2009-2012, Dublin: Department of Justice, Equality and Law Reform.

Department of Planning, Housing and Local Government (2014). Young people leaving state care: joint working protocol between Tusla, the Child and Family Agency and housing authorities, www.housing.gov.ie. 
Empowering People in Care (EPIC) (2016). Submission to Tusla on review of national leaving and aftercare policy 2011, https://www.epiconline.ie/wp-content/uploads/2016/08/Final-Submission-toTusla-on-Review-of-National-Aftercare-Policy.pdf.

European Commission (2007). Green Paper on the future of the Common European Asylum System, Brussels: European Commission.

European Commission (2010). Action Plan on Unaccompanied Minors (2010-2014), $\operatorname{COM}(2010) 213$ final, Brussels: European Commission.

European Commission (2012). Mid-term report on the implementation of the Action Plan on Unaccompanied Minors, COM(2012) 554 final.

European Commission (2015). A European agenda on migration, Brussels: European Commission.

European Commission (2016). Seventh report on relocation and resettlement, $\operatorname{COM(2016)~}$ 720 final, Brussels: European Commission.

European Commission (2017). The protection of children in migration, COM(2017) 211 final, Brussels: European Commission.

European Commission (2018). Progress report on the Implementation of the European Agenda on Migration, COM(2018) 301 final, Brussels: European Commission.

European Migration Network (EMN) (2010). Policies on reception, return and integration arrangements for, and numbers of, unaccompanied minors - an EU comparative study, Brussels: European Migration Network).

European Migration Network (EMN) (2015). Policies, practices and data on unaccompanied minors in the EU Member States and Norway - synthesis report, Brussels: European Migration Network.

European Migration Network (EMN) (2017a). Annual report 2016 on migration and asylum - statistical annex, Brussels: European Migration Network.

European Migration Network (EMN) (2017b). Family reunification of third-country nationals in the EU plus Norway - Synthesis Report, Brussels: European Migration Network.

European Migration Network (EMN) (2018a). Approaches to unaccompanied minors following status determination in the EU plus Norway - synthesis report, Brussels: European Migration Network.

European Migration Network (EMN) (2018b). Asylum and migration glossary 6.0, Brussels: European Migration Network, available at http://emn.ie.

European Union Agency for Fundamental Rights (2015). Guardianship systems for children deprived of parental care in the European Union, with a particular focus on their role in responding to child trafficking, Luxembourg: Publications Office of the European Union.

European Union Agency for Fundamental Rights (2016). Current migration situation in the EU: separated children, Vienna: European Union Agency for Fundamental Rights. 
Eurostat (2018a). '650 000 first-time asylum seekers registered in 2017', Luxembourg: Eurostat, http://ec.europa.eu/eurostat/documents/2995521/8754388/3-2003 2018-AP-EN.pdf/50c2b5a5-3e6a-4732-82d0-1caf244549e3.

Eurostat (2018b). Asylum applicants considered to be unaccompanied minors by citizenship, age and sex: annual data (rounded), Luxembourg: Eurostat, https://ec.europa.eu/eurostat/web/products-datasets/-/migr_asyunaa.

Faas, D., B. Sokolowska, and M. Darmody (2015). "Everybody is available to them": support measures for migrant students in Irish secondary schools', British Journal of Educational Studies, Vol. 63, No. 4, pp. 447-466.

Fletcher, L. (2018). 'Third-level education scheme for asylum seekers stalls', https://www.rte.ie/news/education/2018/0902/991090-department-educationasylum-seekers.

Foreman, M. and M. Ní Raghallaigh (2015). Social workers experiences of working with people living in the direct provision system: submission to the Working Group on the Protection Process, available at www.iasw.ie.

Freyne, P. (2017). “I thought I wasn't a lovable child”: the life of a care-system kid', Irish Times, https://www.irishtimes.com/news/social-affairs/i-thought-i-wasn-t-alovable-child-the-life-of-a-care-system-kid-1.2979200.

Government of Ireland (2013). Resettlement handbook country chapters - Ireland, Dublin: United Nations High Commissioner for Refugees.

Group of Experts on Action against Trafficking in Human Beings (GRETA) (2017). Report concerning the implementation of the Council of Europe Convention on Action against Trafficking in Human Beings by Ireland, Strasbourg: Council of Europe.

Gusciute, E., S. Arnold, and E. Quinn (2016). Integration of beneficiaries of international protection into the labour market: policies and practices in Ireland, European Migration Network, Research Series No. 52, Dublin: The Economic and Social Research Institute.

Health Information and Quality Authority (HIQA) (2017). Monitoring inspection report on children's statutory residential centres under the Child Care Act, 1991, Dublin: HIQA, https://www.hiqa.ie/system/files?file=inspectionreports/4184_CRC_23\%20Augus t\%202017.pdf.

Health Information and Quality Authority (HIQA) (2018a). Monitoring inspection report on children's statutory residential centres under the Child Care Act, 1991, Centre ID OSV-0005624, Dublin: HIQA, https://www.hiqa.ie/system/files?file=inspectionreports/5624\%2C\%20Children\% 27s\%20Residential\%20Centre\%2C\%20Dublin\%20North\%20East\%2C\%2010\%20Jan uary\%202018.pdf.

Health Information and Quality Authority (HIQA) (2018b). Monitoring inspection report on children's statutory residential centres under the Child Care Act, 1991, Centre ID OSV-0004184, Dublin: HIQA, https://www.hiqa.ie/system/files?file=inspectionreports/4184_CRC_30\%20May\% 202018.pdf. 
Health Service Executive (HSE) (2012). Review of adequacy for HSE Children and Families Services 2010, Dublin: HSE, https://www.tusla.ie/uploads/content/Publications_reviewofadequacy2010.pdf.

Hinds, R. (2018). 'A family belongs together': refugees' experiences of family reunification in Ireland, Dublin: Irish Refugee Council, Nasc, and Oxfam.

Horgan, D., S. Martin, J. O'Riordan, and A. Christie (2011). 'A differentiated care system: its contribution to the vulnerabilities of separated migrant children in Ireland', Children's European Citizenship, Vol. 1, No. 1.

Horgan, D. and M. Ní Raghallaigh (2017). 'The social care needs of unaccompanied minors: the Irish experience', European Journal of Social Work, DOI: 10.1080/13691457.2017.1357018.

Horgan, D., J. O'Riordan, A. Christie, and S. Martin (2012). Safe care for trafficked children in Ireland: developing a protective environment, Dublin: Children's Rights Alliance.

Huddleston T., Ö. Bilgili, A. Joki, and Z. Vankova (2015). Migrant integration policy index 2015: Ireland, Barcelona/Brussels: CIDOB and MPG.

Immigrant Council of Ireland (ICI) (2016). Submission to the Migrant Workers' Committee and the Committee on the Rights of the Child General Comment on the Human Rights of Children in the Context of International Migration, Dublin: $\mathrm{ICI}$, https://www.ohchr.org/Documents/HRBodies/CMW/JointGC_CRC_CMW/ICl.pdf.

Immigrant Council of Ireland (ICI) (2018). INIS consultation on the immigration registration of foreign national children, Dublin: ICI, https://www.immigrantcouncil.ie/sites/default/files/201803/2018\%20ICI\%20Submission\%20to\%20INIS\%20Consultation\%20on\%20the\%20I mmigration\%20Registration\%20of\%20Foreign\%20National\%20Children.pdf.

International Organization for Migration (IOM) (2017), 'Child migrants: how little we know', Data Briefing Series No. 10, https://publications.iom.int/system/files/pdf/gmdac_data_briefing_series_issue_ 10.pdf.

International Protection Appeals Tribunal (IPAT) (2017). Guideline No: 2017/5. Appeals from child applicants, Dublin: International Protection Appeals Tribunal.

International Protection Appeals Tribunal (IPAT) (2018). 'Child safeguarding statement of the International Protection Appeals Tribunal', Dublin: International Protection Appeals Tribunal.

International Protection Office (IPO) and UNHCR (2017). 'Prioritisation of applications for international protection under the International Protection Act 2015', Dublin: IPO and INIS, http://www.ipo.gov.ie/en/IPO/Prioritisation_of_International_Protection_Applic ations_IPO_UNHCR_Notice_2017.pdf/Files/Prioritisation_of_International_Protec tion_Applications_IPO_UNHCR_Notice_2017.pdf. 
Irish Human Rights and Equality Commission (IHREC) (2015a). Recommendations on the General Scheme of the International Protection Bill 2015, Dublin: Irish Human Rights and Equality Commission, https://www.ihrec.ie/download/pdf/ihrec_recs_general_scheme_internation_pr otection_bill_26_june_2015.pdf.

Irish Human Rights and Equality Commission (IHREC) (2015b). Ireland and The United Nations Convention on the Rights of the Child: Report by the Irish Human Rights and Equality Commission to the UN Committee on the Rights of the Child on Ireland's combined third and fourth periodic reports, Dublin: Irish Human Rights and Equality Commission, https://www.ihrec.ie/download/pdf/ireland_and_the_united_nations_conventio n_on_the_rights_of_the_child.pdf.

Irish Human Rights and Equality Commission (IHREC) (2017a). Submission to the United Nations Committee on the Elimination of Discrimination Against Women on Ireland's combined sixth and seventh periodic reports, Dublin: Irish Human Rights and Equality Commission, https://www.ihrec.ie/app/uploads/2017/02/Irelandand-the-Convention-on-the-Elimation-of-All-Forms-of-Discrimination-AgainstWomen.pdf.

Irish Human Rights and Equality Commission (IHREC) (2017b). Ireland and the Convention against Torture: submission to the United Nations Committee against Torture on Ireland's second periodic report, Dublin: Irish Human Rights and Equality Commission, https://www.ihrec.ie/app/uploads/2017/07/Ireland-and-theConvention-against-Torture.pdf.

Irish Human Rights and Equality Commission (IHREC) (2018). The right to family reunification for beneficiaries of international protection, Dublin: Irish Human Rights and Equality Commission, https://www.ihrec.ie/app/uploads/2018/06/Theright-to-family-reunification-for-beneficiaries-of-international-protection-June2018.pdf.

Irish Naturalisation and Immigration Service (INIS) (2016). Policy document on non-EEA family reunification, Dublin: Department of Justice and Equality.

Irish Naturalisation and Immigration Service (INIS) (2018). Immigration in Ireland: annual review 2017, Dublin: Department of Justice and Equality.

Irish Refugee Council (IRC) (2012). Direct provision: framing an alternative reception system for people seeking international protection, Dublin: Irish Refugee Council.

Irish Refugee Council (IRC) (2017a). Submission to the United Nations Committee against Torture on the examination of Ireland's national report, Dublin: Irish Refugee Council, https://tbinternet.ohchr.org/Treaties/CAT/Shared\%20Documents/IRL/INT_CAT_C SS_IRL_27964_E.pdf.

Irish Refugee Council (IRC) (2017b). Asylum information database. Country report: Ireland, Brussels: European Council on Refugees and Exiles. 
Irish Refugee Council (IRC) (2018). 'IRC call for education support scheme for young people in asylum process to be made more accessible', media release, 7 September, https://www.irishrefugeecouncil.ie/news/call-for-education-support-scheme-foryoung-people-in-asylum-process-to-be-made-more-accessible/6655.

Irish Refugee and Migrant Coalition (IRMC) (2017). Pathways to protection and inclusion: Ireland's role in global refugee protection and migration movements, Dublin: Irish Refugee and Migrant Coalition.

Irish Refugee Protection Programme (IRPP) (2018). 'IRPP Statistics - 26 Feb 2018', http://www.integration.ie/en/ISEC/IRPP\%20Statistics\%20-

\%20February\%202018.pdf/Files/IRPP\%20Statistics\%20-

\%20February\%202018.pdf.

Joint Committee on Justice and Equality (2017). Report on asylum, immigration and the refugee crisis, Dublin: Department of Justice and Equality.

Joyce, C. and E. Quinn (2009). Policies on unaccompanied minors in Ireland, Dublin: The Economic and Social Research Institute.

Kilkelly, U. (2007). Barriers to the realisation of children's rights in Ireland, Dublin: Ombudsman for Children's Office.

Mannion, K. (2016). Child migration matters: children and young people's experience of migration, Dublin: Immigrant Council of Ireland.

Mannion, K., P. Rojas Coppari, and F. Hurley (2018). Manual on regularisations for children, young people and families, Brussels: Platform for International Cooperation on Undocumented Migrants, http://www.picum.org/Documents/Publi/2018/Regularisation_Children_Manual _2018.pdf.

Martin, S., A. Christie, D. Horgan, and J. O'Riordan (2011). “'Often they fall through the cracks": separated children in Ireland and the role of guardians', Child Abuse Review, Vol. 20, pp. 361-373.

McGinnity, F., É. Fahey, E. Quinn, S. Arnold, B. Maître, and P. O'Connell (2018). Monitoring report on integration 2018, Dublin: The Economic and Social Research Institute.

McGuire, P. and S. Pollak (2016). 'No asylum in Ireland's education system', Irish Times, https://www.irishtimes.com/news/education/no-asylum-in-ireland-s-educationsystem-1.2834317.

Mintern, B. and L. Dorney (2006). 'Separated young people seeking asylum: standing alone?', Irish Journal of Applied Social Studies, Vol. 7, No. 2, pp. 18-26.

Mooten, N. (2006). Making separated children visible: the need for a child-centred approach, Dublin: Irish Refugee Council.

Mullally, S. (2011). 'Separated children in Ireland: responding to "terrible wrongs"', International Journal of Refugee Law, Vol. 23, No. 4, pp. 632-655.

Murray, N. (2016). 'Irish Refugee Council: "Reform aid scheme for asylum seeker students"', Irish Examiner, https://www.irishexaminer.com/ireland/irish-refugeecouncil-reform-aid-scheme-for-asylum-seeker-students-418049.html. 
Murray, N. (2017). 'Only two asylum seekers qualify for third-level grant support', Irish Examiner, https://www.irishexaminer.com/ireland/only-two-asylum-seekersqualify-for-third-level-grant-support-456703.html.

Nasc, the Migrant and Refugee Rights Centre (Nasc) (2016). The loss of family reunification rights in the International Protection Act 2015, Cork: Nasc, http://www.nascireland.org/wp-content/uploads/2016/12/The-Loss-of-FamilyReunification-Rights-in-the-International-Protection-Act.pdf.

Nasc, the Migrant and Refugee Rights Centre (Nasc) (2017). Nasc working paper on the progress of implementation of the McMahon Report, Cork: Nasc, http://www.nascireland.org/wp-content/uploads/2017/12/Nasc-Working-GroupReport-Dec-2017.pdf.

Ní Raghallaigh, M. (2011) 'Social work with separated children seeking asylum', Irish Social Worker, Vol 2.

Ní Raghallaigh, M. (2013). Foster care and supported lodgings for separated asylum seeking young people in Ireland: the views of young people, carers and stakeholders, Dublin: Barnardos and HSE.

Ní Raghallaigh, M., M. Foreman and M. Feeley (2016). Transition: from Direct Provision to life in the community - the experiences of those who have been granted refugee status, subsidiary protection or leave to remain in Ireland, Dublin: Taskforce on Transitional Supports for Persons Granted Status in Direct Provision.

Ní Raghallaigh, M. and A. Sirriyeh (2015). 'The negotiation of culture in foster care placements for separated refugee and asylum seeking young people in Ireland and England', Childhood, Vol. 22, No. 2, pp. 263-277.

Ní Raghallaigh, M. and L. Thornton (2017). 'Vulnerable childhood, vulnerable adulthood: Direct Provision as aftercare for aged-out separated children seeking asylum in Ireland', Critical Social Policy, Vol. 37, No. 3, pp. 386-404.

Office of the Refugee Applications Commissioner (ORAC) (2015). Annual Report - 2014, Dublin: Department of Justice and Equality.

Office of the Refugee Applications Commissioner (ORAC) (2016). Annual Report - 2015, Dublin: Department of Justice and Equality.

Office of the Refugee Applications Commissioner (ORAC) (2017). Summary Report of Key Developments in 2016, Dublin: Department of Justice and Equality.

One Foundation, The (2014). One 10: 2004-2013 Impact Report, Dublin: The One Foundation, http://www.philanthropy.ie/wp-content/uploads/2017/07/One102004-2013-Impact-Report-The-One-Foundation.pdf.

Oxfam (2017). Dear family: how migration policies are keeping families apart. Refugee family reunion in Ireland, Dublin: Oxfam.

Phelan, S. (2015). 'Access to justice and decision making', Making rights real for children: a children's rights audit of Irish law, Dublin: Children's Rights Alliance. 
Quinn, E. (2010). Programmes and strategies in Ireland fostering assisted return to and reintegration in third countries, European Migration Network, Dublin: The Economic and Social Research Institute.

Quinn, E., C. Joyce, and E. Gusciute (2014). Policies and practices on unaccompanied minors in Ireland, European Migration Network, Dublin: The Economic and Social Research Institute.

Reception and Integration Agency (RIA) (2011). Accommodation of aged out minors in RIA accommodation centres, available at www.ria.gov.ie.

Richason, L. (2017). 'Social work for separated children seeking asylum in the Republic of Ireland: setting the standard for child-centred care and protection', Child Care in Practice, Vol. 24, No. 4, pp. 402-412.

Rodríguez-Izquierdo, R.M. and M. Darmody (2017). 'Policy and practice in language support for newly arrived migrant children in Ireland and Spain', British Journal of Educational Studies, DOI: 10.1080/00071005.2017.1417973

Royal College of Physicians of Ireland (2016). Migrant health - the health of asylum seekers, refugees and relocated individuals: a position paper from the Faculty of Public Health Medicine, Dublin: Royal College of Physicians Ireland.

Separated Children in Europe Programme (SCEP) (2009). Statement of good practice: 4th revised edition, http://scep.sitespirit.nl/images/18/219.pdf.

Shannon, G. (2016). Ninth report of the Special Rapporteur on Child Protection: a report submitted to the Oireachtas, https://www.dcya.gov.ie/documents/publications/201611189thReportoftheSpeci alRapporteuronChildProtection.pdf.

Sheridan, A. (2018). Annual report on migration and asylum 2017: Ireland, European Migration Network, Survey and Statistical Report Series, Number 66, Dublin: The Economic and Social Research Institute.

Sirriyeh, A. and M. Ní Raghallaigh (2018). 'Foster care, recognition and transitions to adulthood for unaccompanied asylum seeking young people in England and Ireland', Children and Youth Services Review, Vol. 92, pp. 89-97.

Smyth, C. (2014). 'Children, direct provision and the European Convention on Human Rights' in S. Egan et al. (eds) Ireland and the European Convention on Human Rights: 60 years and beyond, Dublin: Bloomsbury.

Smyth, E., M. Darmody, F. McGinnity, and D. Byrne (2009). Adapting to Diversity: Irish Schools and Newcomer Students, Research Series Number 8, Dublin: The Economic and Social Research Institute.

Spirasi (2017). 61st Session of the UN Committee Against Torture: Spirasi's Submission on Ireland, available at www.ohchr.org. 
Tangermann, J. and P. Hoffmeyer-Zlotnik (2018). Unaccompanied minors in Germany: challenges and measures after the clarification of residence status. Focussed study by the German National Contact Point for the European Migration Network (EMN), Working Paper 80 of the Research Centre of the Federal Office for Migration and Refugees, Nuremberg: Federal Office for Migration and Refugees, https://ec.europa.eu/home-

affairs/sites/homeaffairs/files/11a_germany_uam_2018_en.pdf.

UN Committee on the Rights of the Child (the Committee) (2005). General Comment no. 6: Treatment of unaccompanied and separated children outside their country of origin, $C R C / G C / 2005 / 6$, https://www2.ohchr.org/english/bodies/crc/docs/GC6.pdf

UN Refugee Agency (UNHCR) (2009). Guidelines on international protection: child asylum claims under Articles 1(A)(2) of the 1951 Convention and/or 1967 Protocol relating to the Status of Refugees, Geneva: UNHCR.

UN Refugee Agency (UNHCR) (2017a). Italy - Unaccompanied and separated children (UASC) dashboard: January-December 2017, https://data2.unhcr.org/en/documents/download/61548.

UN Refugee Agency (UNHCR) (2017b). Greece: Sea arrivals dashboard December 2017, https://data2.unhcr.org/en/documents/download/61492.

UN Refugee Agency (UNHCR) (2017c). UNHCR Global Appeal 2018-2019-Building Better Futures, Geneva: UNHCR.

UN Refugee Agency (UNHCR) (2018). Global trends: forced displacement in 2017, Geneva: UNHCR.

UN Refugee Agency (UNHCR), UNICEF and IOM (2017), Refugee and migrant children including unaccompanied and separated children - in the EU: overview of trends in 2016, April, https://data2.unhcr.org/en/documents/download/55971.

UN Refugee Agency Ireland (UNHCR Ireland) (2013). Towards a new beginning: refugee integration in Ireland, Dublin: UNCHR.

UNICEF and REACH (2017). Children on the move in Italy and Greece, Geneva: UNICEF and REACH.

Veale, A., L. Palaudaries, and C. Gibbons (2003). Separated children seeking asylum in Ireland, Dublin: Irish Refugee Council.

Working Group on the Protection Process (2015). Working Group to Report to Government on Improvements to the Protection Process, including Direct Provision and Supports to Asylum Seekers: final report, available at www.justice.ie. 


\section{ANNEX 1}

\section{Simplified international protection application process in Ireland}
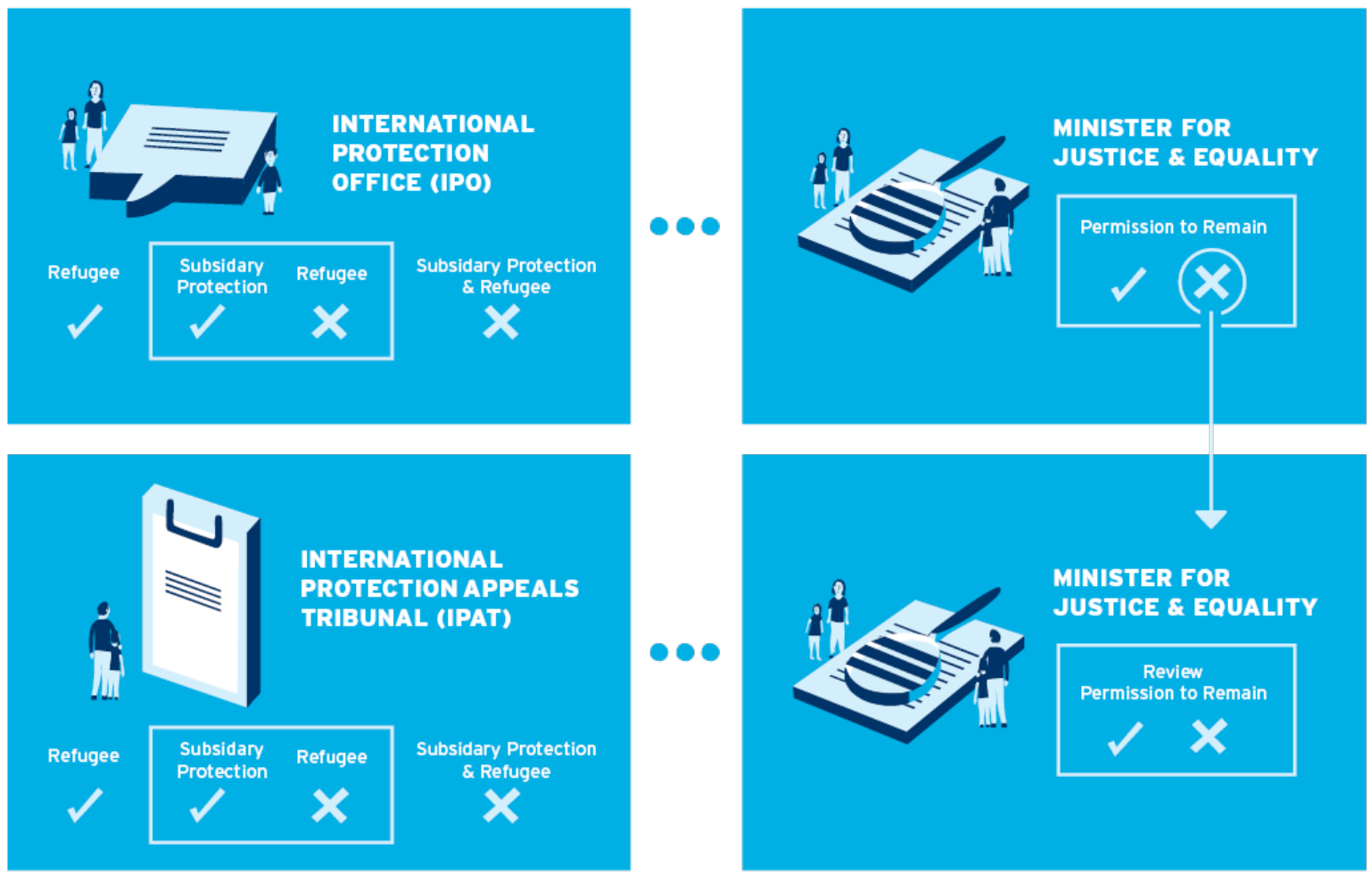

Source: EMN Ireland. See full application process at http://emn.ie/emn/legislation-flow-chart. 
ANNEX 2

\section{Assessment pathways for unaccompanied minors}

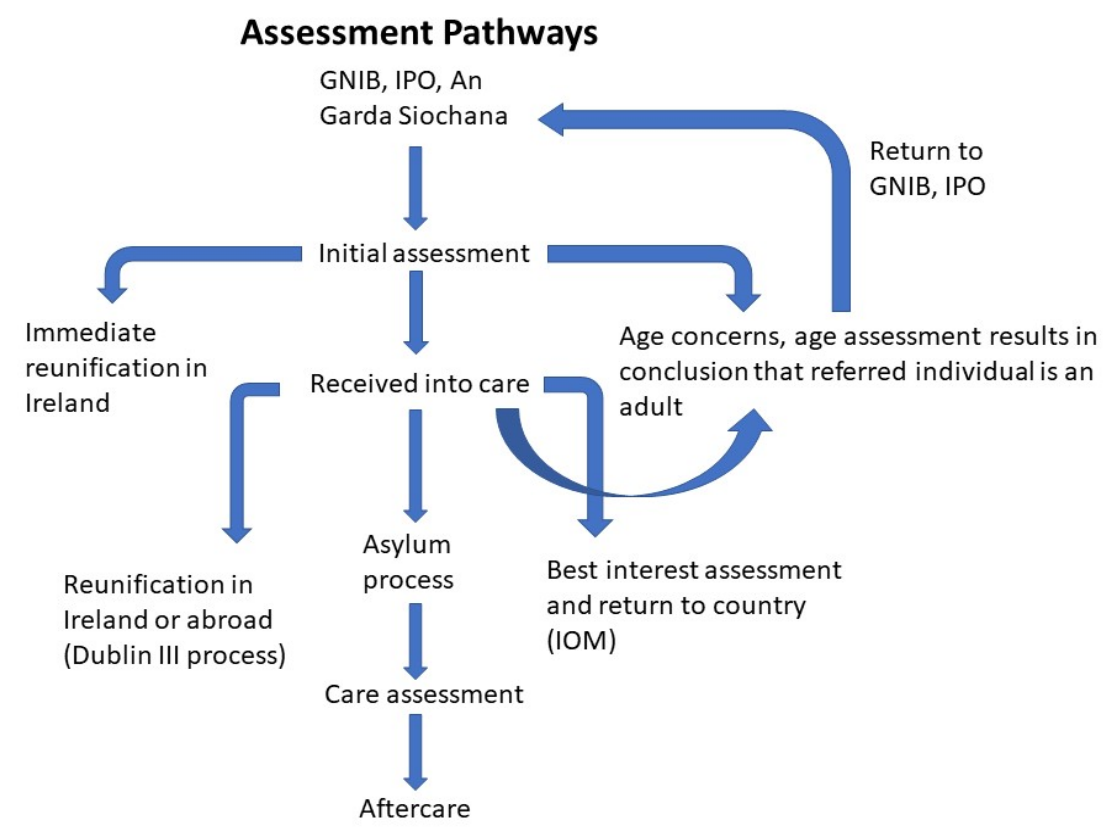

Source: $\quad$ SWTSCSA, October 2018. 
EMN Ireland,

Economic and Social

Research Institute,

Whitaker Square,

Sir John Rogerson's Quay,

Dublin 2, Ireland

Telephone +35318632000

Email emn.ireland@esri.ie

Web www.emn.ie / www.esri.ie

Twitter @EMNIreland

ISBN 978-0-7070-0476-1 